Universidad de Lima

Facultad de Ciencias Empresariales y Económicas

Carrera de Administración

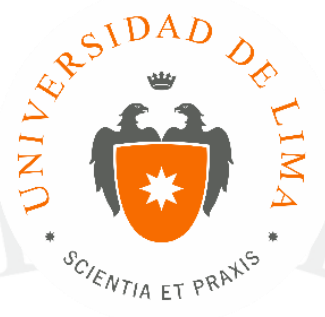

\title{
LA CONGESTIÓN VEHICULAR EN LIMA METROPOLITANA ENTRE LOS AÑOS 2012 Y 2016 AFECTA ECONÓMICAMENTE A LAS EMPRESAS ASEGURADORAS DE VIDA Y A SUS TRABAJADORES
}

Trabajo de investigación para optar la licenciatura en Administración

\section{Antonella Flavia Reghellin Palacios \\ Código 20102649}

\section{Asesor}

Fernando Manfredo Jesús Solís Fúster

$$
\text { Lima - Perú }
$$

Febrero de 2018 


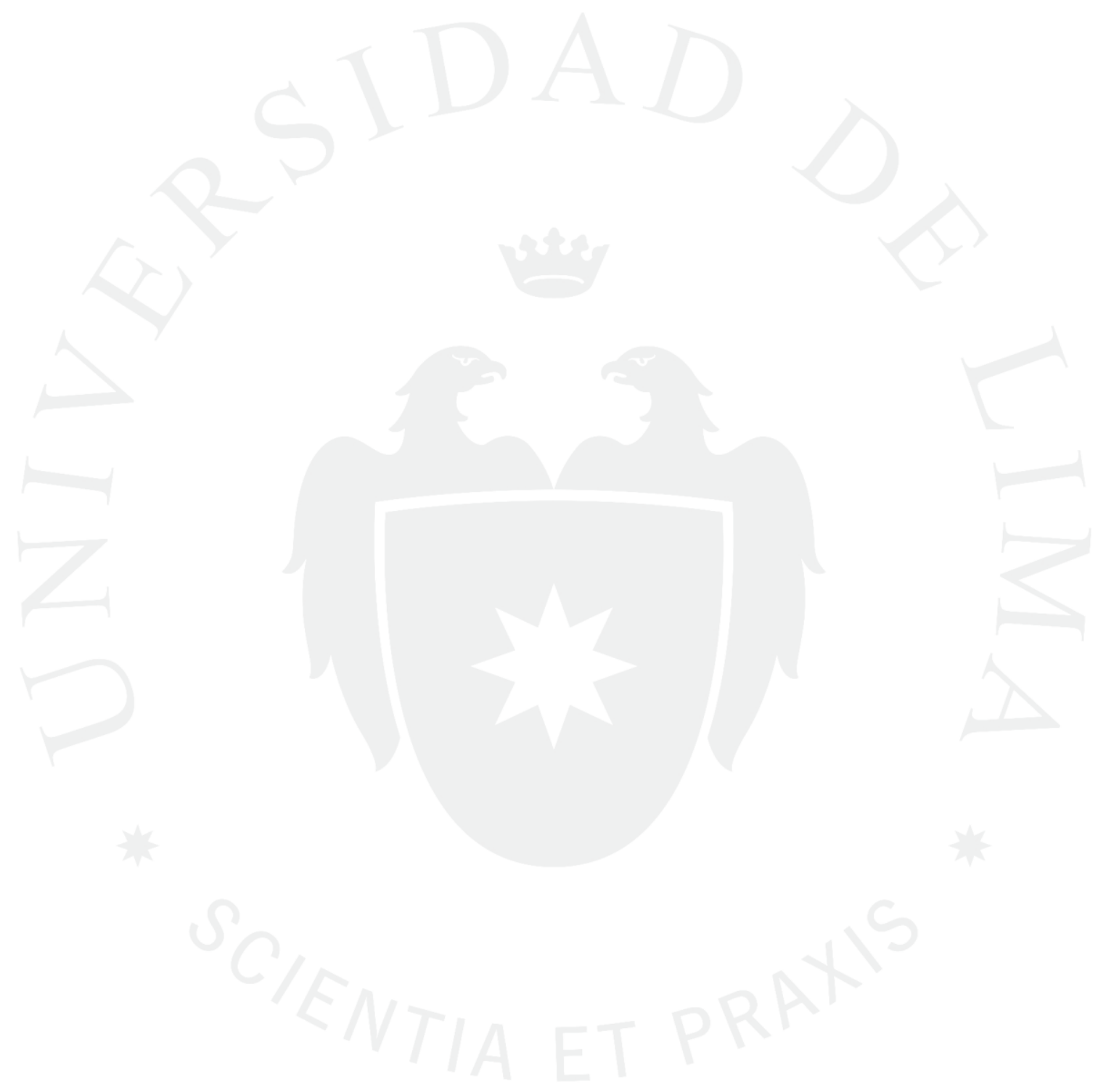




\section{LA CONGESTIÓN VEHICULAR EN LIMA}

METROPOLITANA ENTRE LOS AÑOS 2012 Y 2016 AFECTA ECONÓMICAMENTE A LAS EMPRESAS ASEGURADORAS DE VIDA Y A SUS TRABAJADORES 


\section{TABLA DE CONTENIDO}

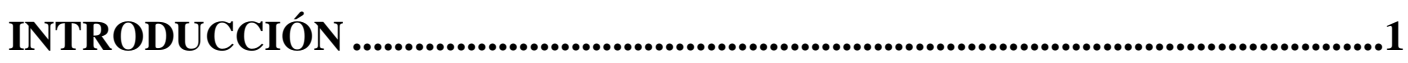

CAPÍTULO I: PROBLEMÁTICA ............................................................................3

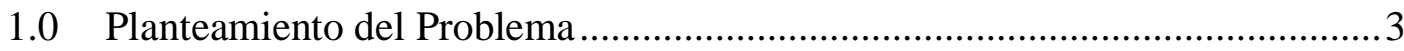

1.1 Justificación e Importancia de la investigación ................................................. 7

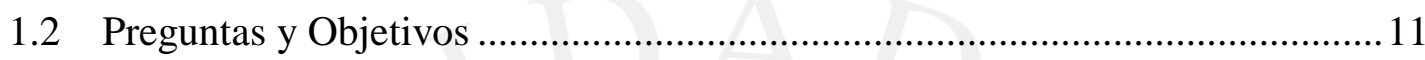

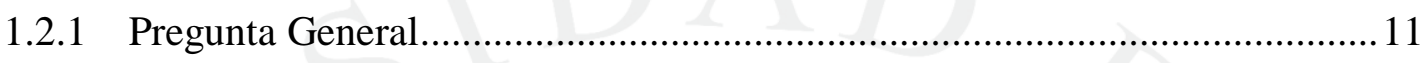

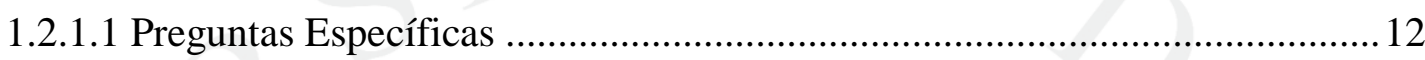

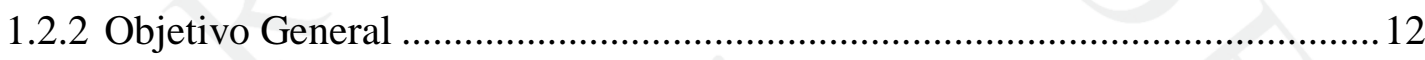

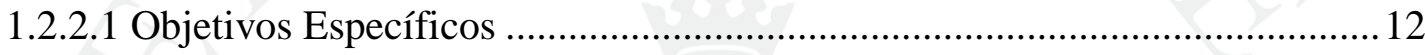

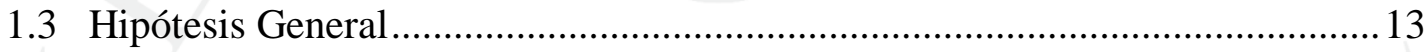

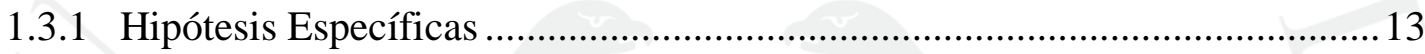

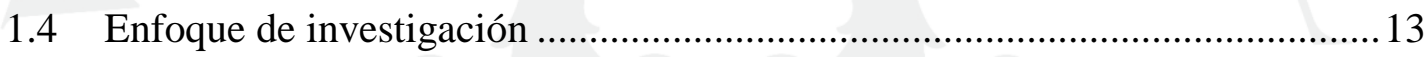

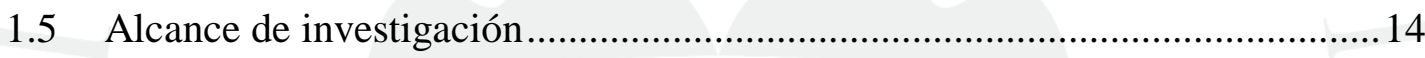

CAPÍTULO II: MARCO TEÓRICO ..................................................................16

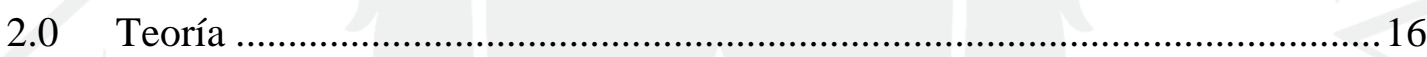

2.1 Posibles causas de la congestión vehicular en Lima ......................................21

2.2 ¿Podría el tráfico estar afectando a las empresas? .............................................35

2.3 Efectos que tiene la congestión vehicular en las personas ...............................36

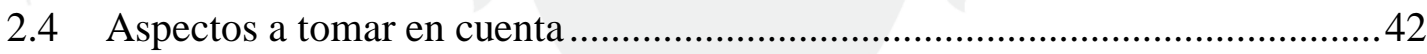

CAPÍTULO III: METODOLOGÍA DE LA INVESTIGACIÓN ........................49

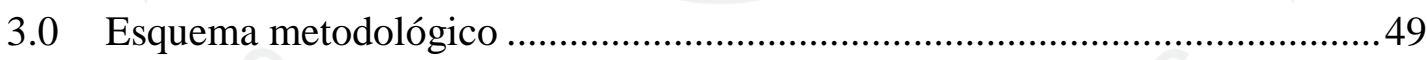

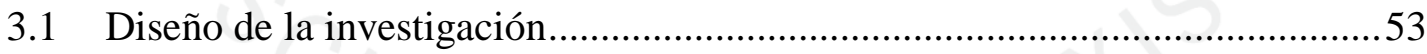

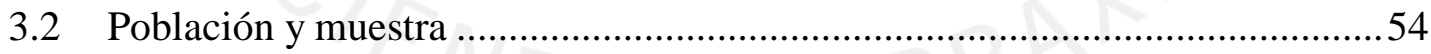

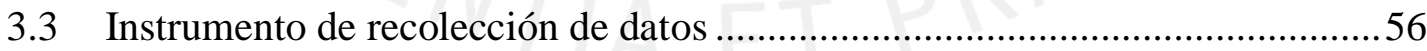

3.4 Criterios empleados para la elaboración de la encuesta ................................57

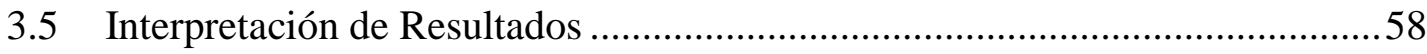

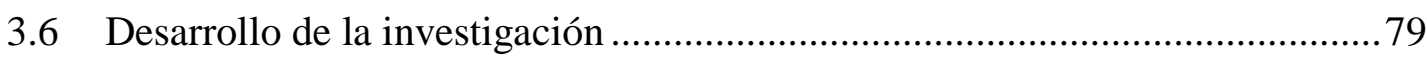

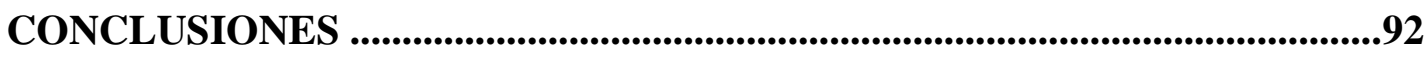

RECOMENDACIONES _.............................................................................................93

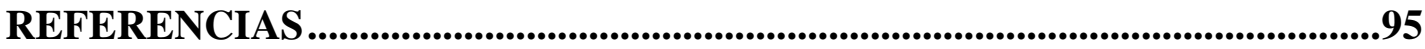

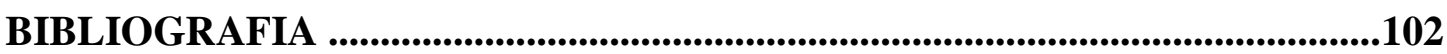




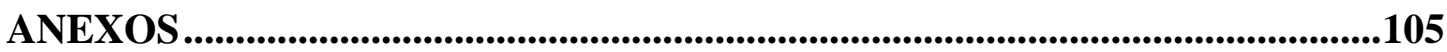




\section{ÍNDICE DE TABLAS}

Tabla 1.1.1 Participación de mercado de las empresas de seguros de vida en el

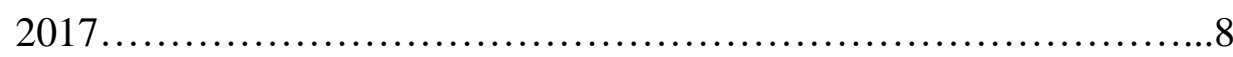

Tabla 2.1.1 Población de Lima desde el 2000 al 2015 ........................................... 22

Tabla 2.1.2 Cuadro comparativo de zonas rurales y urbanas desde 1940 al 2007 .... 23

Tabla 2.1.3 Incentivo económico.............................................26

Tabla 2.1.4 Parque automotor en circulación a nivel nacional, según departamento, $2004-2012$ (unidades) ............................................................. 27

Tabla 2.1.5 Comunidad Andina: Stock del parque vehicular, según países, 2006-2015 (Miles de vehículos) .................................................................... 28

Tabla 2.1.6 Comunidad Andina: Stock del parque vehicular por cada mil habitantes, 2006-2015

Tabla 2.1.7 Indicador número de vehículos por personas en Lima Metropolitana al 2015 29

Tabla 2.1.8 Número de vehículo en Lima por tipo de modelo ............................... 30

Tabla 2.3.1 Efectos que tiene el $\mathrm{CO} 2$ en las personas según concentración de dióxido de carbono y tiempo de exposición 37

Tabla 2.3.2 Número de accidentes vehiculares registrados en todo el Perú desde el 2012 al 2014 40

Tabla 2.4.1 Encuesta Arellano Marketing: ¿Qué acción tomaría para solucionar el

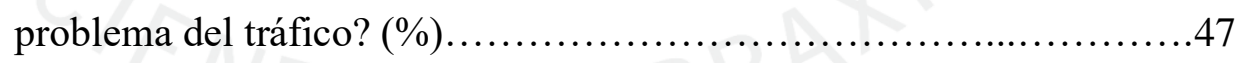

Tabla 2.4.2 Encuesta Arellano Marketing: ¿Cuál es la razón más importante del problema? $(\%)$............................................47

Tabla 3.2.1 Datos utilizados para el cálculo del tamaño de la muestra................54

Tabla 3.6.1 Indicadores de Ganancias y Pérdidas por Empresa por Vendedor al 2016 (en Miles de Nuevos Soles) ............................................................... 84

Tabla 3.6.2 Sueldo de un vendedor......................................... 85 
Tabla 3.6.3 Pérdidas monetarias anuales...................................... 86

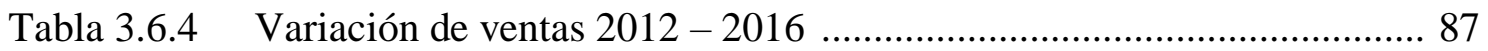

Tabla 3.6.5 Variación en la rentabilidad 2012 - 2016 ............................................. 88

Tabla 3.6.6 Cuadros de gastos anuales por concepto de traslado según puesto y por cómo se movilizan .......................................................................... 91 


\section{ÍNDICE DE FIGURAS}

Figura 1.1.1 Fórmula variable dependiente ..................................

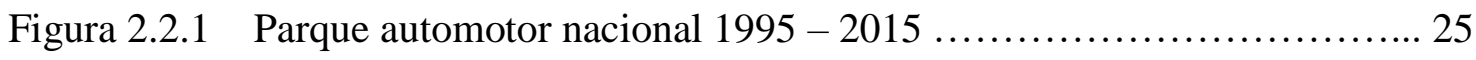

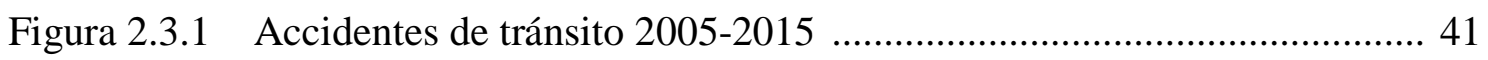

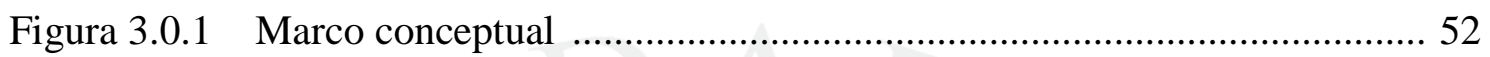

Figura 3.2.1 Fórmula para hallar el tamaño de muestra..............................54

Figura 3.2.2 Organigrama del área Seguros de Vida Corporativos de la empresa

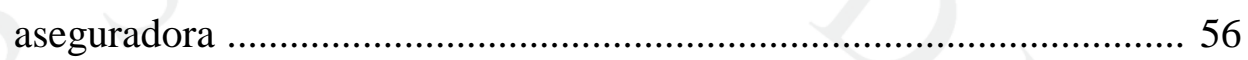

Figura 3.5.1 Pregunta 1 ¿Cuenta con un automóvil propio con el que se moviliza? . 59

Figura 3.5.2 Pregunta 2. ¿Utiliza su vehículo para ir o volver de su centro laboral? 59

Figura 3.5.3 Pregunta 4. ¿Cuánto tiempo tiene que conducir durante un día laborable para ir a su centro de trabajo? ........................................................ 60

Figura 3.5.4 Pregunta 5. ¿Cuánto tiempo tiene que conducir durante un día laborable para llegar a su hogar?

Figura 3.5.5 Pregunta 6. ¿Conduce fuera de los límites de su distrito en la semana por

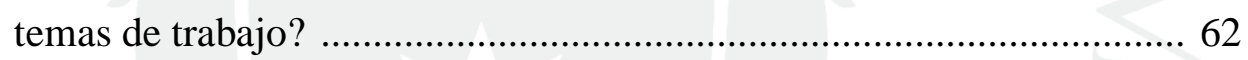

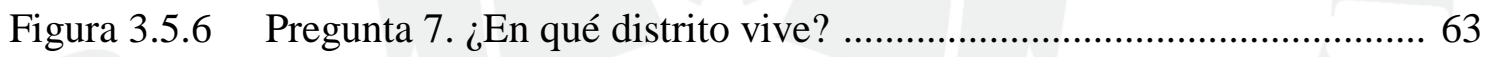

Figura 3.5.7 Pregunta 8. ¿A qué hora sale de su hogar para dirigirse al trabajo? ..... 64

Figura 3.5.8 Pregunta 9. ¿Cuánto suele gastar en combustible semanalmente? ........ 65

Figura 3.5.9 Pregunta 10. ¿Tienes donde estacionar cerca o en tu trabajo? ............. 66

Figura 3.5.10 Pregunta 11. Normalmente, ¿cómo se moviliza? ..................................6 67

Figura 3.5.11 Pregunta 12. Aproximadamente ¿cuánto tiempo emplea viajando en: taxi, autobús, bicicleta, otro? ............................................................. 68

Figura 3.5.12 Pregunta 13. Aproximadamente ¿cuánto tiempo camina al día por motivos laborales?

Figura 3.5.13 Pregunta 14. ¿Cree que el tráfico está afectando su desempeño en el trabajo?

Figura 3.5.14 Pregunta 15. ¿Cuáles son los principales efectos que tiene el tráfico en su salud? 70

Figura 3.5.15 Pregunta 16. ¿La empresa donde trabaja hace algo para contrarrestar los efectos causados por el tráfico? 
Figura 3.5.16 Pregunta 18. ¿Cree que el tráfico esta afectando su desempeño en el trabajo?

Figura 3.5.17 Preguntas 21. ¿Con qué frecuencia pierde sus actividades personales debido a la congestión vehicular?

Figura 3.5.18 Pregunta 22. Si maneja un equipo ¿sus trabajadores se movilizan utilizando el servicio público?

Figura 3.5.19 Pregunta 23. En porcentaje ¿cuántos de sus colaboradores utilizan el servicio público? 76

Figura 3.5.20 Pregunta 24. Si maneja un equipo ¿siente que su equipo se perjudica por la congestión vehicular actual?

Figura 3.5.21 Pregunta 26. En general, ¿qué tan grave es el problema de congestion para su trabajo?

Figura 3.6.1 Mapa de Lima Metropolitana detallando los distritos 83 


\section{ÍNDICE DE ANEXOS}

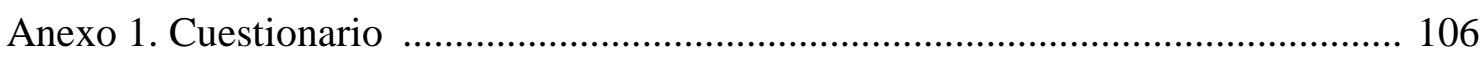

Anexo 2. Encuesta Eliminador............................................. 110 


\section{INTRODUCCIÓN}

El problema del tráfico en las grandes ciudades es un tema conocido y recurrente, experimentado por aquellas personas que viven o que han visitado grandes metrópolis en diferentes partes del mundo. Este problema afecta a todo tipo de individuos, de todo nivel económico y de todas las edades. La contaminación, el estrés y la "pérdida de tiempo" que éste ocasiona, es sin lugar a duda una de las continuas quejas tanto de ciudadanos y turistas como de empresarios y políticos.

El caos de las calles de Lima no es la excepción a la regla, cada día cientos de miles de limeños se quejan y/o lamentan de este problema y sus efectos, excusando la expresión coloquial "el pan de cada día”. Pero lo que no muchos conocen son los enormes efectos económicos negativos que tiene el tráfico en las empresas. Estos son reales, tangibles y medibles que afectan fuertemente a las personas, también a las compañías y por lo tanto la economía del país entero.

Las personas viven planificando las siguientes horas, días, semanas, meses y hasta años. Se establecen objetivos, metas y planes de acción en todos los ámbitos, tanto personales como profesionales, donde el tiempo es un recurso muy valioso. Es así que la expresión "El tiempo es Oro" adquiere una connotación particular, si el tiempo es valioso, ¿cuál es el costo que tiene para las empresas peruanas el tráfico desorganizado y caótico de la ciudad de Lima?

Este trabajo comienza explicando el problema actual del tráfico en la ciudad capital del Perú, identificando las posibles causas que han originado la congestión vehicular, que abarca cada vez mayor parte del día. Luego, se le dará un enfoque más cuantitativo orientado explícitamente a las empresas y personas, mostrando el problema desde un punto de vista diferente, menos conocido por la mayor parte de la población y corporaciones.

Todo esto en aras de que la sustentación científica y cuantitativa permita establecer el verdadero costo y pérdida económica a causa de este problema que aqueja a toda la sociedad peruana.

Dada la complejidad del tema, el trabajo será desarrollado y aplicado a un caso real, en el sector de empresas aseguradoras de vida del mercado peruano, específicamente 
en Pacifico, Rimac, Interseguros, Mapfre y La Positiva que cuentan con el $81.75 \%$ del mercado (SBS, 2017). El informe este enfocado principalmente en el área comercial y cómo estas se ven afectada por la congestión vehicular.

El problema del tráfico es mucho más grave y sus consecuencias son mucho más negativas de lo que la mayor parte de la población, empresas y gobiernos piensan. Es de vital importancia para el desarrollo económico de nuestras compañías y nuestro país implementar soluciones coherentes, apropiadas y sostenibles en el tiempo. La siguiente investigación propone algunos acercamientos considerando diferentes aspectos interconectados.

En conjunto toda esta investigación aportará posibles soluciones que las podrán aplicar tanto las personas como las empresas y hasta los municipios y gobiernos. Estas soluciones se dan a lo largo del trabajo y consideran diferentes aspectos. 


\section{CAPÍTULO I: PROBLEMÁTICA}

Este capítulo explicará cómo se determinó este problema y por qué se desarrolló un interés por profundizar acerca de él. También se dará a conocer el impacto del tráfico vehicular en los resultados de las empresas y sus colaboradores.

\subsection{Planteamiento del Problema}

Diariamente todos los limeños, sin excepción, tienen que lidiar con el tráfico vehicular. En la creencia de que poco o nada pueden hacer al respecto, intentan aprender a vivir con él.

La congestión vehicular empeora cada día y las autoridades no plantean una solución integral. Los embotellamientos se han estado produciendo con más frecuencia alrededor de comienzos del siglo XXI, pero el problema se inicia tiempo atrás. En los últimos 15 años se ha generado un impactante aumento de la población en Lima, incrementada con las migraciones que provienen del interior del país.

A medida que la economía ha ido creciendo, un mayor número de personas cuenta con auto propio. El parque automotor ha crecido, ya que los autos nuevos que han ingresado no han sustituido a los antiguos, sino que se han sumado. A pesar de esto, las vías públicas siguen teniendo las mismas dimensiones y capacidades que hace 50 años. Es así que Lima ha llegado a ser la peor capital de Sudamérica para conducir, esto lo revelo la aplicación Waze en setiembre del 2016 (El Comercio, 2016)

Las personas creen que la capital del Perú tiene un tráfico particular que hace que sea difícil manejar, ganando el dicho "Si manejas en Lima puedes manejar en cualquier lugar”. En esta metrópolis, la congestión vehicular tiene ciertas particularidades ya que es caótica, desordenada, irrespetuosa, no cuenta con una buena infraestructura, entre otras. Pero esta no es la única ciudad del mundo con este problema. El tan reconocido canal televisivo, Discovery Channel (2016), realizó un programa llamado "Don’t drive here" (en español "No maneje aquí"), en donde muestra a Lima entre otras ciudades que 
tienen un tráfico similar. Algunas de estas ciudades son: Delhi, Ciudad de México, Bangkok, Manila y Ulaanbaatar, Mongolia.

Es claro que la ciudad de los Reyes tiene un gran problema en la infraestructura vial, en general las calles son muy angostas y se ponen más carriles donde ya no alcanza. También la condición de las pistas y carreteras es preocupante, donde los huecos y baches que se encuentran perjudican gravemente la fluidez del tránsito de los vehículos.

Lima no cuenta con un planeamiento urbano integral, por eso que las vías no son las adecuadas, sin embargo, tenemos el reto de buscar mejoras en base a lo existente. Contamos con pocos pasos a desnivel y puentes, siendo estos últimos más rápidos de construir y más económicos.

Otro problema en la construcción de infraestructura es el tiempo que demoran en realizar las obras, extendiéndose plazos que inicialmente se plantean en meses y pueden llegar incluso a años entorpeciendo el tráfico. También hay que mencionar que la realización de obras es durante el día haciendo que los vehículos se tengan que desviar por vías alternas. En los países desarrollados las construcciones de vías se realizan a partir de las 10pm y concluyen antes de las 5am, para que así durante las horas que se movilizan más autos estos no se vean tan perjudicados. Según expertos en la movilidad de la Universidad Católica del Perú, el problema infraestructural es el principal factor que genera los accidentes de tránsito (Capital, 2012)

El tema de la construcción de vías no debe ser pensado sólo para la fluidez vehicular, sino también para la interconexión de ciudades y así incentivar la descentralización, pero para lograr esto se deben implementar transportes alternos como trenes, tranvías, ferris, etc. Es muy importante reconocer que a mayor gasto público más se aprecia la moneda y es más fácil combatir cualquier crisis económica. Por otro lado, la creación de transportes alternativos no sólo ayudará a la descentralización de la capital, sino que también generará una mayor interconexión con los países circundantes al Perú, lo cual incrementaría el turismo, el comercio, las relaciones, entre otras, todo esto beneficiando el progreso del país.

Otro gran problema limeño es la informalidad del transporte público, el cual comenzó en los años 90. Los buses son manejados por empresas que no cumplen con las leyes y que permiten a cualquier persona conducir estos vehículos. Esto no sólo sucede en buses también en taxis, cualquier individuo puede poner su cartel de taxi y nadie tiene 
el 100\% de seguridad al subir a ellos. En ambos casos sucede que estos vehículos paran en cualquier lugar a recoger personas, pero también hay que reconocer que no existen lugares apropiados y autorizados para detenerse. Aunque estos existan los mismos pasajeros hacen caso omiso y exigen que los autos paren donde ellos se encuentran en lugar de caminar hasta los lugares permitidos. Pero muy pocos saben cuál es el mayor problema a esta informalidad, está a causado 30,000 muertes en los últimos 10 años, equivalente a la caída de 100 aviones (Ramírez, 2016, párr. 2).

Las personas en general cuando observan el tráfico en las calles sólo ven lo más notorio como: gente irrespetuosa, tumultos de vehículos y personas, embotellamientos, ruido, enojo, entre otras; pero no ven más allá, este problema ya no sólo afecta a las personas que manejan ni ocurre sólo en horas determinadas. Está afectando a toda la población, porque todos necesitan movilizarse tanto como para ir al trabajo, colegio, universidad, centros de estudio, como para hacer las tareas cotidianas como: hacer las compras de la comida, ir al banco, realizar trámites o simplemente pasear y salir de casa.

Es importante recalcar que el tráfico en las calles de Lima muestra un problema mayor, la falta de educación reflejada en la ausencia de valores en las personas, ya que no es humana la manera como se tratan entre ellos, no sólo entre las personas que manejan sino también con los transeúntes y pasajeros.

Por otro lado, el que las personas tarden más tiempo en trasladarse, no es el único problema que está causando la congestión vehicular de la ciudad, también está perjudicando directamente la salud. Como informo el doctor Carlos Bromley (2012), psiquiatra del Ministerio de Salud, en su entrevista con RPP Noticias: "A nivel psiquiátrico, lo común es que se produzcan trastornos de ansiedad y trastornos de depresión. A nivel físico, pueden presentarse las enfermedades cardiacas, las enfermedades de la piel y las enfermedades respiratorias producidas por la contaminación ambiental".

Hay que tomar en consideración que la decisión de las personas de comprar un carro para trasladarse no es sólo por comodidad o porque tienen los bienes necesarios como para hacerlo. En todo el Perú existe un problema mayor que el actual presidente, Pedro Pablo Kuczynski, se ha comprometido a disminuir, este es la delincuencia. (Servindi, 2016) 
La delincuencia ha incrementado en $35.6 \%$ entre octubre 2015 y marzo 2016 (INEI, 2016) y el $90.6 \%$ de los limeños viven atemorizados de ser blanco de algún tipo de delito (Perú 21, 2016). Todo esto ha causado que la población comience a tomar mayores medidas de seguridad como: utilizar alarmas, cámaras, lunas polarizadas, armas de defensa personal, utilizar taxis seguros o movilizarse en autos propios. La delincuencia ha llegado a un punto que ni en un auto particular te sientes seguro, ya que rompen la luna del auto sólo para robar un celular, cartera, billetera o cualquier cosa de valor que este a la vista. En el peor de los casos han matado a personas por un teléfono móvil, como sucedió en el distrito de San Luis el 30 de Julio del 2017 (La República, 2017)

Hasta este punto se han nombrado varios efectos que tiene el problema de la congestión vehicular en la población limeña, pero existe un aspecto que las personas no han notado. El tráfico está perjudicando la economía de las empresas y sus trabajadores, porque cada vez llegan más tarde o tienen que levantarse más temprano para llegar a tiempo, lo que genera que pasen menos tiempo con sus familias o relajándose y más rato atorados en las calles embotelladas. El pasar tantas horas en una congestión tan desordenada e irrespetuosa, como es la de Lima, genera mal humor y las personas llegan con ese sentimiento al trabajo, lo que puedo conllevar a un mal ambiente laboral. Y todo esto termina teniendo efectos monetarios negativos en las personas y empresas.

Este problema no sólo se queda en las personas, si los empleados comienzan a tener un bajo desempeño esto trae consigo que las empresas tengan una menor rentabilidad, lo que termina afectando el PBI del país, lo que significa que indirectamente está afectando a todo el Perú. Esta puede ser una causa por la cual el país no puede seguir progresando para dejar de ser un país tercermundista.

Dicho problema está afectando con más fuerza a todas empresas en donde su fuerza de venta debe de movilizarse para generar ingresos. Por ejemplo, este es el caso de las empresas aseguradoras.

Se suele escuchar que el tráfico empeora porque las autoridades no hacen nada al respecto, pero ellos no notan que esto también los está afectando, ya que llegan tarde o pierden reuniones importantes para el desarrollo del país. Esto se ve reflejado en el cambio de horario de ingreso de los congresistas, su hora de ingreso era a las 8am y votaron para cambiarlo a las 9am (Trome, 2017). Si las autoridades se dieran cuenta de 
los que están perdiendo por las horas que pasan en sus vehículos, tomarían decisión con efectos más rápidos y perdurables en el tiempo.

Es claro que los gobernantes tienen gran parte de la responsabilidad de lo que está pasando actualmente, ya que en el Perú se ve mucho que al cambio de gobierno las obras se paralizan o se cambian leyes que perjudican a los intentos de mejora del transporte peruano. La población tampoco ayuda a generar un cambio, siempre hay un "pero" en todo lo que se trata de hacer, es claro que siempre se van a encontrar perjudicados, pero estas decisiones se toman pensando en un bien común, que beneficie a la mayor parte de la población.

A pesar de todos estos puntos, no todas las soluciones las tienen que realizar el gobierno ni involucran grandes inversiones, acaso ¿usted no puede hacer algo? La respuesta es sí, con ser un poco más tolerante, respetuosos y no pensar sólo en sí mismo es suficiente para comenzar a generar un cambio. También hay que resaltar la importancia de cumplir con las leyes referidas a tránsito vehicular. Si todos los limeños ponen un granito de arena para solucionar el problema se va a observar una gran mejora. Pero el gran problema comienza en el respeto mutuo, como se suele escuchar "el peor enemigo de un peruano es otro peruano".

\subsection{Justificación e Importancia de la investigación}

Actualmente no existen estudios previos sobre este tema tan específico. Por más que sí se han encontrado aplicaciones del tema en otras ciudades del mundo, es muy poca la información que enlaza la congestión vehicular con la economía de un país.

Es cierto que cada vez se puede encontrar más autores hablando sobre el tráfico de Lima, ya que es un tema preocupante y notorio, pero todas estas personas se enfocan en cosas diferentes como: el desorden, la falta de vías públicas apropiadas, el anarquismo al no seguir las leyes de tránsito, la informalidad del transporte público, entre otros.

Por lo que, al tocar este tema en el desarrollo del trabajo se busca concientizar a todas las personas, empresas, corporación y gobiernos que este problema es más serio de lo que creen y esto se va demostrar a través de un caso real que está sucediendo en el sector segurador. 
En el caso del Perú este tema es más serio por la forma de pago que se emplea en la mayoría de empresas, la cual es mensual no por hora trabajada. Si fuera por hora los más perjudicados serían los empleados no necesariamente las empresas, ya que ellas ganarían por el tiempo exacto que trabajó su colaborador.

Las empresas que se ven mucho más afectadas son en las que sus trabajadores se deben de movilizar para gestionar la venta de sus bienes o servicios. Como es el caso de las empresas aseguradoras de vida en las cuales sus vendedores se movilizan a lo largo del día para visitar clientes y vender los diversos productos.

Este trabajo justamente está enfocado en las empresas aseguradoras de Lima Metropolitana y se va a buscar probar que a causa del tráfico estas están perdiendo ingresos teniendo que compensarlo de diversas maneras. El estudio no es de todo el sector, sino de las cinco empresas más representativas del sector, ya que cuentan con más de $80 \%$ del mercado en conjunto (Tabla 1.1.1). Dichas empresas son: Rimac, Pacifico, Interseguros, Mapfre y La Positiva.

Tabla 1.1.1

Participación de mercado de las empresas de seguros de vida en el 2017

\begin{tabular}{|c|c|c|c|c|}
\hline & Empresas & Monto & $\begin{array}{c}\text { Participación } \\
(\%)\end{array}$ & $\begin{array}{l}\text { Porcentaje } \\
\text { Acumulado }\end{array}$ \\
\hline 1 & Pacifico Seguros (1) & 1339799 & 27.19 & 27.19 \\
\hline 2 & Rimac & 1253835 & 25.45 & 52.64 \\
\hline 3 & Interseguro & 496487 & 10.08 & 62.72 \\
\hline 4 & Mapfre Perú Vida & 479841 & 9.74 & 72.46 \\
\hline 5 & La Positiva Vida & 457580 & 9.29 & 81.75 \\
\hline 6 & Seguros Sura & 281992 & 5.72 & 87.47 \\
\hline 7 & Protecta & 140898 & 2.86 & 90.33 \\
\hline 8 & Vida Cámara & 135670 & 2.75 & 93.09 \\
\hline 9 & Ohio National Vida & 132573 & 2.69 & 95.78 \\
\hline 10 & Cardif & 100073 & 2.03 & 97.81 \\
\hline 11 & Chubb Seguros & 66057 & 1.34 & 99.15 \\
\hline 12 & Crecer Seguros & 41743 & 0.85 & 100.00 \\
\hline 13 & Rigel & 140 & 0.00 & 100.00 \\
\hline \multirow{2}{*}{\multicolumn{2}{|c|}{ TOTAL }} & \multicolumn{2}{|c|}{4} & \\
\hline & & 926688 & 100.00 & \\
\hline
\end{tabular}

Fuente: Superintendencia de Banca y Seguros del Perú

Recuperado de: http://www.sbs.gob.pe/app/stats_net/stats/EstadisticaBoletinEstadistico.aspx?p=25\#

También con la ayuda de este estudio se buscará entender la relación y la interacción entre las dos variables (el tráfico y las empresas). Siendo la congestión vehicular la variable independiente y las empresas las dependientes (Figura 1.1.1). 


\section{Figura 1.1.1}

Fórmula de variable dependiente

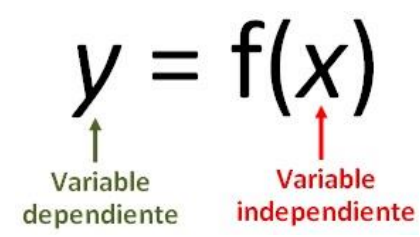

Fuente: Universo Formulas

Recuperado de: http://www.universoformulas.com/matematicas/analisis/variable-dependiente/

A causa de este problema se está desperdiciando un valioso recurso, el tiempo. El ingreso de dinero a las empresas y personas hace que el Perú tenga mayores recursos, estos ganados a través de los diferentes impuestos. Sin el pago de impuestos no se pueden realizar obras públicas, ni se le puede pagar a los empleados del estado, lo que genera huelgas y retrasos en los trabajos. Por lo tanto, todos los peruanos terminan siendo gravemente afectados, porque el Perú no podrá seguir progresando para dejar de ser un país tercermundista.

Tocando el tema gubernamental, este problema está afectando al Perú por intersección de las empresas y personas. A través de esta investigación se busca concientizar también a los gobiernos a poner manos a la obra, ya que gran parte de este es causado por una mala ejecución de los planes gubernamentales o de la descontinuación de los proyectos iniciados en gobiernos anteriores. Y también por el incumplimiento de leyes ya existentes de todos los ciudadanos, incluyendo a los gobernantes.

La realización de nuevas carreteras, la implementación de trenes, la construcción de terminales de buses, entre otros; ayudarían a una descentralización en donde no sólo Lima sería la única ciudad grande del país, sino que todas las provincias podrían tener su propia ciudad moderna con más centros de trabajo, de estudio, lugares recreativos como: centros comerciales, coliseos, piscinas, parques, etc.

Esto es lo que sucede en todos los países desarrollados, ellos mediante la facilidad de transporte han generado un gran número de ciudades grandes e imponentes a lo largo de sus territorios. Estos países logran este desarrollo generando gastos públicos, lo que significa realizar obras como: carreteras, ampliación de carreteras, coliseos, colegios, universidades, etc. 
Lima Metropolitana está tratando de involucrase en este tema y buscado soluciones, por lo cual, ha creado una entidad para gestionar el tráfico vehicular. Esta lleva el nombre de Protránsito, esta tiene el difícil trabajo de elaborar iniciativas para lograr una adecuada gestión del tránsito en la ciudad (El Comercio, 2017). Le colocaron este nombre porque "Pro" significa "a favor de" o "partidario de" y "tránsito", palabra proveniente de transitar, que quiere decir "ir o pasear de un punto a otro por las vías o parajes públicos”. (Quispe, 2017)

Es importante recalcar que la mayoría de personas creen que sólo existe trabajo en Lima, pero esto no es así, a lo largo de todo el territorio peruano existe materia prima demandada en todo el mundo como: minerales y agricultura en la sierra, madera y frutas en la selva y peces en la costa. Estos materiales no están siendo debidamente explotados y en Lima se está concentrando la mayor parte de la manufactura, siendo más económica fuera de esta ciudad.

El que existan más oportunidades de progreso, crecimiento y desarrollo para las personas también aportaría a que la delincuencia disminuya, ya que mayormente esta existe y aumenta por falta de empleos. El peligro de las calles perjudica a todos, si la ciudad fuera segura sería más sencillo trabajar de donde se encuentren gracias a la tecnología que existe actualmente, resolviendo un poco el tema del tráfico vehicular. Es por esto es que el presidente Pedro Pablo Kuczynski, ha prometido reducir la delincuencia, la cual comienza cortando de raíz la corrupción (La República, 2017)

En esta investigación no sólo se conocerán los efectos que tiene la congestión vehicular sobre las personas, empresas y gobierno, sino también conocerán cuáles son las causas por las cuales el tráfico en Lima está cada vez peor, lo cual no sólo se genera por la falta de infraestructura y control del transporte público. Existen factores que van más allá de lo obvio y que tiene orígenes desde el siglo XX como: el aumento de la población, el número significativo de vehículos, la informalidad, la falta de leyes claras y la aplicación de la misma, la corrupción, entre otros.

Uno punto importante es conocer que se puede hacer al respecto para así poder generar un cambio en la ciudad de Lima con respecto al tráfico vehicular. Existen diferentes cosas que se pueden implementar para generar un progreso y no todas implican grandes inversiones, en la mayoría sólo se necesita de un poco de compromiso y decisión de las personas. 
Se aportará a las empresas información con la cual pueden combatir la impuntualidad, la cual se cree que es cultural, ya que los peruanos son reconocidos por tardones y hasta tienen un horario especial "La hora peruana". A pesar de esto la congestión vehicular aporta mucho a que estas impuntualidades sean peores. También enfrentarían la falta de productividad, el cansancio y mal genio del personal. Con esto podrán no sólo mejorar la rentabilidad de la empresa sino también el clima laboral; los trabajadores se sentirán entendidos, motivados y se creará una fidelización del personal, lo que involucra una reducción de rotación del personal, traducido en personas más capacitadas en las diferentes actividades del negocio y se invertiría menor tiempo y dinero en selección del personal y capacitaciones. Todo esto claramente aportará a la rentabilidad de las empresas y como se ha mencionado antes, el que las empresas tengan un mayor ingreso termina reflejándose en el progreso del Perú.

Cómo dijo el presidente Pedro Pablo Kuczynski en el discurso de 28 de julio del 2017: "Es inaceptable que millones de peruanos pasen horas de su día detenidos en el tráfico. Necesitamos avanzar. No perdamos el tiempo. Vamos a arreglar el tránsito en Lima y en las grandes ciudades”. (La República, 2017)

\subsection{Preguntas y Objetivos}

Al ser conscientes de este gran problema que va más allá de las calles de Lima y que los efectos que tiene no sólo afectan a las personas, sino también a las empresas y hasta al país, es más fácil determinar tanto el objetivo general como los objetivos específicos de esta investigación.

\subsubsection{Pregunta General}

¿Cuál es el impacto económico del tráfico vehicular entre los años 2012 y 2016 en las empresas (Pacifico, Rimac, Interseguros, Mapfre y La Positiva) y los trabajadores del sector seguros de vida? 


\subsubsection{Preguntas Específicas}

1) ¿Qué ocasionó que el tráfico vehicular en la ciudad de los Reyes llegue a los niveles actuales?

2) ¿Cuál es el impacto económico en las empresas de seguros de vida en Lima Metropolitana entre el 2012 y el 2016 ?

3) ¿Cuál es el impacto económico en los trabajadores del sector seguros de vida en la ciudad capital del Perú entre el 2012 y el 2016?

\subsubsection{Objetivo General}

Determinar cuál es el impacto económico del tráfico vehicular entre los años 2012 y 2016 en las empresas aseguradores de vida de Lima Metropolitana y en sus trabajadores.

\subsubsection{Objetivos Específicos}

Para poder llegar al objetivo general se requiere de objetivos específicos, los cuales se detallan a continuación:

- Determinar y analizar cuáles fueron los detonantes para que el problema de la congestión vehicular en Lima llegue a la situación actual.

- Cuantificar el efecto económico de la congestión vehicular en las empresas aseguradoras en el rubro de seguros de vida entre el año 2012 y 2016 en Lima Metropolitana.

- Cuantificar el efecto económico del tráfico vehicular en los trabajadores de las empresas aseguradoras de vida entre el año 2012 y 2016 en la capital del Perú. 


\subsection{Hipótesis General}

El tráfico vehicular afecta económicamente a las empresas aseguradoras de vida de Lima Metropolitana entre los años 2012 y 2016 y a sus trabajadores.

\subsubsection{Hipótesis Específicas}

1) Se ha llegado a la congestión vehicular actual debido al crecimiento de la población, del parque automotor y de la economía del país.

2) El crecimiento del parque automotor ha generado perjuicios económicos en las empresas aseguradoras de vida de Lima Metropolitana entre los años 2012 y 2016, lo que se refleja en sus ingresos.

3) La aglomeración de autos de Lima Metropolitana afecta económicamente los ingresos de los trabajadores de empresas aseguradoras vida entre los años 2012 y 2016.

\subsection{Enfoque de investigación}

El tema de esta investigación se puede desarrollar de diferentes maneras, pero en esta oportunidad se le dará un enfoque mixto en donde se observarán datos cuantitativos y cualitativos. Se ha recopilado información de encuestas obteniendo resultados números y se han hecho investigaciones y cálculos para poder apreciar numéricamente lo que está sucediendo. También se ha podido realizar entrevistas buscando la opinión de los empleados y de los medios de comunicación sobre el problema actual del tráfico vehicular en Lima.

Con respecto a la entrevista, esta se realizó a un gerente comercial de seguros de vida corporativos de una de las empresas líderes de seguros. Para así, entender mejor cómo funcionan las empresas de seguros de vida. Es por esto que se decidió entrevistar al Gerente de Distribución de Seguros de Vida Corporativos, porque es una persona que tiene como función principal manejar y controlar varios equipos comerciales, por lo cual, sabe muy bien cómo funciona la mayor parte del área en ámbitos generales. 
Por otro lado, se han realizado encuestas a colaboradores de seguros de vida de las empresas Pacifico, Rimac, Interseguros, Mapfre y La Positiva, ya que estas empresas cuentan con más de $80 \%$ del mercado (como se vio en la Tabla 1.4.1), buscando que sean de diferentes puestos para conocer el punto de vista de todos.

En la encuesta se han realizado diferentes preguntas, pero primero se ha divido entre las personas que tienen vehículos propios y las que no, ya la pérdida de tiempo es diferente para las personas que conducen y las que se movilizan con transporte público. También se ha buscado que la encuesta la llenen personas que viven cerca y lejos de su centro de trabajo para saber cómo se movilizan y el tiempo que les toma.

Es así que se hará una comparación entre estas muestras de encuestados. Se estudiará los resultados obtenidos para entender mejor la manera cómo la congestión vehicular afecta económicamente a los trabajadores, y para encontrar algunas maneras como ayudarlos a superar las diferentes dificultadas que genera el tráfico en su vida laboral.

Para este trabajo el método que se utilizará es el estudio de casos, ya que es utilizado en las áreas de ciencias sociales. Como en esta oportunidad se está trabajando con la información obtenida en las entrevistas y encuestas realizadas a parte del personal de las empresas aseguradora, este método encaja perfectamente para el estudio.

\subsection{Alcance de investigación}

Para la realización de esta investigación se aplicará un alcance exploratorio, ya que ayudará a descubrir ideas y obtener nuevos conocimientos y así poder familiarizarse con este problema relativamente desconocido.

Por otro lado, se estarán estableciendo prioridades para investigaciones futuras, por eso se dice que el alcance exploratorio les prepara el terreno a los otros estudios. También permite ser más flexible, lo que genera que se cuente con una investigación más amplia y dispersa. Pero a pesar de esto, hay que tener en cuenta que este tipo de investigación tiene un riesgo alto, por lo cual, se necesita tener paciencia, serenidad y receptividad para que el resultado final sea el adecuado. 
Como este trabajo se pretende examinar un problema de investigación poco estudiado, ya que nunca se ha abordado antes en el Perú este tema específico. Por más que es un problema notorio, son muy pocos los autores que se están enfocando en él. Se ha podido encontrar información peruana sobre el tráfico, pero no sobre como este afecta económicamente a las empresas y a las personas. Por esto, como no se cuenta con estudios previos exactos, la mayor parte de lecturas realizadas corresponde a estudios de otros países. 


\section{CAPÍTULO II: MARCO TEÓRICO}

En este capítulo se comienza a investigar del tema con la ayuda de diferentes fuentes de información, que se obtuvieron gracias a diversas bases de datos. En conjunto todo lo averiguado determinará los factores del problema.

El capítulo es desarrollado en cuatro partes para entender mejor cómo comenzó la congestión vehicular en la capital del Perú, qué efectos tiene tanto en las personas como en las empresas y algunas soluciones que otros autores plantearon.

\subsection{Teoría}

Antes de comenzar con la investigación se van a explicar teóricamente las definiciones más relevantes con el fin de poder entender mejor toda la explicación del trabajo.

Primero comencemos con el tema principal de este trabajo: la congestión, está refiriéndose directamente a la vehicular o de tránsito. El diccionario de la Lengua Española (Real Academia Española, 2017) define la congestión como "acción y efecto de congestionar o congestionarse" y congestionar significa "obstruir o entorpecer el paso, la circulación o el movimiento de algo".

Realizando una inclusión de ambos significados, se puede concluir que la congestión es la acción y efecto de obstruir o entorpecer el paso, circulación o movimiento, en este caso de las vías de transporte. Esta explicación permite entender por qué se utiliza este término cuando se habla de tráfico vehicular en Lima.

Los autores Alberto Bull e Ian Thomson (2002) definen la congestión vehicular como: "la condición en que existen muchos vehículos circulando y cada uno de ellos avanza lenta e irregularmente" (p.110). Ellos indican que tanto su definición como la del diccionario son de carácter subjetivo y no conllevan a una precisión suficiente. Hay que recalcar que es claro que ellos la definen de la manera en que las personas observan el tráfico vehicular.

Se puede llegar a una definición uniendo los significados que nos brindan estos autores, por lo cual, la congestión automotriz es considerada como una condición en la 
cual el flujo de vehículos en las vías es muy denso o está saturado, esto se debe principalmente, al exceso de demanda de las vías y por el número de carros en ellas. Todo esto, genera que los autos no puedan circular con fluidez por las diferentes vías de la ciudad.

Es importante conocer que es una empresa aseguradora, a qué se dedica y cuál es su importancia. "Las compañías aseguradoras son empresas dedicadas a la venta de pólizas de seguros, suelen proporcionar sus servicios a instituciones o particulares; una de sus mayores funciones es ofrecer protección ante imprevistos que puedan representar una importante pérdida monetaria para el asegurado.

Las compañías aseguradoras suelen vender distintos servicios, entre ellos podemos observar una división importante: los seguros generales, los cuales se encargan de proteger un bien inmueble; y los seguros de vida, los cuales resguardan un bien intangible.

Para contar con la protección el asegurado o contratante debe pagar una cantidad llamada prima, ésta suele ser establecida de manera conjunta por el contratante y la aseguradora, también suele contemplar el valor del bien que se está asegurando. La prima puede ser de mayor o menor cantidad dependiendo de la totalidad que se quiera asegurar del bien, así mismo, se calcula en conjunto con el deducible, ya que entre más caro sea el deducible, menor costo tendrá la prima, y viceversa.

La actividad de las compañías aseguradoras es importante porque protege ante riesgos económicos asegurables. Una empresa de seguros puede diferir de otra en cuanto a los servicios que ofrece y los costos que cobra por estos.

Las compañías aseguradoras funcionan de la siguiente manera: por medio de las aportaciones de los contratantes es posible cubrir los siniestros que se vayan presentando, el hecho de que una compañía de seguros no tenga que hacer frente a todos los siniestros al mismo tiempo, es lo que permite mantener el negocio. Las aseguradoras tienen bien calculado el riesgo de que se produzca un accidente, de esta manera siempre tienen la solvencia para responder ante el gasto de un siniestro.

Algunos de los servicios que se pueden encontrar en una empresa aseguradora son: seguros para autos, seguros de gastos médicos, seguros educacionales, seguros empresariales, seguros de vida y seguro de vivienda”. (SiSeguros, 2017) 
Las empresas aseguradoras tienen con recurso primordial a sus vendedores o como algunas empresas la llaman asesores. Ivan Thompson (2017) explica que "El vendedor es el elemento más importante de las ventas personales porque permite establecer una comunicación directa y personal con los clientes actuales y potenciales de la empresa, además, porque tiene la facultad de cerrar la venta y de generar y cultivar relaciones personales a corto y largo plazo con los clientes.”.

Para la American Marketing Association (A.M.A.) "el vendedor (salesperson) es una persona que está implicada ante todo en el proceso personal de asistir y/o de persuadir a los clientes potenciales para que compren un producto o servicio para el beneficio mutuo del comprador y el vendedor".

Según el Diccionario de Marketing de Cultural S.A., "vendedor es un término que, en sentido genérico, designa a una persona física o jurídica que se dedica a la venta de bienes o servicios. Hoy en día, el término representante de ventas abarca un amplio espectro en la economía, que va desde el repartidor hasta el creador de demanda, pasando por el receptor del pedido o el técnico".

En una empresa aseguradora los vendedores forman la fuerza de ventas, lo cuales mediante su productividad brindan ingresos económicos a dichas empresas y a su persona. Por lo tanto, la productividad de los trabajadores se ve reflejada en la economía de las empresas, esta es definida por la Real Academia Española (RAE, 2017) como: “capacidad o grado de producción por unidad de trabajo, superficie de tierra cultivada, equipo industrial, etc." o en términos económicos "relación entre lo producido y los medios empleados, tales como mano de obra, materiales, energía, etc.”.

Los ingenieros Francisco Javier Rodríguez y Luis Gómez Bravo (1991) tienen otro punto de vista, ya que ellos creen que este concepto siempre es vinculado a expresiones matemáticas producto/insumos y a su operacionalización cuantitativa, por lo cual, puede ser mal interpretada o le pueden reducir su importancia. Los ingenieros mencionan que: "la productividad evalúa la capacidad del sistema para elaborar los productos que son requeridos (que se adecuan al uso) y a la vez del grado en que aprovechan los recursos utilizados, en decir el valor agregado, el cual tiene dos vertientes para su incremento: 1) producir lo que el mercado (cliente) valora y; 2) hacerlo con el menor consumo de recursos." (p.32) 
La definición que le otorgo el autor Joseph Prokopenko (1987), es una combinación entre lo que dice el diccionario y los ingenieros. El menciona que "la productividad también puede ser definida como la relación entre la cantidad y calidad de bienes o servicios producidos y la cantidad de recursos utilizados para producirlos" (p.3). Joseph explica que "la productividad es un instrumento comparativo para gerentes y directores de empresa, ingenieros industriales, economistas y políticos” (p. 3). Pero él además tiene una definición diferente: "La productividad también puede definirse como la relación entre los resultados y el tiempo que lleva conseguirlos" (p. 3).

Por lo que, la productividad se puede explicar cómo la capacidad de una persona de ser productivo, eficiente y eficaz; lo que quiere decir que la persona es capaz de realizar sus funciones de tal manera que llega a sus metas y objetivos en el tiempo adecuado y con la menor cantidad de recursos necesarios.

Por lo tanto, si el personal de una empresa es productivo esta va a generar una buena rentabilidad. Pero ¿qué quiere decir esto? La Real Academia Española (2017) define la rentabilidad como: "cualidad de rentable" o "capacidad de rentar", entonces ellos explican que rentable es: "que produce renta suficiente o remuneradora". Lo que quiere decir que reduciendo los gastos la empresa aun cuenta con liquidez para seguir funcionando e invirtiendo y esto es lo que explica América Ivonne Zamora Torres (2008). Ella indica que "la rentabilidad es la relación que existe entre la utilidad y la inversión necesaria para lograrla, ya que mide tanto la efectividad de la gerencia de una empresa, demostrada por las utilidades obtenidas de las ventas realizadas y utilización de inversiones, su categoría y regularidad es la tendencia de las utilidades” (p. 57)

Gitman (1992) la explica de una manera más detallada, definiéndola como "una medida que relaciona los rendimientos de la empresa con las ventas, los activos o el capital. Esta medida permite evaluar las ganancias de la empresa con respecto a un nivel dado de ventas, de activos o la inversión de los dueños. La importancia de esta medida radica en que para que una empresa sobreviva es necesario producir utilidades. Por lo tanto, la rentabilidad está directamente relacionada con el riesgo, si una empresa quiere aumentar su rentabilidad debe también aumentar el riesgo y, al contrario, si quiere disminuir el riesgo, debe disminuir la rentabilidad..." (p. 62)

Viéndola de otro punto de vista, la rentabilidad también tiene un enfoque en marketing y es así que Guiltinan y Gordon (1984) la plantea como "la eficiencia general 
de la gerencia, demostrada a través de las utilidades obtenidas de las ventas y por el manejo adecuado de los recursos, es decir la inversión, de la empresa..." (p. 117).

Por lo tanto, integrando todas las definiciones anteriores, la rentabilidad puede ser definida como el resultado mayor a la inversión inicial obtenido al final de un periodo determinado, siendo este no necesariamente monetario, también pueden ser beneficios. Es un dato número cuantificable, uno de los más importantes, ya que demuestra cuán eficiente es la organización en temas de ingresos. Está es medida con fórmulas financieras en donde se involucran la utilidad, ventas, activos y capital de la empresa.

Si existe una alta rentabilidad de las empresas del país, este se refleja en el Producto Bruto Interno (PBI), el cual es definido por Domingo Begazo y Torres Agurto (2009) de tres maneras:

- "Es el valor monetario del conjunto de bienes y servicios finales producidos en un período de tiempo determinado y en un territorio económico determinado" (p. 44).

- "Es el indicador que mide la actividad económica de un país, es el ratio que calcula a cuánto asciende la producción total de un país" (p. 44).

- "Se define como el valor total de los bienes y servicios generados en el territorio económico durante un período de tiempo, que generalmente es un año, libre de duplicaciones" (p. 44).

Ellos también indican que el PBI puede ser definido como "el valor añadido en el proceso de producción y mide la retribución a los factores de producción que intervienen en el proceso de producción".

Por lo que, se puede decir que el Producto Bruto Interno está constituido por todos los productos, bienes y servicios de una determinada área, este es medido en un tiempo fijado, por lo general de un año. Este muestra la actividad económica del territorio, por lo cual, la variabilidad de la producción total del mismo.

Por último, es relevante conocer la definición de economía. Según la Real Academia Española esta es "la administración eficaz y razonable de los bienes", también 
es "un conjunto de bienes y actividades que integran la riqueza de una colectividad o un individuo" y como "ahorro de trabajo, tiempo u otros bienes o servicios." (RAE, 2017)

Economipedia (2017) la describe como: "Una ciencia social que estudia la forma de administrar los recursos disponibles para satisfacer las necesidades humanas. Además, también estudia el comportamiento y las acciones de los seres humanos.

Como los recursos del planeta son escasos y desgraciadamente, no todos podemos disponer de todo, nos vemos obligados a administrar esos bienes para conseguir lo que nos falta. La ciencia económica envuelve la toma de decisiones de los individuos, las organizaciones y los Estados para asignar esos recursos escasos".

\subsection{Posibles causas de la congestión vehicular en Lima}

Con la ayuda de las definiciones y términos vistos anteriormente, será más fácil comprender el desarrollo de la investigación. Comenzando entendiendo cómo es que ha ido empeorando la congestión vehicular en los últimos años en la ciudad capital del Perú.

Enfocándonos sólo en el tráfico en Lima, hay que entenderlo un poco más por qué este ya no es sólo en horas punta, sino que sucede a lo largo de todo el día. Para esto hay que conocer los antecedentes de la Ciudad de Los Reyes.

Según el último censo del 2007 realizado por el Instituto Nacional de Estadísticas e Informática (INEI, 2007) la población de Lima Metropolitana era de 8 millones 473 mil personas, como se puede ver en la tabla 2.1.1, lo que representaba el $29.91 \%$ de la población total del Perú. Desde esa fecha la población de la capital ha crecido en un 7\% llegando al número de 9 millones 111 mil personas a los 482 años de fundada la ciudad de Lima (INEI, 2017), demostrando que más del 28\% de la población peruana se encuentra en la capital. Con la ayuda de este último dato y la tabla 2.1.1, se puede apreciar que el crecimiento constante de la población ha comenzado a decaer. Esto en general se debe a un mayor control de fertilidad que comenzó en el gobierno de Fujimori. 
Tabla 2.1.1

Población limeña del 2000 al 2015

\begin{tabular}{rrr} 
& Año & Población \\
LIMA 2000 & $7,767,873$ \\
& 2001 & $7,913,690$ \\
\hline 2002 & $8,057,558$ \\
\hline 2003 & $8,199,172$ \\
\hline 2004 & $8,338,208$ \\
\hline 2005 & $8,474,342$ \\
\hline 2006 & $8,605,145$ \\
\hline 2007 & $8,730,820$ \\
\hline 2008 & $8,855,022$ \\
\hline 2009 & $8,981,440$ \\
\hline 2010 & $9,113,684$ \\
\hline 2011 & $9,252,401$ \\
\hline 2012 & $9,395,149$ \\
\hline 2013 & $9,540,996$ \\
\hline 2014 & $9,685,490$ \\
\hline 2015 & $9,834,631$
\end{tabular}

Fuente: Instituto Nacional de Estadísticas e Informática (s. f.)

Recuperado de: http://proyectos.inei.gob.pe/web/poblacion/

¿A qué se debe que en Lima se encuentra la mayor cantidad de personas? Se investigó en la historia del Perú y desde el año 1940 se comenzó a observar una fuerte cantidad de migrantes del campo a la ciudad. Como se aprecia en el siguiente cuadro (tabla 2.1.2), antes la mayor parte de la población se encontraba en el campo y en el 2007 ya se observa un claro cambio de esto. 
Tabla 2.1.2

Cuadro comparativo de zonas rurales y urbanas desde 1940 al 2007

\begin{tabular}{|c|c|c|c|c|c|c|c|}
\hline \multirow[b]{2}{*}{ Año } & \multirow{2}{*}{ Total } & \multicolumn{2}{|c|}{ Población } & \multicolumn{2}{|c|}{ Incremento intercensal } & \multicolumn{2}{|c|}{$\begin{array}{l}\text { Tasa de crecimiento } \\
\text { promedio anual ( } \% \text { ) }\end{array}$} \\
\hline & & Urbana & Rural & Urbana & Rural & Urbana & Rural \\
\hline \multirow[t]{2}{*}{1940} & 6207967 & 2197133 & 4010834 & & & & \\
\hline & & & & 2501045 & 1197734 & 3,7 & 1,2 \\
\hline \multirow[t]{2}{*}{1961} & 9906746 & 4698178 & 5208568 & & & & \\
\hline & & & & 3360317 & 271145 & 5.1 & 0,5 \\
\hline \multirow[t]{2}{*}{1972} & 13538208 & 8058495 & 5479713 & & & & \\
\hline & & & & 3033428 & 433574 & 3,6 & 0,8 \\
\hline \multirow[t]{2}{*}{1981} & 17005210 & 11091923 & 5913287 & & & & \\
\hline & & & & 4366676 & 676470 & 2,8 & 0.8 \\
\hline \multirow[t]{2}{*}{1993} & 22048356 & 15458599 & 6589757 & & & & \\
\hline & & & & 5351689 & 12112 & 2,1 & 0,01 \\
\hline 2007 & 27412157 & 20810288 & 6601869 & & & & \\
\hline
\end{tabular}

Nota: Perú: Población censada, urbana y rural y tasa de crecimiento en los censos

Fuente: INEI - Censo Nacional de Población y Vivienda 1940, 1961, 1981,1993 y 2007

Recuperado de www. grupo4cultura.wordpress.com

¿A qué se debió esta migración? Existen diferentes causas por las cuales las personas decidieron dejar sus tierras y comenzar de cero en la ciudad capital. Algunas de ellas son: la construcción de carreteras que les facilito su traslado, el desarrollo de los medio de comunicación, la crisis que afectó el agro entre 1940 y 1945 como consecuencia de la segunda guerra mundial, la menor mortalidad infantil en Lima en comparación de las provincias, las posibilidades de una mejor remuneración, el crecimiento de la administración pública y la posibilidad de acceder a niveles educativos más altos, los movimientos terroristas iniciados en la década de 1980 y la explosión tecnológica de las décadas de 1990 y el 2000. (Blog WorldPress.com, 2010)

Con esta explicación se entiende un poco más el motivo por el cual la mayoría de personas habitan en Lima. Pero hay que reconocer que no sólo ha aumentado la población, sino también la capacidad adquisitiva de los individuos. El Banco Central de Reserva del Perú ha demostrado que el Producto Bruto Interno ha incrementado en 4.5\%, pero a pesar de esto el desempleo también lo ha hecho en 7\%, sólo en Lima Metropolitana (BCR, 2016). Por otro lado, hay que mencionar que el ex presidente, Ollanta Humala, decreto un aumento de cien soles en la Remuneración Mínima Vital. Paso de ser S/.750 a S/.850, esto tuvo vigencia en mayo del 2016 (El Comercio, 2016). 
Todos estos incrementos conllevan a que las personas puedan gastar su dinero ya no sólo en bienes primarios, sino que ahora les alcanza para comprar en otro tipo de bienes como vehículos, por lo cual, esto ha contribuido a que el número de autos aumente. "En el mes de abril del 2016, la venta e inscripción de vehículos livianos y pesados nuevos en la Superintendencia Nacional de los Registros Públicos (Sunarp), creció 2.7\% alcanzando las 15,251 unidades, informó la Asociación Automotriz del Perú (AAP)" (Gestión, 2016).

La decisión de los limeños de comprar vehículos no se debe sólo a que tienen la capacidad económica para hacerlo, ni es sólo para trasladarse con más comodidad, también influye mucho la seguridad. Actualmente, el problema de delincuencia en Lima es muy grave, las personas ya no se sientes seguras ni en sus hogares. Es por esto que el utilizar vehículos propios es una medida de seguridad, al igual que utilizar lunas polarizadas, contar con alarmas, tener un seguro, guardar los objetos de valor en la maletera, parquear en playas de estacionamiento, contar con algún tipo de defensa, entre otras medidas.

Muchos creen que el problema de delincuencia se genera por la falta de empleo y si puede ser una decisión extrema que toman las personas por necesidad. Si se piensa en todas esas personas que migran a Lima desde las diversas provincias, pensando que en la capital van a encontrar empleo y no lo hacen, sólo les queda: pedir dinero en las calles, tener trabajos improvisados como ambulantes o hacer algo ilegal.

Retomando al tema del volumen de autos existentes en Lima, observando la figura 2.1.1 en donde se puede entender mejor cómo es que el parque automotor nacional se ha desenvuelto desde 1995 hasta el 2015, considerando que a partir del 2004 se comenzó a considerar las motos y las mototaxis. 
Figura 2.1.1

Parque automotor nacional 1995 - 2015

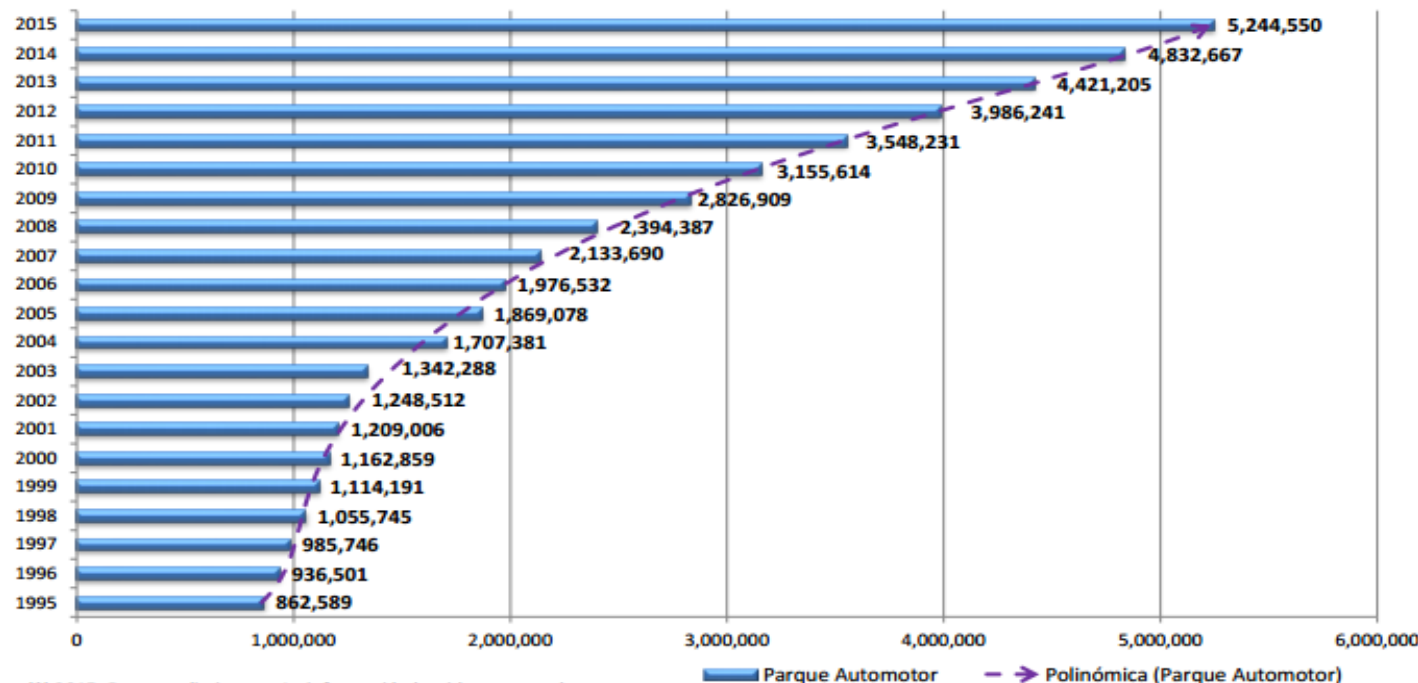

(*) 2015: Datos preliminares - La información ha sido provectada

Nota: A partir del año 2004 los vehículos menores (mototaxis y motos) están considerados en el total del parque automotor nacional.

Fuente: Superintendencia Nacional de los Registros Públicos

Recuperado de https://www.mtc.gob.pe/cnsv/estadisticas/Parque\%20vehicular\%20nacional\%2019952015.pdf

El señor Quispe Candi (2013) reveló que: “En los años noventa en el Perú existían cerca de 650 mil vehículos. Hoy existen 2 millones 200 mil vehículos y sólo en Lima hay 1 millón 200 mil vehículos que, por desinterés de las autoridades, no ha estado preparada para albergar una cantidad tan abrumadora de unidades de transporte. Por lo tanto, esto demuestra que Lima es una ciudad sin planificación" (como se citó en Rischmoller, 2013).

Asimismo, se observa que es mínimo el número de vehículos que se dan de baja por ya no estar en condiciones de seguir circulando, 267 en el primer semestre del 2015 para ser exactos (RPP Noticias, 2015). Siendo así que estos se arreglan de cualquier manera para mantenerlos en circulación. Esto incrementa el número de accidentes en pistas y carreteras y dadas las condiciones de los vehículos, se ocasiona una mayor congestión vehicular.

El gobierno está intentado retirar los vehículos en mal estado y desecharlos con el Programa de Chatarreo de Protransporte. Este programa sólo acepta Camioneta Rural, 
Microbús u Ómnibus. Ellos compran los vehículos en mal estado siendo los importes los que aparecen en la tabla 2.1.3.

Tabla 2.1.3

Incentivo económico

\begin{tabular}{|l|c|c|}
\hline \multicolumn{1}{|c|}{ Tipo de Vehículo } & Antigüedad & $\begin{array}{c}\text { Certificado de Chatarreo } \\
\text { (US\$) }\end{array}$ \\
\hline $\begin{array}{l}\text { Camioneta Rural } \\
\text { (de 10 a 16 asientos) }\end{array}$ & De 20 a 24 años & 5,000 \\
\cline { 2 - 3 } & De 25 a más años & 4,000 \\
\hline $\begin{array}{l}\text { Microbús } \\
\text { (de 17 a 33 asientos) }\end{array}$ & De 20 a 24 años & 7,500 \\
\cline { 2 - 3 } & De 25 a más años & 6,000 \\
\hline $\begin{array}{l}\text { Ómnibus } \\
\text { (de 34 asientos a más) }\end{array}$ & De 20 a 24 años & 10,000 \\
\hline
\end{tabular}

Fuente: Protransporte

Recuperado de: http://www.protransporte.gob.pe/programa_de_chatarreo.pdf

En la tabla 2.1.4 se puede apreciar mejor cómo están distribuido el parque automotor del Perú en las diferentes provincias, en donde claramente se puede apreciar que Lima está muy por encima de los demás departamentos en número de vehículos. 
Tabla 2.1.4

Parque automotor en circulación a nivel nacional, según departamento, 2004 - 2012 (unidades)

\begin{tabular}{|c|c|c|c|c|c|c|c|c|c|}
\hline Departamento & 2004 & 2005 & 2006 & 2007 & 2008 & 2009 & 2010 & 2011 & 2012 \\
\hline Total & 1361403 & 1440017 & 1473530 & 1534303 & 1640970 & 1732834 & 1849690 & 1979865 & 2137837 \\
\hline Amazonas & 1975 & 2020 & 2103 & 2168 & 2218 & 2292 & 2390 & 2407 & 2400 \\
\hline Áncash & 19293 & 19382 & 19757 & 20354 & 21001 & 21309 & 22086 & 23322 & 25418 \\
\hline Apurimac & 3730 & 3816 & 3879 & 3916 & 3934 & 3973 & 3969 & 3966 & 4039 \\
\hline Arequipa & 78858 & 79544 & 81293 & 84829 & 91674 & 98270 & 106521 & 118985 & 134533 \\
\hline Ayacucho & 3882 & 3919 & 3969 & 4153 & 5404 & 5572 & 5716 & 5784 & 5941 \\
\hline Cajamarca & 8882 & 9501 & 10256 & 11255 & 12383 & 13563 & 15107 & 17320 & 19673 \\
\hline Cusco & 35342 & 35705 & 36204 & 37592 & 39688 & 42175 & 45090 & 48491 & 53675 \\
\hline Huancavelica & 1043 & 1061 & 1080 & 1103 & 1216 & 1291 & 1319 & 1317 & 1323 \\
\hline Huánuco & 10968 & 10886 & 10836 & 10892 & 11255 & 11382 & 11864 & 12576 & 13476 \\
\hline Ica & 22692 & 22753 & 22834 & 23170 & 25498 & 25691 & 26135 & 26419 & 26551 \\
\hline Junin & 43468 & 43648 & 44454 & 46091 & 47769 & 49404 & 51094 & 53118 & 56237 \\
\hline La Libertad & 97590 & 153777 & 152847 & 153251 & 155411 & 156646 & 158672 & 162026 & 167325 \\
\hline Lambayeque & 37967 & 38263 & 38744 & 39930 & 41920 & 43689 & 45881 & 49440 & 53902 \\
\hline Lima & 866881 & 885636 & 912763 & 957368 & 1036850 & 1106444 & 1195353 & 1287454 & 1395576 \\
\hline Loreto & 5336 & 5286 & 5215 & 5154 & 5132 & 5089 & 5089 & 5211 & 5313 \\
\hline Madre de Dios & 823 & 819 & 827 & 870 & 913 & 941 & 986 & 1027 & 1062 \\
\hline Moquegua & 9417 & 9622 & 10394 & 11418 & 12202 & 12692 & 13348 & 14003 & 14608 \\
\hline Pasco & 4772 & 5232 & 5514 & 6075 & 6807 & 7187 & 7351 & 7292 & 7238 \\
\hline Piura & 31731 & 31734 & 31828 & 32314 & 33497 & 34650 & 36367 & 39099 & 42404 \\
\hline Puno & 25642 & 25874 & 26452 & 28062 & 29889 & 31645 & 34169 & 37074 & 40543 \\
\hline San Martin & 10277 & 10156 & 10033 & 9969 & 9917 & 9977 & 10151 & 10418 & 10926 \\
\hline Tacna & 30549 & 31119 & 32011 & 33944 & 35911 & 38457 & 40465 & 42318 & 44430 \\
\hline Tumbes & 2958 & 3009 & 3025 & 3042 & 3040 & 3054 & 3086 & 3119 & 3257 \\
\hline Ucayali & 7327 & 7255 & 7212 & 7383 & 7441 & 7441 & 7481 & 7679 & 7987 \\
\hline
\end{tabular}

Nota: Información estimada, considera la tasa de baja anual. Incluye la provincia constitucional del Callao.

Fuente: Ministerio de Transporte y Comunicaciones - Oficina General de Planificación y Presupuesto.

Recuperado de https://www.inei.gob.pe/estadisticas/indice-tematico/traffic-accidents/

Obteniendo información más actualizada, la Comunidad Andina publicó el 20 de diciembre del 2016 un informe del parque vehicular de todos los países que la componen. Y como se ve en la tabla 2.1.5, Perú se encuentra en segundo lugar con respecto a qué países cuenta con un mayor número de vehículos. 


\section{Tabla 2.1.5}

Comunidad Andina: Stock del parque vehicular, según países, 2006-2015 (Miles de vehículos)

\begin{tabular}{|c|c|c|c|c|c|c|c|c|c|c|}
\hline Pais & 2006 & 2007 & 2008 & 2009 & 2010 & 2011 & 2012 & 2013 & 2014 & 2015 \\
\hline Comunidad Andina & 7886 & 8676 & 9740 & 10878 & 12323 & 13715 & 15243 & 17272 & 19190 & 20742 \\
\hline Bolivia & 602 & 700 & 843 & 906 & 966 & 1087 & 1212 & 1332 & 1461 & 1580 \\
\hline Colombia & 4345 & 4922 & 5514 & 6241 & 6910 & 7662 & 8536 & 9796 & 11143 & 12110 \\
\hline Ecuador & 962 & 920 & 989 & 904 & 1291 & 1418 & 1509 & 1723 & 1753 & 1925 \\
\hline Perú & 1977 & 2134 & 2394 & 2827 & 3156 & 3548 & 3986 & 4421 & 4833 & 5127 \\
\hline
\end{tabular}

Nota: Se realizaron ajustes en las cifras del Perú en el periodo 2006-2015

Fuente:

Bolivia: Registro Único de Administración Tributaria (RUAT).

Colombia: Departamento Administrativo Nacional de Estadística (DNAE), Ministerio de Transporte.

Ecuador: Agencia Nacional de Tránsito, Instituto Nacional de Estadística y Censo (INEC).

Perú: Ministerio de Transporte y Comunicaciones (MTC), Superintendencia Nacional de Registros Públicos

(SUNARP).

Recuperado de http://intranet.comunidadandina.org/Documentos/DEstadisticos/SGDE755.pdf

La tabla 2.1.5 muestra el número de vehículos por cada mil habitantes. Considerando que en Lima existen aproximadamente 9 mil personas, sólo la capital cuenta con 1'481,400 automóviles. Esto nos demuestra que en tan sólo dos años el número de autos en provincia a aumentando más que el de la capital. 
Tabla 2.1.6

Comunidad Andina: Stock del parque vehicular por cada mil habitantes, 2006-2015

\begin{tabular}{lrrrrrrrrrr}
\multicolumn{1}{c}{ Pais } & $\mathbf{2 0 0 6}$ & $\mathbf{2 0 0 7}$ & $\mathbf{2 0 0 8}$ & $\mathbf{2 0 0 9}$ & $\mathbf{2 0 1 0}$ & $\mathbf{2 0 1 1}$ & $\mathbf{2 0 1 2}$ & $\mathbf{2 0 1 3}$ & $\mathbf{2 0 1 4}$ & $\mathbf{2 0 1 5}$ \\
Comunidad Andina & $\mathbf{8 3 , 4}$ & $\mathbf{9 0 , 5}$ & $\mathbf{1 0 0 , 3}$ & $\mathbf{1 1 0 , 6}$ & $\mathbf{1 2 2 , 7}$ & $\mathbf{1 3 4 , 8}$ & $\mathbf{1 4 7 , 9}$ & $\mathbf{1 6 5 , 5}$ & $\mathbf{1 8 1 , 5}$ & $\mathbf{1 9 3 , 8}$ \\
Bolivia & 62,5 & 71,2 & 84,1 & 88,6 & 92,7 & 102,3 & 112,0 & 120,9 & 130,3 & 138,5 \\
Colombia & 100,1 & 112,1 & 124,0 & 138,8 & 151,8 & 166,4 & 183,2 & 207,9 & 233,8 & 251,2 \\
Ecuador & 71,7 & 67,6 & 71,6 & 64,5 & 86,0 & 92,9 & 97,2 & 109,2 & 109,4 & 118,3 \\
Perú & 70,2 & 74,9 & 83,1 & 97,0 & 107,1 & 119,1 & 132,3 & 145,1 & 156,8 & 164,6 \\
\hline
\end{tabular}

Nota: Elaborado con las estadísticas del parque vehicular suministrado por la fuente y las proyecciones de población de los institutos

nacionales de estadística.

Fuente: Registro Único de Administración Tributaria (RUAT) de Bolivia, Ministerio de Transporte y Departamento Administrativo Nacional de

Estadística (DANE) de Colombia, Agencia Nacional de Tránsito e Instituto Nacional de Estadística y Censos (INEC) de Ecuador, Ministerio de

Transportes y Comunicaciones (MTC) y Superintendencia Nacional de Registros Públicos (SUNARP) del Perú. Decisión 751. Resolución 1470.

Recuperado de http://intranet.comunidadandina.org/Documentos/DEstadisticos/SGDE755.pdf

Con toda la información anteriormente analizada, se puede concluir que casi el $30 \%$ de la población peruana se encuentra en Lima y el $28.89 \%$ de vehículos del país están en la capital. Para tener una mejor imagen del número de autos que existen en Lima, ya que no existe una estadística exacta, se ha elaborado un indicador que muestra cuántos vehículos por personas existen en la capital.

Tabla 2.1.7

Indicador número de vehículos por personas en Lima Metropolitana al 2015

\begin{tabular}{|l|c|}
\hline VARIABLES & $\mathbf{2 0 1 5}$ \\
\hline Número de vehículos & 1'481,400 \\
\hline Número de personas & 9 ' 834,631 \\
\hline INDICADOR & $\mathbf{6 . 6 4}$ \\
\hline
\end{tabular}

Nota: Elaboración propia.

Fuente: INEI y Comunidad Andina

Recuperado de http://www.inei.gob.pe/ y http://www.aap.org.pe/ 
Como se puede apreciar en la tabla 2.1.7, el indicador informa que hay 6.64 vehículos por persona en Lima Metropolitana hasta el año 2015. Tomando conciencia de este número, sólo el 7.6\% (Encuesta Lima Cómo vamos, 2015) de limeño tienen auto propio. Entonces, ¿a qué se debe este gran número de vehículos? esto se da principalmente a la popularización de alquiler de autos para taxi y por las empresas de buses o "combis". Lima Cómo Vamos hizo un estudio sobre cómo se movilizan los limeños, en donde ellos hicieron un calcular por tipo de vehículo.

Tabla 2.1.8

Número de vehículo en Lima por tipo de modelo

\begin{tabular}{|l|l|}
\hline Automóviles & 680,938 \\
\hline Station Wagon & 181,527 \\
\hline Camionetas pick up & 148,103 \\
\hline Camionetas rurales & 237,894 \\
\hline Camionetas panel & 27,798 \\
\hline Ómnibus & 38,301 \\
\hline Camiones & 90,042 \\
\hline Remolcadores & 22,908 \\
\hline Remolques y semi-remolques & 25,517 \\
\hline Motos & 36,372 \\
\hline Mototaxis & 32,346 \\
\hline
\end{tabular}

Nota: Parque automotriz por tipo de vehículo en el departamento de Lima

Fuente: Lima Cómo Vamos

Recuperado de http://www.limacomovamos.org

Con la tabla 2.1.8 queda claro que el mayor número de vehículos en la ciudad son de transporte público. Según investigaciones al menos de cada 10 limeños, 8 se movilizan en transporte público, que no necesariamente tiene que ser en buses también pueden ser en taxis. Y esto está reflejado en que "hoy, en Lima circulan diariamente más de 182 mil taxis, según el municipio metropolitano, de los cuales 86 mil 445 son formales, 35 mil 
están autorizados por la Municipalidad del Callao y se estima que más de 61 mil son informales. Pues bien, esta cantidad es cinco veces mayor que el promedio de las capitales de Latinoamérica” (La Republica, 2016)

Por lo tanto, en Lima existen 210 mil taxis recorriendo la ciudad a lo largo del día, siendo este el mayor número de taxis en Latinoamérica (Navarro S. 2014). Si se compara con Nueva York, que tiene casi el mismo número de habitantes que la capital del Perú, la Gran Manzana cuenta con 30 mil taxis, son casi 200 mil taxis menos que en Lima (Rischmoller D, 2013). Pero Nueva York no es el único ejemplo "Buenos Aires (Argentina), Santiago (Chile) y Madrid (España) tienen 13, 4 y 5 taxis por cada 1.000 habitantes. Por lo tanto, en Lima sobran más del 130\% de taxis” (La Republica, 2016)

Con estas comparaciones se sobreentiende que no es necesario que esta cantidad de taxis circulen por la ciudad a lo largo del día. Hay muchas horas del día en que estos vehículos están vacíos y sólo generan un gran número de autos innecesarios. Si se les comenta esto a los taxistas una de sus respuestas es: "No hay trabajo por eso tengo que "taxear"” y es verdad como se vio anteriormente el desempleo se ha incrementado. Pero ellos no son conscientes que generan el $72 \%$ de la congestión vehicular limeña, esto significa que el $60 \%$ de las pistas son ocupadas por los taxis y sólo están cubriendo el $4 \%$ de la demanda. Por lo cual, es un gran daño el que están causando a la capital, no sólo a las vías de transporte sino también al medio ambiente y ellos no son conscientes de ello.

Todo esto no significa que las personas utilicen el transporte público porque es la única forma que tienen para movilizarse. Se conoce que el 30\% de los hogares en Lima cuentan con por lo menos una bicicleta, pero sólo el $0.8 \%$ la utiliza como medio de transporte. Es momento de que esto cambie, las personas cuentan con los medios, pero no tienen la iniciativa de utilizarlos.

Actualmente, las diferentes municipalidades de Lima como: San Borja, San Isidro, Miraflores y Santiago de Surco, están incentivando el traslado en bicicleta colocando bicicletas públicas, promoviendo el día sin auto, implementando ciclovías, entre otros. Esto no sólo ayuda a disminuir el número de vehículos circulantes, sino que promueve el deporte y estudios demuestran que la actividad física disminuye el estrés, mal humor y ayuda a que el sistema inmunológico este más activo, lo que se refleja en más fuerte. 
Volviendo al debate del número de vehículos, este problema no se da sólo porque las personas están comprando más carros, sino que no hay rotación de los mismos. Que quiere decir esto, que existen vehículos con muchos años de antigüedad que siguen circulando, en vez de ser desecharlos las personas los reparan y los vuelven a vender.

Esto se está tratando de evitar con la Ley N²9237, norma que crea el Sistema Nacional de Inspecciones Técnicas Vehiculares, en la cual los vehículos de más de 5 años de antigüedad tienen que pasar por una revisión técnica anual. Se realizó esta ley para contribuir con el medio ambiente, pero también para que los autos más antiguos ya no puedan circular oficialmente y así disminuir el número de autos.

A pesar de estas medidas a mediados del 2013 se registraron 2,109 multas por conductores que no presentaban revisiones técnicas actualizadas (Han multado a 2.109 conductores por no tener revisión técnica en lo que va del año, 2013) lo que nos refleja que muchas personas no tienen interés en cumplir con esta norma, o saben que sus vehículos no pasarían la prueba y por eso no la realizan.

Una de las causas por las que las personas compran vehículos usados en lugar de carros nuevos puede ser por la diferencia de precios y también porque existe un impuesto vehicular que se aplica a los automóviles de hasta 3 años de antigüedad. "El Impuesto al Patrimonio Vehicular, de periodicidad anual con una tasa del 1\% de la base imponible, grava la propiedad de los vehículos, automóviles, camionetas, station wagons, camiones, bus y ómnibus. Este debe ser pagado por el propietario durante 3 años, contados a partir del año siguiente al que se realizó la primera inscripción en el Registro de Propiedad Vehicular." (Servicio de Administración Tributaria de Lima, 2015).

En la mayoría de países desarrollados esto no funciona así, es completamente al revés. Se promueve que sólo existan vehículos en buen estado, por lo cual, los mayores a 20 años aproximadamente deben pagar un impuesto bastante alto. Esto no sólo se realiza para que existe más rotación del parque vehicular sino también para contribuir con el medio ambiente, los autos más antiguos son los más contaminantes. Es por esto, que en otros países se utiliza mucho el leasing vehicular, así las personas siempre cuentan con autos nuevos y no hay que preocuparse por todos los problemas que conlleva tener un vehículo antiguo.

En el Perú es muy común encontrar transporte informal, el cual comenzó en los años veinte en donde la informalidad aumentaba con más rapidez que la parte formal. El 
problema actual es que todo lo que vemos es informal "las llamadas "empresas" o comités, la forma de operar y administrar el servicio, la forma de alquilar los vehículos, los establecimientos de las rutas, las variantes de cada línea, los mismos buses son informales porque no hay relación entre su tamaño y su tipo de servicio ya que esto último no existe; las paradas son informales, el horario de trabajo, el "pregonéo" de las rutas, los "dateros", las horas de trabajo, la vestimenta de los operarios, la música estridente que ponen en los vehículos, etc”. (Reyna C. 2009)

Combatir todos estos aspectos para volverlos formales va a ser la parte más difícil, ya que las personas se encuentran acostumbradas a esto y no quieren cambian. Pero es por esto que se necesita de una reforma vehicular la cual se debe de realizar con un buen plan estratégico para que las personas no piensen que están siendo atacadas con el cambio, al contrario, se sientan beneficiadas y entiendan que es una gran mejora.

Algo muy cierto es lo que dijo el señor Quiste, "Lima es una ciudad que no fue planeada", lo que genera que las vías no sean las adecuadas para el número de autos y no tienen una buena infraestructura, la mayoría parecen ser improvisadas, por lo que, de una calle de tres carriles se pasa una de uno carril, generando embotellamientos.

Se puede confirmar esta improvisación de ciudad con todas las invasiones que se observan en los cerros y así comenzaron muchos distritos como el Rimac y creado hace poco Mi Nuevo Perú. También nos damos cuenta de las condiciones de las vías al ver todos los huecos que se tienen que esquivar para no dañar los vehículos, estos retrasan más el tráfico y hasta pueden causar accidentes. Estos dos son un claro ejemplo del problema que tenemos con respecto a las condiciones de las calles que están afectando la fluidez de las mismas.

A pesar de que se está demostrando estadísticamente que ha aumentado, tanto el número de personas, como de vehículos en Lima, el Gobierno no está dando la importancia debida a estos números, por lo cual no están tomando cartas en el asunto y lo están dejando pasar. Aunque se intentó hacer una reforma de transporte público esta no fue exitosa porque no se aplicó de la manera adecuada, pero tampoco se están realizando obras planificadas para incrementar el número de vías vehiculares. Aunque actualmente se escucha mucho sobre el subterráneo que se está elaborando su construcción es tan complicada y cara que va a tomar muchos años para que esté concluido. 
Como se ha mencionado la construcción de vías y transporte alterno no es lo único que se puede hacer para mejorar esta situación, pero si es muy importante porque el Perú necesita descentralizarse. El que se creen trenes, tranvías, carreteras, estaciones de buses, etc. ayudaría que todas las ciudades del país se encuentren conectadas, esto permitiría que se genere más empleo, que toda la materia prima con la que cuenta el país se explote adecuadamente, que se genere más gasto público con la creación de: coliseos, estadios, centros de estudio, lugares de entretenimiento, etc. Es importante recalcar que el contar con grandes gastos públicos fortalece la moneda, lo cual ayuda a combatir las diferentes crisis económicas que puedan existir en el mundo.

También hay que considerar el aspecto cultural, todos los que manejan y hasta las personas que no lo hacen se puedan dar cuenta de la falta de respeto a las leyes, autoridades y hasta entre las mismas personas. Se puede notar la diferencia cultural y educativa cuando se maneja en los diferentes distritos de Lima, en algunos de estos con mejores niveles económicos las personas son mucho más respetuosas y tolerantes al conducir. En cambio, en otros lugares de la ciudad las personas son muy agresivas, siempre están a la defensiva, es como si se creyeran dueños de las calles.

Esta falta de respeto a las leyes se refleja en todas las papeletas que se aplican y en las que se deberían de aplicar, pero como existe mucha corrupción en la policía nacional, se dejan de poner papeletas a cambio de un monto de dinero, lo cual genera que más personas no paguen multas las cuales sirven para pagar sueldos y arreglar las diferentes vías. Para poder cambiar esta situación, el gobierno anterior del presidente Ollanta Humala creó un plan de lucha contra la corrupción en la cual se creó estrategias para combatirla y hasta una manual del denunciante (Presidencia del Consejo de Ministros, 2015). Esto debe ser difundiendo para poder ver algún cambio en el futuro.

En el discurso de 28 de julio del 2017 el presidente Pedro Pablo Kuczynski anuncio el nuevo proyecto de ley de la creación de la Autoridad de Transporte Urbano para Lima y Callao (La República, 2017). El cual busca ordenar el caos vehicular existente en las principales ciudades del Perú. 


\section{2 ¿Podría el tráfico estar afectando a las empresas?}

Ni las personas, ni el gobierno son conscientes de cuánto está afectando el tráfico vehicular a las empresas. Todos piensan que este es un problema cotidiano, que sólo afecta a las personas directamente y que probablemente no tenga solución ya que habitan en un país claramente desorganizado. Pero ¿saben cuánto están perdiendo no sólo las personas sino también las empresas a causa del tráfico? Lo que conlleva a que también afecte al desarrollo del país.

En el condado de Palm Beach, Aruba, se realizó un estudio de cómo está afectando el tráfico a las empresas. Este demostró que "en un condado que se gana 32,524 dólares al año; 625 dólares a la semana; 15.63 dólares por hora. Si los 172,00 trabajadores llegan 10 minutos tarde sumarían 28,666 horas perdidas de productividad (suponiendo que todo el mundo es productivo en el trabajo desde la hora de inicio) entonces, por sólo 10 minutos el valor de pérdida de trabajo sería de casi medio millón de dólares 448,049 dólares para ser específicos" (Lowery, 1995).

Hay que tomar en cuenta que en este país como en muchos otros las personas ganan por hora trabajada, si no acuden a tiempo a sus trabajos esos minutos no son considerados en su paga. En cambio, en Perú si llegas tarde es la empresa la que pierde, porque a las personas se les da un sueldo que tiene el concepto de paga por día trabajado no exactamente por horas trabajadas.

Esto nos demuestra que las empresas están perdiendo mucho y más aún si las personas se demoran más de 10 minutos como suele suceder en nuestro país. Como menciona Legge (2013) en su artículo de cómo el tráfico está afectando a las empresas de forma directa, "el costo económico es tangible: la productividad perdida, lenta entrega de bienes y servicios, por lo que, las empresas generan una mayor capacidad ociosa".

En esta investiga este es el punto se detallará con más profundidad, ya que el caso de estudio es sobre cómo afecta el tráfico a las empresas, específicamente a las aseguradoras de vida, las cuales tienen como recurso primordial a sus vendedores que deben de trasladarse de un lado a otro para poder generar ventas. Y esta movilización es afectada a causa de la congestión vehicular. 


\subsection{Efectos que tiene la congestión vehicular en las personas}

Enfocándonos en cómo la congestión vehicular está afectando a las personas en su vida diaria. El diario Perú21 (2013) publicó un estudio realizado por César Fajardo sobre el tráfico limeño, indicando que este perjudica el rendimiento de las personas. Los resultados publicados fueron los siguientes: $69 \%$ de los peruanos sienten que no rinden debidamente en el trabajo a causa del denso y cotidiano tráfico en la cuidad, el 47\% tarda entre 30 minutos y una hora en llegar a su centro de trabajo, 76\% afirman que están considerando cambiarse de empleo por este hecho y el $72 \%$ utiliza transporte público para acudir a su trabajo.

Combinando esta información con la obtenida en el estudio de la empresa IBM (2010) realizada a 8,192 automovilistas en 20 ciudades de los cinco continentes llamado IBM Commuter Pain Survey. Los encuestados afirman que el tráfico ha empeorado en los últimos tres años. Este estudio demostró que el $57 \%$ de los encuestados afirmaban que el tráfico afecta su salud, $29 \%$ mencionan que afecta su desempeño laboral y escolar. Pero también afecta en la calidad de vida de las personas, porque si el tráfico fuera más fluido podrían pasar más tiempo con sus familias y/o amigos, podrían practicar más actividades recreativas, dormirían más y serían más eficientes en el trabajo.

Según estudios realizados en el Hospital de Harvard Medical School (2012), el estrés generado por las largas horas de espera al día en el tráfico no es el único problema que genera en la salud la cogestión vehicular, también provoca problemas físicos y en las relaciones interpersonales.

Con respecto a los problemas de salud, las partículas de dióxido de carbono que se inhalan durante las largas horas de traslado en vehículos producen problemas en el sistema respiratorio, también aumentan la probabilidad de tener problemas cardíacos o hasta de sufrir un infarto.

El estudio realizado por el Centro Canadiense de Seguridad y Salud Ocupacional (1997) sobre las largas horas de exposición al dióxido de carbono reveló los resultados que aparece en la tabla 2.3.1. También mencionan que varias muertes se atribuyeron a la exposición a concentraciones superiores del $20 \%$. 
Tabla 2.3.1

Efectos que tiene el $\mathrm{CO} 2$ en las personas según concentración de dióxido de carbono y tiempo de exposición

\begin{tabular}{|c|c|l|}
\hline $\begin{array}{c}\text { Concentraciones de } \\
\text { CO2 }\end{array}$ & $\begin{array}{c}\text { TIEMPO } \\
\text { (minuto) }\end{array}$ & \multicolumn{1}{c|}{ AFECTA } \\
\hline Más altas que 0.035\% & & Ocasiona problemas de respiración y provoca excitación \\
\hline Desde 3.3\% a 5.4\% & 15 & Genera problemas respiratorios \\
\hline $7.50 \%$ & & $\begin{array}{l}\text { Produce sensación de inhabilidad para respirar (disnea), } \\
\text { incremento del pulso, jaqueca, mareos, sudor, fatiga, } \\
\text { desorientación y distorsión visual desarrollada }\end{array}$ \\
\hline Entre 6.5\% a 7.5\% & 20 & Disminuye el rendimiento mental \\
\hline $6.50 \%$ & 70 & Genera irritabilidad y malestar \\
\hline Desde 6\% a 30\% & $20-30$ & Afecta el corazón \\
\hline $10 \%$ & 1.5 & $\begin{array}{l}\text { Produce parpadeo ocular, excitación y actividad muscular } \\
\text { aumentada y contracción }\end{array}$ \\
\hline Más de 10\% & & $\begin{array}{l}\text { Dificultad para respirar, audición deficiente, náuseas, } \\
\text { vómitos, sensación de estrangulamiento, sudor, estupor por } \\
\text { varios minutos con pérdida de conciencia a los 15 minutos }\end{array}$ \\
\hline $30 \%$ & & Ocasiona inconsciencia y convulsiones \\
\hline
\end{tabular}

Nota: Elaboración propia

Fuente: Recursos Naturales Canadienses de Seguridad y Salud Ocupacional, 1997

Los efectos del $\mathrm{CO} 2$ pueden ser más pronunciados con esfuerzo físico, tal como trabajo pesado, por lo cual, los obreros que trabajan reparando calles y están expuestos directamente al $\mathrm{CO} 2$ tienen muchas probabilidades de sentir algunos de los efectos mencionados en la tabla 2.3.1. Este estudio es preocupante, porque con sólo salir a las calles de Lima podemos ver como los vehículos, mayormente buses, camiones y autos viejas botan grandes cantidades de dióxido de carbono, al cual no tenemos como refugiarnos.

No sólo nosotros somos los perjudicados con el $\mathrm{CO} 2$, también hay que pensar en el medio ambiente, si no contribuimos a disminuir la polución los efectos que se van a generar en nuestro mundo nos van a afectarnos directamente. El incremento de $\mathrm{CO} 2$ en la atmosfera está generar los siguientes efectos en nuestro planeta:

- "La temperatura media de la superficie terrestre se ha incrementado a lo largo del siglo $\mathrm{XX}$ en $0,6^{\circ} \mathrm{C}$. En el siglo XXI se prevé que la temperatura global se incremente entre 1 y $5^{\circ} \mathrm{C}$. 
- En el Siglo XXI el nivel del mar subirá entre 9 y $88 \mathrm{~cm}$, dependiendo de los escenarios de emisiones considerados.

- Incremento de fenómenos de erosión y salinización en áreas costeras.

- Aumento y propagación de enfermedades infecciosas.

- Desplazamiento de las especies hacia altitudes o latitudes más frías, buscando los climas a los que están habituados. Aquellas especies que no sean capaces de adaptarse ni desplazarse se extinguirán.

- Aumento en frecuencia e intensidad de los fenómenos meteorológicos extremos." (Frers, 2016)

Se sabe que los efectos que se observar actualmente como la reducción de la capa de ozono, no tienen solución, pero si se puede hacer algo para que no se siga perjudicando el medio ambiente a causa de los errores humanos. Algunas de las medidas que se pueden tomar son:

- "Las empresas eléctricas, responsables del $24 \%$ de la emisión de dióxido de carbono $\left(\mathrm{CO}_{2}\right)$ deben aumentar su eficiencia, utilizar los combustibles y procesos que emitan menos gases efecto invernadero y aumentar la proporción de energías renovables.

- Las industrias consumidoras de energía, responsables del $16 \%$ de emisiones de dióxido de carbono $\left(\mathrm{CO}_{2}\right)$ deben optimizar sus procesos para aumentar su eficiencia.

- Fomentar formas de transporte que consuman menos energía por viajante como transporte público, carburantes menos contaminantes, entre otras medias.

- Fomentar la eficiencia energética de los edificios, y consumir más eficientemente la energía en las oficinas y en el hogar. 
- Aumentar las superficies vegetales que actúan como sumideros, es decir que absorben carbono, evitar la deforestación y aumentar las repoblaciones, especialmente de especies arbustivas.” (Frers, 2016)

Ya existen empresas e instituciones que están tomando consciencia del $\mathrm{CO} 2$ que generan. Por ejemplo, una de las empresas aseguradoras que se está viendo en este estudio anualmente mide la cantidad de dióxido de carbono que genera a través de una encuesta a sus colaboradores, en donde las preguntas varían entre cuánto se movilizan, cómo se trasladan, si tiene auto propio y si van solos. Con los resultados de esta encuesta toman la decisión que aportar al medio ambiente de alguna manera. Años atrás se realizó un plan de forestación, también de reciclaje y este año se está trabajando para implementar el car pull en la empresa.

El ayuntamiento de San Diego, Estados Unidos, también decidió tomar cartas en el asunto. En el año 1995 y realizar un programa que ayuda a la disminución de la congestión del tráfico y del smog generado por los vehículos. En dicho programa participaron 580 empresarios y 708 sitios de trabajo, y consistía en la siguiente ordenanza: "todas las empresas con 100 o más trabajadores deberán de incrementar el número de viajes compartidos en un $2 \%$ anual. Los empleadores que no cumplan con la meta tendrían que presentar un plan de gestión de transporte que especifique cómo se podría reducir el número de empleados que se trasladan solos en sus vehículos". (Sutherland, 1995)

Por otro lado, hay problemas más notorios como el estrés, antes mencionado, causado por la ansiedad a estar largar horas expuesto al tráfico y la obesidad a causa de la falta de actividad física. A causa del tráfico las personas suelen sentir cansancio, agotamiento y hasta enojo antes de iniciar sus jornadas laborales. Esto puede reducir su concentración y eficiencia al desempeñar sus funciones laborales, lo cual puede perjudicar la rentabilidad de las empresas.

Según investigaciones el estrés y el malestar generado por el tráfico no sólo se debe a las largas horas de espera, sino también por los malos e imprudentes conductores, ¿quién no ha renegado nunca mientras maneja? a todos les ha pasado y si este mal humor perdura por largas horas puede traer problemas en el hígado. 
Después de ver todos los efectos que tiene el tráfico vehicular en las personas se puede sobre entender que las personas se pueden sentir mal mientras manejan. Pueden sentir: estrés, cansancio, frustración, etc. y a causa de esto tener un accidente. También puede suceder por no contar con la infraestructura adecuada y por reparos de vías inoportunas. En Lima diariamente ocurren accidentes de tráfico y la siguiente tabla lo demuestra.

Tabla 2.3.2

Número de accidentes vehiculares registrados en todo el Perú desde el 2012 al 2014

\begin{tabular}{|c|c|c|c|}
\hline Departamento & 2012 & 2013 & 2014 \\
\hline Total & 92289 & 102938 & 98773 \\
\hline Amazonas & 425 & 542 & 441 \\
\hline Áncash & 2177 & 2476 & 2339 \\
\hline Apurímac & 579 & 525 & 606 \\
\hline Arequipa & 5558 & 6438 & 5497 \\
\hline Ayacucho & 854 & 1074 & 1028 \\
\hline Cajamarca & 3142 & 3029 & 2042 \\
\hline Callao & 3528 & 3543 & 3366 \\
\hline Cusco & 1685 & 4055 & 3939 \\
\hline Huancavelica & 162 & 86 & 162 \\
\hline Huánuco & 988 & 1648 & 4194 \\
\hline Ica & 1542 & 1907 & 1433 \\
\hline Junín & 3049 & 3627 & 2557 \\
\hline La Libertad & 4278 & 4787 & 4501 \\
\hline Lambayeque & 2809 & 3302 & 3263 \\
\hline Lima & $52 \quad 047$ & $54 \quad 408$ & $53 \quad 486$ \\
\hline Loreto & 445 & 265 & 391 \\
\hline Madre de Dios & 117 & 479 & 441 \\
\hline Moquegua & 744 & 892 & 641 \\
\hline Pasco & 126 & 90 & 45 \\
\hline Piura & 3178 & 4089 & 3718 \\
\hline Puno & 781 & 1154 & 740 \\
\hline San Martín & 1011 & 1281 & 1197 \\
\hline Tacna & 1418 & 1608 & 1313 \\
\hline Tumbes & 476 & 483 & 418 \\
\hline Ucayali & 1170 & 1150 & 1015 \\
\hline
\end{tabular}

Fuente: Ministerio del Interior - Dirección de Gestión en Tecnología de la Información y ComunicacionesDirtepoles - PNP.

Recuperado de https://www.inei.gob.pe/estadisticas/indice-tematico/traffic-accidents/ 
Como se observa en la tabla 2.3.2 en Lima ocurren más del 50\% de los accidentes de todo el país. Este número es a causa de una combinación de todos los efectos que tiene la congestión vehicular de Lima en las personas, los problemas en infraestructura, la cantidad de vehículos que existen, entre otros. Un dato interesante es el que se puede apreciar en la figura 2.3.1, la cual muestra que más del 90\% de los accidentes son en las ciudades y no en las carreteras, por más que se conoce que en la red vial no urbana los accidentes son más graves.

Figura 2.3.1

Accidentes de tránsito 2005-2015

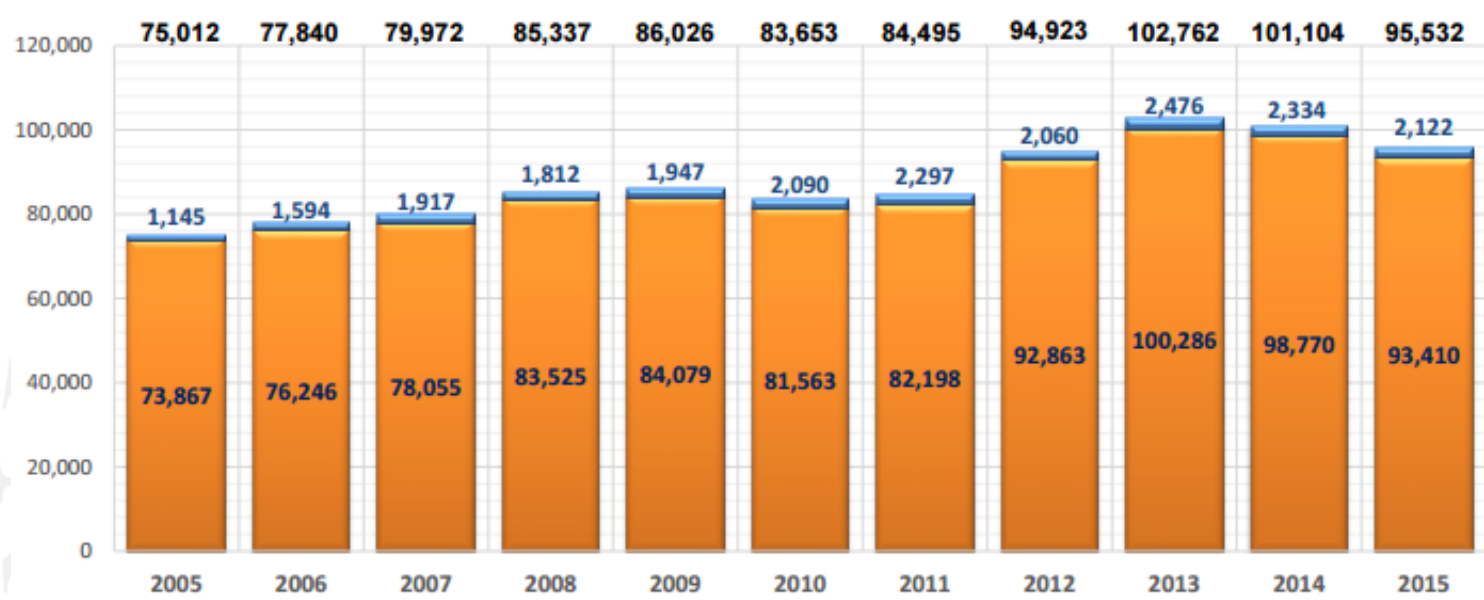

Fuente: Policía Nacional del Perú - Dirección de Estadística

Recuperado de https://www.mtc.gob.pe/cnsv/estadisticas/Accidentes\%20de\%20Transito\%2020052015.pdf

Es importante también tener en cuenta a las personas que trabajan manejando, no sólo los empleados de transporte público ni los taxistas, los vendedores también entran en esta lista. La salud de ellos es la más afectada, no sólo con los datos anteriormente mencionados sino también con detalles que no se están considerando como: la falta de movilidad de las piernas que genera varices, artritis, entre otras enfermedades, también el tener que alimentarse mientras me moviliza puede causar problemas digestivos y hasta tener que aguantar a llegar a un baño público puede ser un gran problema tanto en la vejiga como en su salud en general. 
Por otro lado, alguna vez se han puesto a pensar cuanto ruido genera las vías rápidas como la Avenida Javier Prado, Av. Paseo de la Repúblico (Vía Expresa) o la carretera Panamericana. Por ejemplo, la Javier Prado es una de las avenidas principales de Lima, por lo cual, muchas personas tienen que pasar por ella para llegar a sus destinos, pero una cosa es pasa ella y otra muy diferente es vivir o trabajar en ella o cerca.

Las personas que habitan al frente de esta avenida son muy perjudicadas por el ruido. Deben de mantener las ventanas cerradas todo el tiempo para no verse afectados. Tampoco es fácil dormir en estos hogares, ya que existen muchos accidentes de tráfico y se escuchan las sirenas de las ambulancias, bomberos, policías, etc.

¿Ustedes creen que estas personas descansan lo suficiente? Puede ser que ya estén acostumbradas, pero nunca va a ser agradable. Lo peor es que normalmente las personas quieren salir del tráfico y llegar a sus casas a relajarte, pero esto no es posible para estas personas que viven en los alrededores de esta avenida, ya que el ruido es un recordatorio constante del tráfico que existe en la ciudad. Todas las avenidas de la ciudad generan este tipo de molestia, pero esta es una de las más preocupantes por su congestión a lo largo de todo el día.

\subsection{Aspectos a tomar en cuenta}

Varios autores mencionan que la única solución al tráfico es realizar una reforma de transporte donde, de acuerdo a la ciudad, se desarrolle un nuevo sistema de transporte público, las vías públicas se amplíen y se eliminen todos los vehículos más antiguos y con problemas técnicos.

Se espera que se elaboren más autopistas, pero no sólo pensando en la demanda actual sino también proyectándose a la cantidad de vehículos que van a circular en los próximos años. Como expresa Legge (2013): "La experiencia ha demostrado con las carreteras que, si lo construyes, ellos vendrán". Esto quiere decir que con más carreteras existirán más vehículos recorriéndolas. Sólo hay que mirar los 12 carriles que existen en las autopistas de Los Ángeles, California, ellos cuentan con la infraestructura, pero igual las vías rápidas siguen congestionadas.

Otro caso más extremo es el de China, en donde se registró el peor embotellamiento de la historia el cual tuvo una duración de 12 días. Este se generó por 
un feriado largo en que la mayoría de las personas salieron de la ciudad y regresaban en horas muy cercanas. Esto nos demuestra que por más que exista la infraestructura nunca va a ser suficiente, ni de las dimensiones adecuadas para que todos los autos de la ciudad fluyan en estas vías al mismo tiempo.

Hay que tomar en consideración que Perú es un país que no cobra por el uso de las autopistas, sólo cobra peaje en las carreteras. Este tipo de cobranzas se realizan en la mayoría de los países desarrollados y en los que están en crecimiento como Chile. Sin este cobro y con el impuesto a la gasolina descendiendo ¿cómo se van a crear más carreteras? El único impuesto que puede aportar es el vehicular anteriormente mencionado.

No necesariamente se tiene que incrementar el número de autopistas para que el volumen vehicular en horas punta disminuya, ya que actualmente existen 5067 obras publicas de las cuales el $90 \%$ son en las vías de transporte como: carreteras, pistas, veredas, pasajes, etc. y el tráfico sigue igual o peor.

Una de las maneras de disminuir la congestión vehicular sin tener que hacer grandes cambios es que el gobierno prohíba la distribución de mercadería, riego, recojo de basura, etc. en las horas punta

y que circulen sólo en las noches, ya que estos camiones entorpecen más el tráfico, porque se quedan parados en plena vía pública.

También se tiene que tener en tomar en cuenta que los policías de tránsito que deben estar para "agilizar el tráfico" pero normalmente lo entorpecen más, por lo cual, se debe de considerar que los policías de tránsito sólo lo dirijan cuando los semáforos estén malogrados, como hacen todos los países. Pero las autoridades mencionan que los policías de tránsito deben de estar presentar, ya que las personas no respetan el semáforo o no son tolerantes ni respetuosos como para no bloquear una intersección.

Un dato interesante es que el gobierno tuvo la iniciativa de crear el Consejo Nacional de Seguridad Vial, pero por más que siguen haciendo estadísticas, las campañas cesaron en el 2013. Existen varias mejoras que el gobierno debería implementar como:

- $\quad$ "Mejora el diseño de paraderos de transporte público.

- Eliminar los cuellos de botella en vías principales. 
- Construir óvalos.

- Construir de puentes peatonales y separadores.

- Mejorar la señalización y cruceros peatonales.

- Parchar de huecos.

- Mayor consideración por parte de choferes y peatones.

- Exigir la revisión técnica.

- Formalizar los taxistas.

- Implementar taxímetros.

- Reducir las de rutas de transporte público.

- Sacar de circulación vehículos con más de 25 años de antigüedad.

- Circular en determinados días de la semana.” (Di Negro G. May 2012)

Proexpansión también hizo su propio estudio de las posibles soluciones como: Frenar la importación de vehículos nocivos para el tránsito y transporte, especialmente los provenientes del régimen especial de importación de CETICOS y ZOFRATACNA, poner en marcha sistemas de desguace o chatarreo para facilitar la salida de vehículos obsoletos, peligrosos y altamente contaminantes, incentivar el ingreso y circulación de vehículos de mayor capacidad y menor consumo de combustible (eficientes) o que usen combustibles menos contaminantes, otorgándoles privilegio de circulación a vehículos de menor tamaño, especialmente los particulares y establecer un impuesto vehicular a los automóviles de más de 5 años. Este impuesto debe ser progresivo, en función de la antigüedad y edad del automóvil. (Proexpansión, 2008)

Como se vio anteriormente, si se combate el exceso de taxis se podría apreciar un tráfico más ligero. En este punto el gobierno tiene que tomar cartas y calcular cuántos taxis se necesitan, de todas maneras, se va a necesitar que el número de taxis aumenten 
en las horas punta ya que, si existe la demanda, pero esto no significa que deben de transitar a lo largo de todo el día generando tráfico y contaminación del medio ambiente.

Esto es sólo uno de los puntos en los cuales el gobierno puede aportar, pero si no existiera el impuesto particular vehicula, más personas comprarían vehículos nuevos y se generaría lo posibilidad de desechar un mayor número de autos en malas condiciones, también aportarían al crecimiento del PBI con el mayor número de ventas de automóviles.

Las empresas también pueden colaborar con la fluidez del tránsito vehicular, así como lo hace la Universidad de Yale ayudando a sus empleados dándoles 25,000 dólares para que vivan cerca de la universidad y vayan caminando o en bicicleta a trabajar, claro está que esto es casi imposible de aplicar en Perú, pero nos da una idea de que las empresas también pueden aportar.

Por otro lado, la empresa Nike en Oregón también hace lo mismo que la Universidad de Yale aparte de que les dan unas zapatillas gratis a sus trabajadores para motivarlos. La Universidad de Massachusetts de Farmacia y Servicios de Salud ubicada en Boston, también incentiva a sus colaboradores a realizar actividades que no impliquen el traslado en vehículos (Mac, 2013).

En Perú las empresas también pueden aportar coordinando que los horarios de ingreso no sean los mismos y así las horas punta no serían de 7:30am a 9:00am, sino que se prolongarían y el número de autos sería menor. O también las empresas podrían colocar buses para sus colaboradores, para que así el número de vehículos circulante sea menor y que las personas que van en el servicio público de buses vaya más cómoda y relajada.

Otra opción es que las empresas tengan estacionamientos en puntos clave de la ciudad y que de ahí salgan buses constantes llevando a los trabajadores a sus centros de trabajo, así la concentración de vehículos no será en un solo punto y los empleados demorarían menos en trasladarse y tendrían un lugar seguro donde dejar sus vehículos.

Una medida de solución a este problema que pueden aplicar las empresas es optar por un esquema más flexible llamado "agile working" o en español "tele trabajo", el cual consiste en que los empleados puedan trabajar desde diferentes lugares de forma digital. Este esquema puede ser usado por los empleados siempre y cuando cumplan con su trabajo y logren sus metas y objetivos. 
Si se les presenta esta opción a las empresas las pueden considerar como un gran gasto, pero se puede aplicar la política empresarial BYOD (Bring your own device) la cual explica a los trabajadores que lleven sus propios dispositivos para realizar un tele trabajo efectivo y económico. La gran complicación de esto son los robos de los equipos como de la información confidencial, por lo tanto, se tendría que crear un gran sistema de control y seguridad para no tener estos problemas. Algunas empresas peruanas, ya están intentando aplicar un tipo de teletrabajo permitiéndoles a sus trabajadores tener un E-day al mes, lo que consiste en trabajar en la computadora desde la comodidad de sus hogares.

No todas las soluciones involucran la participación de las empresas o del gobierno, las mismas personas pueden aportar a la agilización del tráfico. Con ayuda de las aplicaciones móviles que existen en la actualidad, como Waze anteriormente mencionada, todas las personas pueden contribuir colgando información sobre congestión vehicular, accidentes de tránsito y hasta de control policial. El estar informados hará que las personas utilicen vías alternas y no se congestione más el tráfico.

Arellano Marketing realizo una encuesta a: peatones, conductores y policías dicha encuesta dio como resultado posibles acciones para solucionar el problema del tráfico (Tabla 2.3.1) y las razones que causan este problema (Tabla 2.3.2). Los resultados demostraron que se debe incidir en el cambio de actitud de las personas. "Esto se logra a través de la educación. El sondeo demuestra que todos son conscientes de las normas, pero que le echan la culpa al otro de no cumplirlas", destacó Rolando Arellano, Gerente General de Arellano Marketing (Perú21, 2013). 
Tabla 2.4.1

Encuesta Arellano Marketing: ¿Qué acción tomaría para solucionar el problema del tráfico? $(\%)$

\begin{tabular}{|c|c|c|c|c|c|c|}
\hline \multicolumn{7}{|l|}{$\begin{array}{l}\text { WQué acción tomaria para solucionar } \\
\text { el problema del tráfico? (x) }\end{array}$} \\
\hline Educación & 41 & 44 & 32 & 16 & 9 & 22 \\
\hline Implementar mecanismos reguladores & 32 & 32 & 24 & 35 & 29 & 15 \\
\hline Planificar reordenamiento & 21 & 21 & 25 & 21 & 21 & 5 \\
\hline Sectorizar las vias de circulación de unidades & 15 & 16 & 15 & 7 & 1 & - \\
\hline Sancionar severamente & 14 & 14 & 25 & 4 & 1 & 12 \\
\hline Mejorar el transporte público & 12 & 13 & 15 & 1 & - & 4 \\
\hline Mejorar vias & 11 & 11 & 16 & 13 & 17 & 2 \\
\hline Disminuir el parque automotor & 8 & 8 & 10 & 7 & 6 & - \\
\hline Reducir el transporte público & 6 & 7 & 3 & - & 3 & - \\
\hline Coordinar tránsito con la ejecución de obras & 0.1 & - & 3 & - & - & - \\
\hline Otros & 0.3 & - & 3 & 3 & 5 & - \\
\hline No precisa & 2 & 2 & 2 & - & 2 & 7 \\
\hline
\end{tabular}

Recuperado de: https://peru21.pe/lima/punto-colapso-lima-soporta-enorme-volumen-vehiculos-92350

Tabla 2.4.2

Encuesta Arellano Marketing: ¿Cuál es la razón más importante del problema? (\%)

\begin{tabular}{|c|c|c|c|c|c|c|}
\hline \multicolumn{2}{|c|}{ W Cual es la razón más importante del problema? (x) } & \multicolumn{5}{|c|}{ 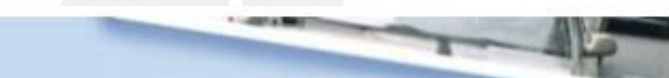 } \\
\hline Razones & TOTAL & Peatón & $\begin{array}{l}\text { Conductor } \\
\text { de auto } \\
\text { particular }\end{array}$ & Taxista & $\begin{array}{l}\text { Chofer de } \\
\text { transporte } \\
\text { pubilico }\end{array}$ & $\begin{array}{l}\text { Policiade } \\
\text { transito }\end{array}$ \\
\hline Excesivo parque automotor & 32 & 31 & 32 & 47 & 59 & 38 \\
\hline Primacia de los intereses personales & 20 & 21 & 20 & 18 & 3 & 24 \\
\hline Infreestructura vial desarticulada de la realidad & 19 & 19 & 25 & 19 & 5 & 11 \\
\hline Inadecuado planeamientovial & 17 & 18 & 15 & 5 & 8 & 3 \\
\hline Deficiente educacón vial & 16 & 17 & 31 & - & 5 & 5 \\
\hline No hay señalización necesaria & 15 & 16 & 9 & 5 & 8 & 18 \\
\hline Pasividad de las autoridades & 10 & 10 & 16 & 10 & 10 & - \\
\hline Informalidad & 8 & 9 & 6 & 6 & 5 & 1 \\
\hline El parque automotor en mal estado & 7 & 7 & 3 & - & - & - \\
\hline Falta de transporte público idóneo & 3 & 4 & 3 & - & - & - \\
\hline Lacivdad está mal diseñada & 1 & - & 3 & - & 7 & - \\
\hline Noprecisa & 4 & 4 & 4 & 5 & - & - \\
\hline
\end{tabular}

Recuperado de: https://peru21.pe/lima/punto-colapso-lima-soporta-enorme-volumen-vehiculos-92350

Esto son algunos pequeños ejemplos y opciones que pueden aplicar tanto las personas, empresas y hasta el gobierno para ayudar a que la congestión vehicular sea 
menor en la ciudad. Entonces, si todos ponen un pequeño grano de arena para generar cambios en el tráfico los resultados serán muy grandes. 


\section{CAPÍTULO III: METODOLOGÍA DE LA INVESTIGACIÓN}

Este es el capítulo más importante de todo el trabajo de investigación, ya que es acá donde se determinará si la hipótesis de que el tráfico está afectando actualmente la productividad de los trabajadores es correcta o no.

El desarrollo de este capítulo ayuda a entender cómo es que se va a realizar la investigas, qué método se ha diseñado, en qué estudio se ha basado la evaluación y a quiénes se le aplicará este experimento todo con el objetivo de que los resultados sean confiables. Se podrá conocer cómo es que se desarrolló el cuestionario, como fue el desarrollo de este en las personas encuestadas y, por último, observar los resultados que se obtuvieron de las encuestas realizadas.

\subsection{Esquema metodológico}

Son muy pocos los estudios que se han elaborado en donde se investigue el impacto del tráfico en la economía de las empresas y de las personas. Uno de los trabajos realizados es el de Takyi Harriet, Kofi Poku y Anin Kwabena Emmanuel. Ellos realizaron una evaluación de la congestión del tráfico y sus efectos en la economía en la ciudad metropolitana de Kumasi en Ghana.

Ghana es un país del oeste de África. Al 2016 contaba con una población de aproximadamente 28 millones de personales, lo cual significa una población media, ya que existen 118 habitantes por km2 (Expansión, 2016, párr.4). En los últimos años, el país ha crecido demográfica y económicamente, con un Índice de Desarrollo Humano (IDH) de 0,579 y un Producto Bruto Interno (PBI) de más de 130 mil millones de dólares (Wikipedia, 2017). Su ciudad capital, Kumasi, cuenta con una población de 1,468,609 (Web Calendar, 2017) lo que significa que el 19\% de la población del país se encuentra en la metrópolis.

En esta ciudad, la gran parte de los vehículos son propios o taxis, es por esto que se genera una relación entre nivel de ingresos y propietario de autos. Pero el problema 
del tráfico en esta metrópolis se debe a la capacidad limitada de las vías, los espacios para estacionar, disfuncionalidad de las señales de tránsito, el comportamiento de los conductores, vehículos antiguos malogrados, estado de las calles y la cantidad de automóviles.

En el estudio, los autores defienden su teoría de que existe una relación entre transporte y productividad. Para comprobarla explican que un sistema de transporte urbano efectivo permite abrir puerta a nuevas oportunidades de crecimiento, no sólo para las empresas sino para las actividades sociales de la población. Aseguran que para contar con un buen sistema se debe de tener una buena infraestructura, ya que este es un punto clave y afecta directamente la eficiencia y capacidad del transporte urbano. Una buena infraestructura involucra espacio de las pistas, señales de tránsito, parqueos, terminales de transporte, vehículos y usuarios.

El gran problema de la congestión vehicular son los tiempos que involucra movilizarse de un punto a otro. Esto afecta a todas las personas, pero está perjudicando a empresas que trabajan en un rubro donde su productos o servicios debe ser enviado o trasladado. Ellos deben de incrementar sus precios porque sus costos se ven afectados por mayor pago al personal, el combustible utilizado y el mantenimiento de los vehículos. Es acá que el concepto de just-in-time no puede ser empleado correctamente por las empresas y esto hace que los negocios no sean tan competitivos.

El tiempo es un punto clave, pero existen otros aspectos que también están siendo perjudicados por la efectividad del transporte, algunos de estos son: influencia en el costo de hacer negocios, tiempos de viaje, fiabilidad de pronósticos, comodidad y seguridad de los viajeros.

Los autores, atribuyen las causas de la congestión al aumento de la densidad poblacional, los incidentes de carretera como choques y los vehículos malogrados en ellas. Todo esto restringe la capacidad de las vías y dificultan el buen flujo de tráfico.

Uno de los causantes de la congestión vehicular son los estacionamientos, estos ocupan mucho espacio físico lo cual incrementa costo y demanda de zonas urbanas. Pero la necesidad de estacionamientos se da porque el uso de autos propios es masivo. Se debería usar más el transporte público y menos los vehículos particulares, pero se necesita de un buen sistema público de buses y trenes para que los traslados sean efectivos y las personas opten por esta opción. 
Un buen sistema de transporte es la llave para un crecimiento sustentable de la economía, porque contaría con la capacidad de enlazar a las personas con sus trabajos, llevar los productos demandados a su punto de venta, la cadena logística de los transportistas de suministros sería la correcta y por ende el comercio nacional e internacional. Pero para lograrlo las autoridades deben de capacitar a policías de tránsito eficientemente para que estos aporten al mejoramiento del sistema.

La congestión vehicular está impidiendo nuestro libre movimiento y eso afecta las actividades comerciales y reduce productividad. Las tareas de los negocios dependen de la logística de tiempo de entrega y en la actualidad los costos operativos de las empresas han aumentado.

Estas condiciones de tráfico afectan a todos, en la medida de que se está consumiendo más combustible, perjudicando el medio ambiente por la contaminación y la mayor explotación de petróleo, afectar el ecosistema repercuta en la salud de las personas al ser parte de este. 
Figura 3.0.1

Marco Conceptual

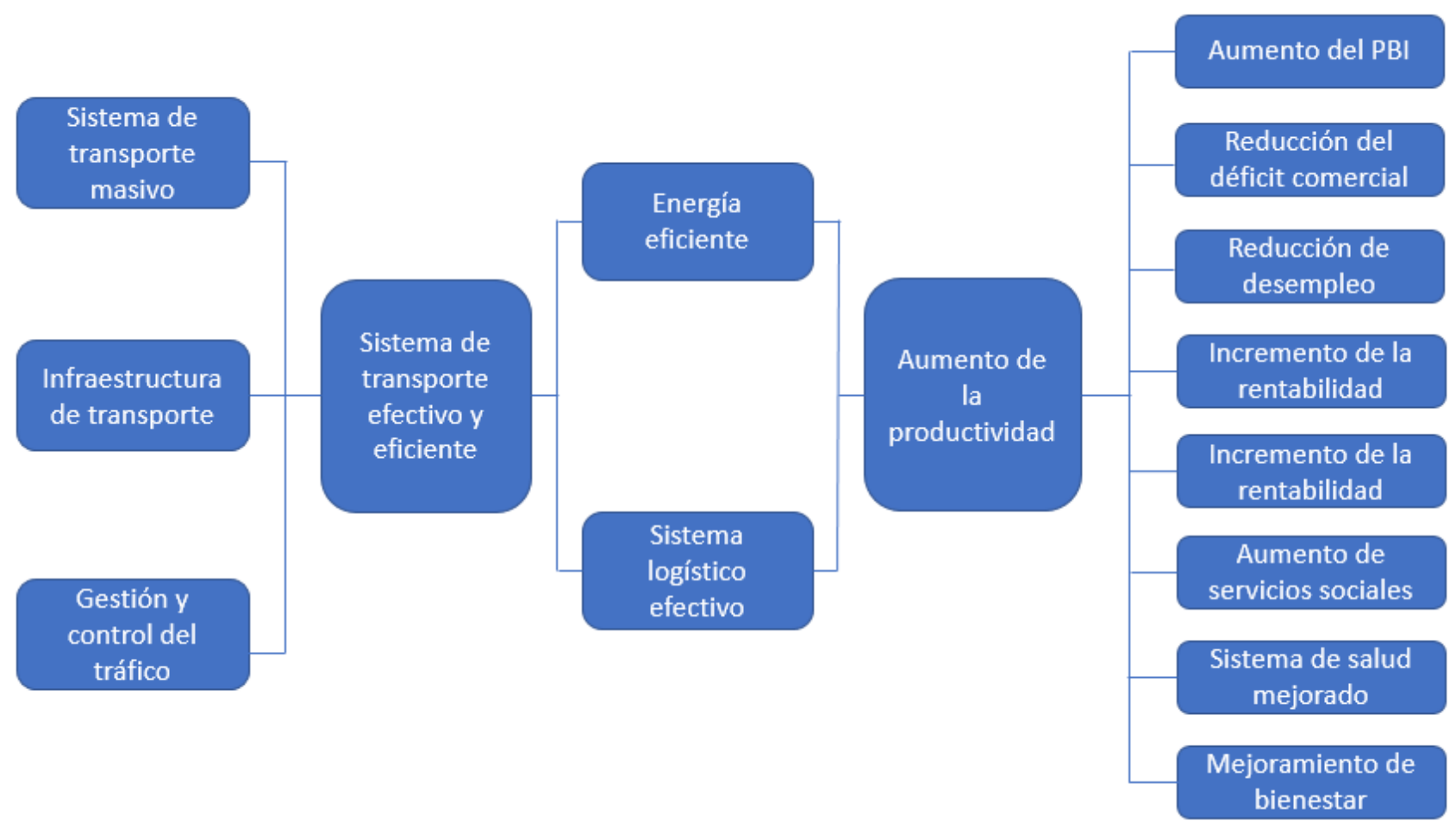

Adaptado y modificado de Karlsson (2007)

Recuperado de: Internation Journal of Business and Social Science

La figura 3.0.1 muestra la situación del transporte en Ghana y un resultado potencial si se obtiene un buen sistema de transporte. Comienza explicando las medidas que se deben de tomar para contar con un eficiente sistema público de transporte. Si a este se le aumenta la demanda de energía y un efectivo sistema logístico se podrá incrementar la productividad. Esta mejora vería reflejada en la economía del país.

Entrando a la metodología, al momento de la investigación esta fue dividida en dos sectores: público y privado. En donde la muestra del sector públicos fueron 300 conductores de mini buses y taxis. En el sector privado fueron 150 personas escogidas al azar. La evaluación se realizó en el distrito central de negocios de la ciudad metropolitana de Kumasi, la cual cuenta con veintiún vías reconocidas por su congestión vehicular, de estas se escogieron cinco para realizar el estudio.

A toda la población se le realizó un cuestionario, el cual boto los siguientes resultados. El mayor número de vehículos en la ciudad son taxis, seguido por automóviles 
propios y luego buses. Los conductores del sector publico demostraron que a causa del tráfico están realizando menos viajes lo que les genera menores ingresos.

En el caso de la muestra del sector privado se quiso identificó que los empleados trabajan en promedio 9 horas y media al día, pero pierden cincuenta y dos minutos porque llegar tarde al trabajo. Esto representa un $9.4 \%$ menos de productividad en las horas de trabajo diarias, lo que significa que son dos días menos de trabajo al mes.

Para esta investigación se va a utilizar una metodología propia apoyada en el estudio anterior realizado en Ghana. Este informe se basará sólo en el sector privado, específicamente en las empresas aseguradoras de vida (Pacifico, Rimac, Mapfre, Interseguros y La Positiva) de Lima Metropolitana y en sus trabajadores, ya que son ellos los que se deben de movilizar diariamente para conseguir ventas e ingresos para la empresa.

\subsection{Diseño de la investigación}

Este trabajo se basa en la investigación de un problema existente, se buscarán los factores que lo generan y posibles soluciones con la ayuda de entrevistas presenciales a algunos gerentes y encuestas online que se les realizaran a empleados de diversos puestos de las empresas seguradoras de vida Pacifico, Rimac, La Positiva, Mapfre y La Positiva.

Se ha ttomado como base la evaluación realizada por Takyi Harriet, Kofi Poku y Anin Kwabena Emmanuel. Se ha determinado que el diseño de esta investigación es no experimental, ya que en este estudio no se tiene que elaborar ninguna situación específica para desarrollar el tema, sino que se toma una situación existente que no la elabora el investigador, que en este caso es el tráfico en Lima que se aprecia actualmente en las calles de la ciudad.

En una investigación de este tipo las variables independientes ya han ocurrido, por lo cual, no se pueden alterar ni influir en ellas, esto significa que el investigador no tiene el control directo sobre dichas variables al igual que de sus efectos.

Al tener claro de que el diseño de investigación es no experimental se puede determinar que es transaccional o transversal, porque en este trabajo se está recolectando datos en un momento determinado para poder describir las variables y así poder analizar su incidencia e interrelación en un momento dado. Es como tomarle una fotografía a un 
suceso, uno cuenta con la imagen y solo la va a analizar, ya que esta no se puede alterar o cambiar.

\subsection{Población y muestra}

Para poder obtener el tamaño de la muestra precisa se ha tenido que aplicar la fórmula matemática.

Figura 3.2.1

Formula para hallar el tamaño de muestra

$$
\mathrm{n}=\frac{N \cdot Z^{2} \cdot p \cdot(1-p)}{(N-1) \cdot \mathrm{e}^{2}+Z^{2} \cdot p \cdot(1-p)}
$$

Recuperado de: http://www.datakey.galeon.com/muestra.html

En este caso se está aplicando la fórmula a las empresas de seguros de vida: Pacifico, Rimac, Interseguros, Mapfre y La Positiva que representan más de $80 \%$ del mercado peruano. En total estas cuentan con 7’250 personas entre: ejecutivos, personal administrativo y fuerza de ventas. Según estos datos se obtiene el siguiente resultado:

\section{Tabla 3.2.1}

Datos utilizados para el cálculo del tamaño de la muestra

\begin{tabular}{|l|r|}
\hline \multicolumn{2}{|c|}{ Datos para cálculo de la muestra } \\
\hline Nivel de confianza & $90 \%$ \\
\hline Abscisa $\left(\mathrm{Z}^{2}\right)$ & 1.84 \\
\hline Tamaño de población $(\mathrm{N})$ & $7 ’ 250.00$ \\
\hline Probabilidad $(\mathrm{p})$ & $50 \%$ \\
\hline Error $(\mathrm{e})$ & $10 \%$ \\
\hline Tamaño de la muestra $(\mathrm{n})$ & 83.67 \\
\hline
\end{tabular}

Nota: elaboración propia

Según el resultado de la formula, el tamaño de la muestra debe ser de encuestar al menos a 84 personas para que los resultados obtenidos sean confiables. Por lo tanto, en el presenta trabajo se ha encuestado a 100 trabajadores de las empresas de seguros de vida más representativa nombradas anteriormente. Entre la muestra se encuentran personas de diferentes cargos y han sido escogido de manera aleatoria, para que así los resultados sean precisos. 
Se ha elaborado un organigrama típico de un área de seguros de vida que muestra los diferentes cargos y el número de personas por puesto (figura 3.2.1). Con este se puede conocer cómo se distribuyen las áreas de las empresas de seguros de vida. Se debe de considerar que las empresas abarcan las siguientes áreas:

- Seguros de Vida Corporativos

- Rentas Vitalicias

- Seguros Previsionales

- Seguros de Desgravamen Hipotecario

- Seguros de Vida Ley 
Figura 3.2.2

Organigrama del área Seguros de Vida Corporativos de la empresa aseguradora.

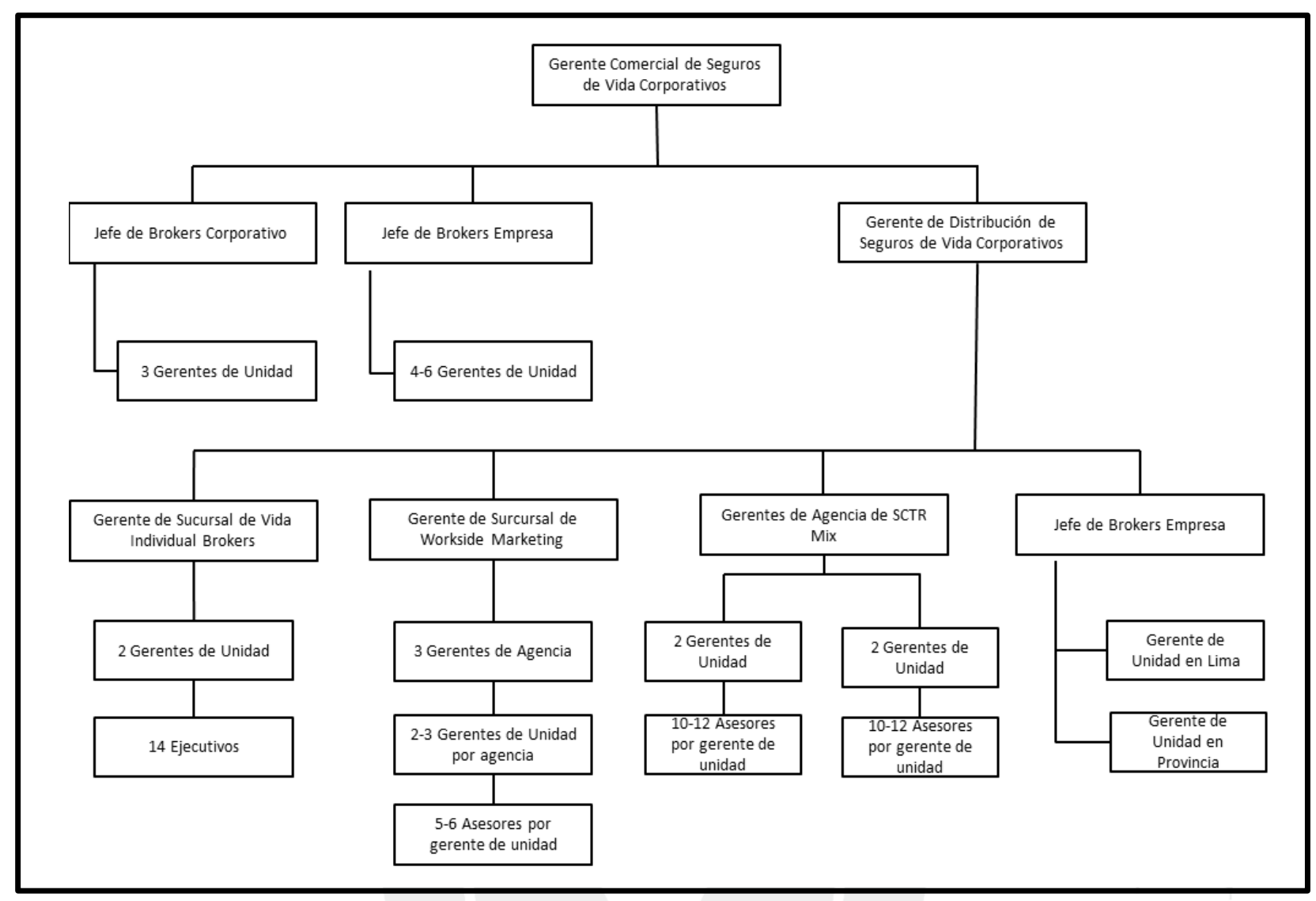

Nota: Elaboración propia.

Fuente: Datos obtenidos de entrevistas al personal.

Recuperado de la entrevista al Gerente de Distribución de Seguros de Vida Corporativos.

\subsection{Instrumento de recolección de datos}

Ahora que se tiene detectado el tamaño de la población como de la muestra, lo que trae consigo saber más o menos a cuántas personas se tienen que encuestar para obtener resultados relevantes de esta investigación.

Es momento de determinar que instrumento de recolección de datos se va a utilizar. Como se van a realizar encuestas a varias personas de diferentes puestos del área Seguros de Vida Corporativos de las distintas empresas aseguradoras del país, el instrumento más adecuado es un cuestionario que abarcan los diferentes aspectos del 
tema. En conjunto estas preguntas ayudaran a conocer mejor la opinión de los trabajadores y poder dar una solución óptima del problema.

Para la elaboración de este cuestionario se tuvo que realizar una investigación minuciosa en diferentes fuentes, para poder obtener cuestionarios previamente analizados y comprobados que aporten a la elaboración del listado de preguntas, para llegar al objetivo esperado y se tenga la tranquilidad de que estas preguntan han sido anticipadamente utilizadas para otra investigación que ha tenido buenos resultados. Por lo general, estas preguntas han tenido que ser adaptas al tema de investigación y aumentándole preguntas propias para que el cuestionario otorgue los resultados que se buscan.

Este cuestionario está conformado por tres partes: tráfico, salud y productividad. La primera parte, sobre la congestión, esta dividió en preguntas dirigidas a personas que cuentan con un vehículo propio y otras que no cuentan con uno. Las preguntas a personas que cuentan con vehículo son más extensas, ya que se cree que son ellas las más afectadas por el tráfico, porque es diferente tener que manejar a ser pasajero. La segunda parte, relacionada a la salud, está pensada en como el tráfico afecta la salud de la persona en temas de estrés, cansancio, etc. y como todo esto termina perjudicando el desempeño de los empleados en su trabajo. Por último, la tercera parte que está referida a la productividad y al desempeño de las personas en sus centros laborales. Este punto también ayuda a saber en cuento está participando las empresas para solucionar este problema.

\subsection{Criterios empleados para la elaboración de la encuesta}

Para la elaboración del cuestionario se tuvo que investigar de diferentes autores, métodos que ya se hayan utilizado y preguntas aplicadas anteriormente en experimentos para asegurar que los resultados sean confiables.

La encuesta comienza con una pregunta clave que separa a los encuestados entre los que cuentan con vehículo propio y los que no. Al detectar esta diferentes se comienzas haciendo preguntas específicas para cada muestra, realizando preguntas más precisas a las personas que cuentan con carro, ya que las personas que manejas se ven más afectadas por el tráfico. 
En ambos casos las preguntas buscan saber cómo se movilizan, cuánto tiempo invierten en trasladarse y qué tan largas son sus trayectorias. Luego las preguntas son para ambas muestras, en donde principalmente se busca saber qué opinan los encuestados sobre la congestión vehicular de Lima, qué efectos tienen en ellos y qué hacen para contrarrestarlos.

Por último, las preguntas son sobre desempeño para saber si el tráfico afecta en su productividad laboral. También hay preguntas específicas para los jefes y gerentes, en donde se busca saber cuánto saben ellos de los efectos que tiene la congestión en sus equipos, ya que el desempeño de los supervisores depende de los resultados de sus colaboradores.

En el Anexo 1 se encuentra la encuesta completa que se aplicó, con un contenido de 26 preguntas. Este se destinó a 100 personas del área de seguros de vida de las diferentes empresas aseguradoras de Lima Metropolitana, las cuales ya fueron especificadas anteriormente. Se buscó que los trabajadores que la resuelvan sean de diferentes puestos para obtener mejor resultados.

\subsection{Interpretación de Resultados}

A continuación, se van a presentar los resultados de cada pregunta. Se comenzó con una pregunta que permite distinguir la cantidad de personas que cuentan con un vehículo, pero no necesariamente que lo utilizan para ir a su centro de trabajo. En donde los resultados fueron los siguientes: 


\section{Figura 3.5.1}

Pregunta 1 ¿Cuenta con un automóvil propio con el que se moviliza?

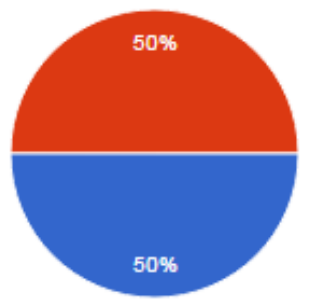

$\begin{array}{lll}\text { Sí } & 50 & 50 \% \\ \text { No. Pasar a la pregunta } 11 & 50 & 50 \%\end{array}$

Nota: Elaboración propia.

Fuente: Resultados de las encuestas.

Como se ve en la Figura 3.5.1, la mitad de los empleados van al trabajo en auto particular y la otra mitad utiliza medios alternativos, los cuales serán detallados en la pregunta 11. Luego, se decidió ir más a fondo con la primera pregunta y hacer que los encuestados especifique si utilizan su vehículo para ir al trabajo. Y como podemos ver en la Figura 3.5.2 sólo cinco personas dijeron que no lo utilizaban para ir a su centro laboral, la razón se observa en la pregunta 3. En donde la respuesta fue que no contaba con un espacio para estacionar, problema común en la zona financiera de San Isidro.

Figura 3.5.2

Pregunta 2. ¿Utiliza su vehículo para ir o volver de su centro laboral?

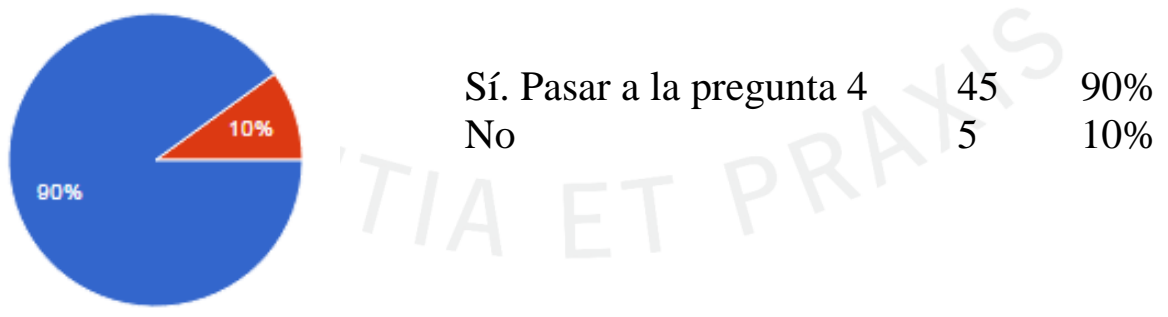

Nota: Elaboración propia.

Fuente: Resultados de las encuestas. 
El no tener donde estacionar es una clara causa por la cual las personas prefieren ir al trabajo con otros medios de transporte. Pero hay que tener en cuenta que existen otros motivos como vivir cerca al trabajo y preferir ir en bicicleta o caminando, también por temas de gasto en combustible, ya que es más económico movilizarse en el servicio público que en tu propio vehículo. No sólo por temas de gastos en combustibles, sino también por todo lo que implica tener un carro como: mantenimiento, cambio de aceite, renovación de llantas, etc.

Luego, se quería conocer el tiempo que las personas tardaban conduciendo para llegar a sus centros laborales. Los resultados (Figura 3.5.3) demostraron que pasan mucho tiempo sólo de ida al trabajo. Estos largos periodos manejando antes de llegar a realizar sus labores generan estrés y cansancio. Estos síntomas se ven luego reflejados en la manera como llegan a su centro de trabajo, lo cual, les puede afectar en diferentes aspectos como: conflictos laborales, estrés excesivo que repercuta en la salud, mal desempeño, etc. Por otro lado, las treinta personas que respondieron que tardan menos de media hora, se debe a que viven cerca de su centro de trabajo.

Figura 3.5.3

Pregunta 4. ¿Cuánto tiempo tiene que conducir durante un día laborable para ir a su centro de trabajo?

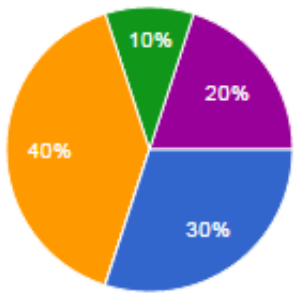

Menos de media hora
Media hora
Más de media hora
Una hora
Más de una hora

$\begin{array}{ll}15 & 30 \% \\ 0 & 0 \% \\ 20 & 40 \% \\ 5 & 10 \% \\ 10 & 20 \%\end{array}$

Nota: Elaboración propia.

Fuente: Resultados de las encuestas.

Continuando con la encuesta, también es importante saber cuánto se demoran los trabajadores para llegar a sus hogares, ya que esto significa menos tiempo de descanso para ellos. Lo cual, quiere decir que llegan a sus casas estresados y pueden comenzar a 
tener problemas en su hogar y este tipo de conflictos siempre perjudica a las personas en su desempeño laboral.

\section{Figura 3.5.4}

Pregunta 5. ¿Cuánto tiempo tiene que conducir durante un día laborable para llegar a su hogar?

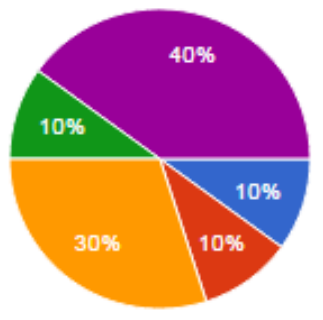

Menos de media hora
Media hora
Más de media hora
Una hora
Más de una hora

$\begin{array}{ll}5 & 10 \% \\ 5 & 10 \% \\ 15 & 30 \% \\ 5 & 10 \% \\ 20 & 40 \%\end{array}$

Nota: Elaboración propia.

Fuente: Resultados de las encuestas.

Como se ve en los resultados (Figura 3.5.4), el 40\% se demora más de una hora para llegar a sus hogares. Esto ocurre porque normalmente las horas pico de salida del trabajo son más largas que las de la mañana, porque las personas no salen al mismo tiempo de sus trabajos y suele pasar que trabajan más de 8 horas para concluir sus labores del día. Por otro lado, en las tardes las personas siempre quieren llegar rápido a sus casas para estar con sus familias y hacer sus cosas personales, por esto le toman más importancia a llegar rápido a sus casas que a sus trabajos.

Después se aplicó una pregunta que resultaba importante para conocer las distancias que tienen que recorrer los empleados por temas de trabajo, ya que saber qué tan lejos conducen equivale a mayores gastos. Esta pregunta se relaciona con la anterior porque juntas se puede terminar si la distancia recorrida tiene relación con el tiempo que tardan. 


\section{Figura 3.5.5}

Pregunta 6. ¿Conduce fuera de los límites de su distrito en la semana por temas de trabajo?

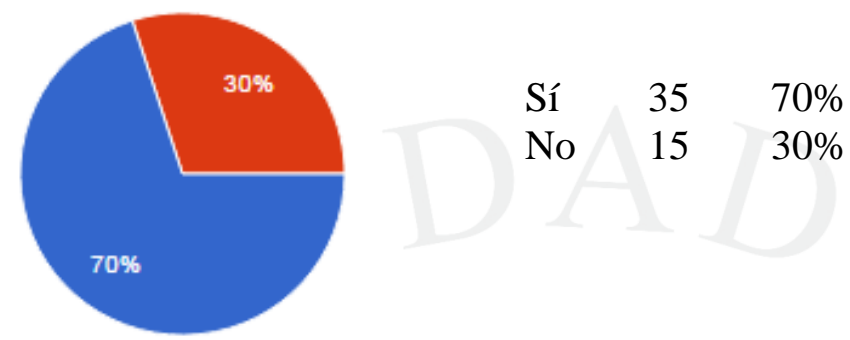

Nota: Elaboración propia.

Fuente: Resultados de las encuestas.

Los resultados (Figura 3.5.5) botaron que la mayoría de empleados se tiene que movilizar fuera de sus distritos por temas de trabajos. Esto significa que se tienen que movilizar largas distancias, no sólo para llegar a sus oficinas sino también por citas, reuniones, etc. Esto sucede porque por lo general los distritos son bastante extensos y sus reuniones suelen ser en distritos alejados.

Siguiendo con el tema de la distancia recorrida era importante conocer el distrito en donde viven los trabajadores, ya que esto puede afectar mucho en temas de traslado: tiempo, trayecto, etc. Con esta información se puede determinar con más exactitud el kilometraje que recorren sólo para aplicar su hora de fuerza. 
Figura 3.5.6

Pregunta 7. ¿En qué distrito vive?
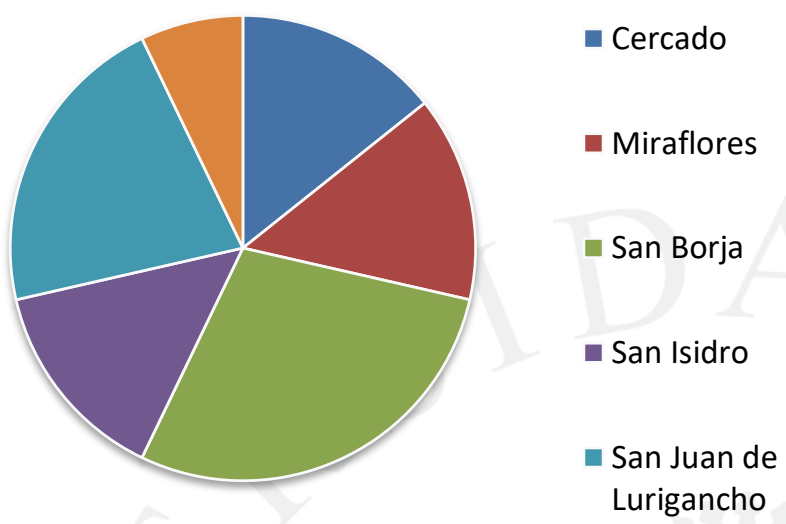

\begin{tabular}{|l|r|r|}
\hline Cercado de Lima & 10 & $14.29 \%$ \\
\hline Miraflores & 10 & $14.29 \%$ \\
\hline San Borja & 20 & $28.57 \%$ \\
\hline San Isidro & 10 & $14.29 \%$ \\
\hline San Juan de Lurigancho & 15 & $21.43 \%$ \\
\hline Santiago de Surco & 5 & $7.14 \%$ \\
\hline
\end{tabular}

Nota: Elaboración propia.

Fuente: Resultados de las encuestas.

Como se pude ver en la Figura 3.5.6, gran porcentaje habita en San Borja, distrito no tan lejano a los centros de trabajo ubicado en San Isidro. Entre estos dos distritos existe una distancia de siete kilómetros aproximadamente. Pero por más de que no vivan tan lejos, las personas si tiene que pasar tráfico para ir y regresar de su oficina. Con este dato ya se puede negar la teoría de que a mayor distancia mayor tiempo, porque esto demuestra que por más que se encuentren cerca igual tardan en llegar.

Hablando del tiempo, se cree que el retraso en las mañanas tiene que ver con la hora en que las personas salen de sus casas, ya que por más que la mayoría vive en San Borja indican que se demoran más de media hora en llegar. Por lo tanto, en la siguiente pregunto se busca saber la hora de salida de sus hogares. 
Figura 3.5.7

Pregunta 8. ¿A qué hora sale de su hogar para dirigirse al trabajo?

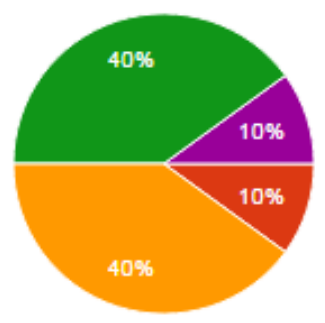

Antes de las 6am

$0 \quad 0 \%$

Entre las 6 y 6:30am

$0 \quad 0 \%$

Entre las 6:30y 7am

$5 \quad 10 \%$

Entre las 7 y 7:30am

$20 \quad 40 \%$

Entre las 7:30 y 8am

Entre las 8 y 8:30am

$20 \quad 40 \%$

$5 \quad 10 \%$

Nota: Elaboración propia.

Fuente: Resultados de las encuestas.

Se puede ver (Figura 3.5.7) que la mitad de los encuestados si demuestran preocupación por llegar temprano, por lo cual salen más de una hora antes de la hora de entrada. Pero la otra mitad sale con el tiempo un poco justo considerando que a partir de las 7:30am el tráfico es mucho más denso. Esto se da porque no sólo los trabajadores deben llegar a sus centros de trabajo, los escolares también tienen que llegar a tiempo a sus colegios y los estudiantes universitarios igual.

Como se mencionó anteriormente, otra causa por la cual las personas deciden no manejar y trasladarse en transporte público, es debido al gasto generado por el combustible. Es por esto que se quería conocer con más exactitud cuánto gastan sólo en combustible. 


\section{Figura 3.5.8}

Pregunta 9. ¿Cuánto suele gastar en combustible semanalmente?

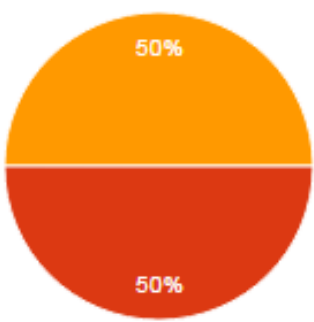

Menos de 50 soles $\quad 0 \quad 0 \%$

Entre 50 y 100 soles $25 \quad 50 \%$

Más de 100 soles $\quad 25 \quad 50 \%$

Nota: Elaboración propia.

Fuente: Resultados de las encuestas.

Como se observa, los gastos en combustible varían entre 50 y más de 100 soles semanales. Número considerable, teniendo en cuenta que la mayor parte de estos empleados ganan por comisiones de ventas. Sería bueno que las empresas tomen consciencia de esto y ayude a sus empleados en el tema de gastos de transporte o que les ofrezca un medio alternativo. Por ejemplo, las compañías podrían invertir en una línea de buses que transiten todo el día para que los trabajadores puedan ir a sus centros de trabajo y a sus diferentes citas con más comodidad y de una manera económica.

Como se vio en la respuesta de la pregunta 3 el no tener donde estacionar es un problema para las personas que tienen que movilizarse en su auto. Es por esto que se buscó conocer si todos los que acudían a sus trabajos en auto cuentan con un espacio donde estacionar. 
Figura 3.5.9

Pregunta 10. ¿Tienes donde estacionar cerca o en tu trabajo?

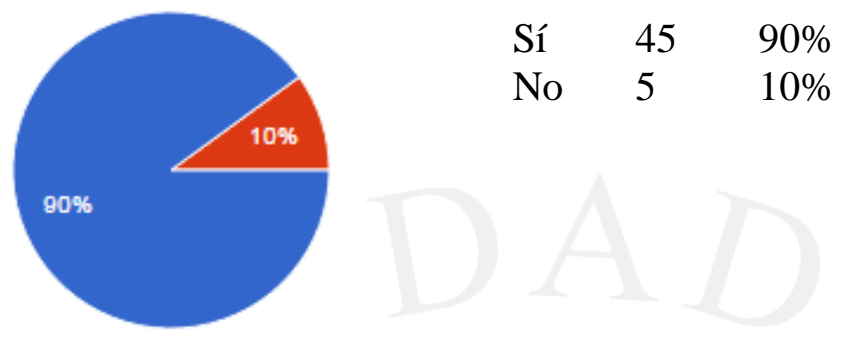

Nota: Elaboración propia.

Fuente: Resultados de las encuestas.

En este caso sólo cinco de las personas encuestadas respondieron que no tiene un lugar donde estacionar. Los que respondieron que sí debe ser a que son gerentes o empleados de excelencia y tienen derecho a estacionamiento en su mismo centro de trabajo o en parqueos cercanos, en donde la empresa donde trabaja paga mensualmente para que sean abonados. Este es un beneficio otorgado por las empresas a personas con buen desempeño. También se da el caso que las mismas personas buscan estacionamientos cercanos y pagan para ser abonado, en este gasto sale de sus bolsillos.

Luego, se comenzó con las preguntas dirigidas a las personas que no cuentan con un auto propio para movilizarse y tienen que trasladarse de otras maneras. Es importante saber cómo es que la mayoría de empleados se movilizan. 
Figura 3.5.10

Pregunta 11. Normalmente, ¿cómo se moviliza?

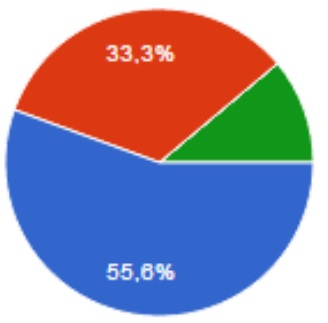

$\begin{array}{lll}\text { Taxi } & 50 & 55 \% \\ \text { Autobús } & 30 & 33 \% \\ \text { Bicicleta } & 0 & 0 \% \\ \text { Peatón } & 10 & 11 \% \\ \text { Otro } & 0 & 0 \%\end{array}$

Nota: Elaboración propia.

Fuente: Resultados de las encuestas.

A pesar de que se creía que el mayor porcentaje iba a responder que se movilizaba en autobús, la mayoría respondió que se movilizan en taxi. Estos resultados si fueron impactantes, ya que gastar diariamente sólo ida y vuelta del trabajo en taxis debe ser muy costoso, pero deben de preferir pagar un poco más para llegar rápido y estar cómodos, que pasar por todas las incomodidades que genera movilizarse en autobús.

Por otro lado, como ya se conoce que la mayoria de personas se traslada en taxi se suposo que el movilizarse en autobus es más lento y tedioso que trasladarse en taxi, pero esto no es lo que demuestran los resultados de la siguiente pregunta sobre cuánto tardan en viajar. 
Figura 3.5.11

Pregunta 12. Aproximadamente ¿cuánto tiempo emplea viajando en: taxi, autobús, bicicleta, otro?

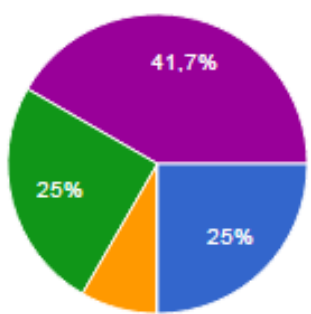

Menos de media hora

Media hora

Más de media hora

Una hora

Más de una hora
$13 \quad 25 \%$

$0 \quad 0 \%$

$4 \quad 8.3 \%$

$13 \quad 25 \%$

$21 \quad 41.7 \%$

Nota: Elaboración propia.

Fuente: Resultados de las encuestas.

$\mathrm{Al}$ igual que las preguntas 4 y 5 la mayor parte de personas de demoran más de una hora en trasladarse de un lugar a otro. Hay que tener en consideración que todo este tiempo perdido podría ser empleado para realizar actividades más productivas, ya sean de temas de trabajo como personales.

Se quiso averiguar si los empleados empleaban otros medios más saludables para movilizarse como es caminar o ir en bicicleta. Por lo que se desarrolló esta pregunta no sólo para saber si utilizan medios alternos es una opción para los empleados, sino que el evitar el tráfico ayudar a bajar los porcentajes de estrés, al estar al aire libre y sin la preocupación de que involucra la congestión vehicular. 
Pregunta 13. Aproximadamente ¿cuánto tiempo camina al día por motivos laborales?

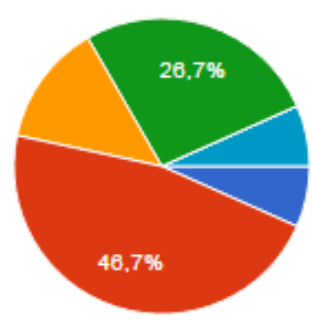

No camino

Menos de media hora

Media hora

Más de media hora

Una hora

Más de una hora

$\begin{array}{ll}5 & 6.7 \% \\ 35 & 46.7 \% \\ 10 & 13.3 \% \\ 20 & 26.7 \% \\ 0 & 0 \% \\ 5 & 6.7 \%\end{array}$

Nota: Elaboración propia.

Fuente: Resultados de las encuestas.

Al ver los resultados (Figura 3.5.12) se pude determinar que estos números pueden mejorar si se comienza a incentivar a las personas a caminar o ir en bicicleta cada vez que tengan la oportunidad. Por ejemplo: en su refrigerio deberían de dar una vuelta para relajarse, si tienen que ir a otra sede pueden ir caminando ya que estas no están lejos la una de la otra, si caminan un poco es posible que se les sea más fácil conseguir transporte público más despejado. Y estos no son los únicos beneficios de estar al aire libre, esto también es muy bueno para la salud tanto mental como física.

Con la siguiente pregunta se comienza a presentar el tema sobre cómo afecta el tráfico en el desempeño directamente al encuestado. Esta es una pregunta clave para saber que tanto saben los empleados sobre los efectos que tiene el tráfico en su productividad laboral. 
Figura 3.5.13

Pregunta 14. ¿Cree que el tráfico está afectando su salud?

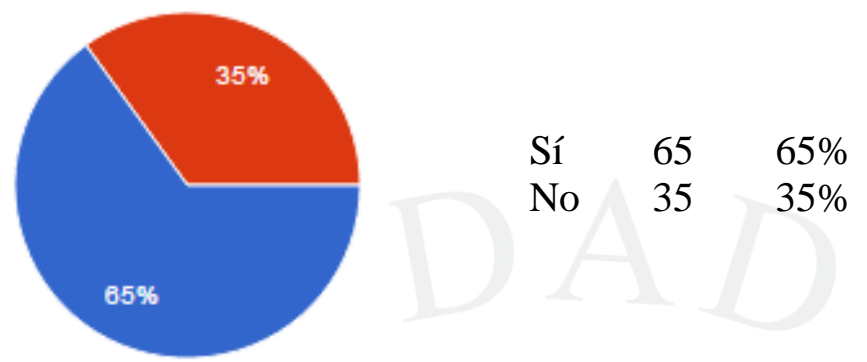

Nota: Elaboración propia.

Fuente: Resultados de las encuestas.

Como se puede apreciar (Figura 3.5.13), la gran mayoría si cree que el tráfico los afecta, pero existe un porcentaje significativo que piensa que este problema no los perjudica. Estos datos son muy importantes, ya que ahora se sabe que se les tiene que informar más a los empleados sobre los efectos que tiene la congestión vehicular de la ciudad en ellos.

Por más que algunos trabajadores respondieron que el tráfico no les afecta, el que respondan sobre cuáles son los principales efectos que tiene este problema en su salud demuestra que en el fondo sí reconocen que el tráfico les perjudica en ciertos aspectos.

\section{Figura 3.5.14}

Pregunta 15. ¿Cuáles son los principales efectos que tiene el tráfico en su salud? (Se puede marcar más de una opción)

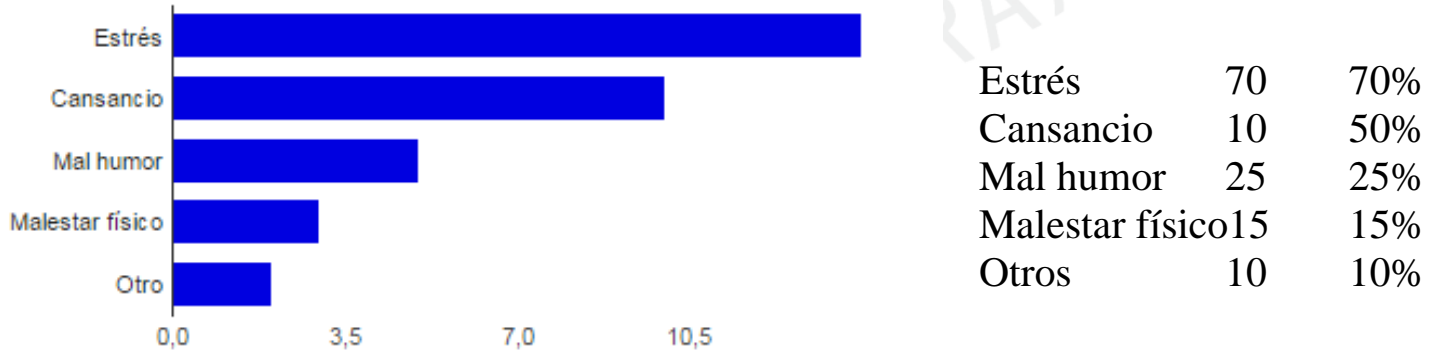

Nota: Elaboración propia.

Fuente: Resultados de las encuestas. 
Analizando los resultados que la Figura 3.5.14, estos demuestran lo que se ha venido mencionando anteriormente. La gran mayoría de personas reconocen que el tráfico les genera estrés, también cansancio y mal humor. Ahora que se reconocido el problema de la congestión vehicular limeña, no es de menos saber si las empresas aseguradoras donde trabajan los encuestados están haciendo algo para ayudar a sus colaboradores a contrarrestar los efectos del tráfico. Por lo que se realizó la siguiente pregunta:

Figura 3.5.15.

Pregunta 16. ¿La empresa donde trabaja hace algo para contrarrestar los efectos causados por el tráfico?
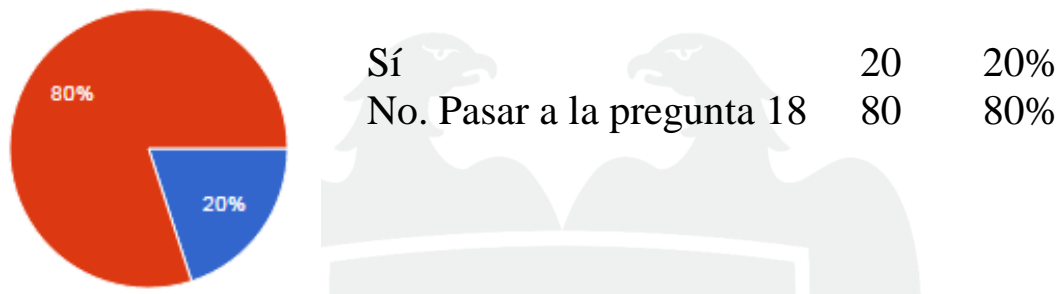

Nota: Elaboración propia.

Fuente: Resultados de las encuestas.

Estos resultados (Figura 3.5.15) son preocupantes, ya que con un problema de esta magnitud las empresas deberían ser la primera interesada en apoyar a sus trabajadores. Estas respuestas también se pueden estar dando porque los empleados no saben lo que la empresa donde trabajan está haciendo. Lo cual, tampoco está bien, ya que significa que lo que está haciendo las compañías para ayudar no está llegando a los empleados. Esta teoría se pudo confirmar con las respuestas de los empleados que respondieron sí en la pregunta 16, ya que luego se les pregunto qué es lo que hace la empresa. Algunas de las respuestas fueron las siguientes:

- Actividades de recreación, reuniones de integración.

- Se encuentra en un convenio con la Municipalidad de San Isidro para fomentar el uso de bicicletas una vez al mes. 
- Existe el flex time que es una medida para llegar una hora después o una hora antes a tu horario normal de trabajo.

Son muy interesantes estos resueltos y nos indican que las empresas si están tratando de aportar diversas soluciones a los empleados para que no sean perjudicados por el tráfico vehicular. Luego del desarrollo de toda esta investigación, es claro que las compañías pueden hacer mucho más.

La siguiente pregunta fue decisiva en esta investigación, ya que esta involucraba el tráfico con los resultados en el trabajo de los colaboradores. En la cual se buscaba saber que tan conscientes son los empleados de este efecto de la congestion vehicular en el trabajo de las personas.

Figura 3.5.16

Pregunta 18. ¿Cree que el tráfico esta afectando su desempeño en el trabajo?

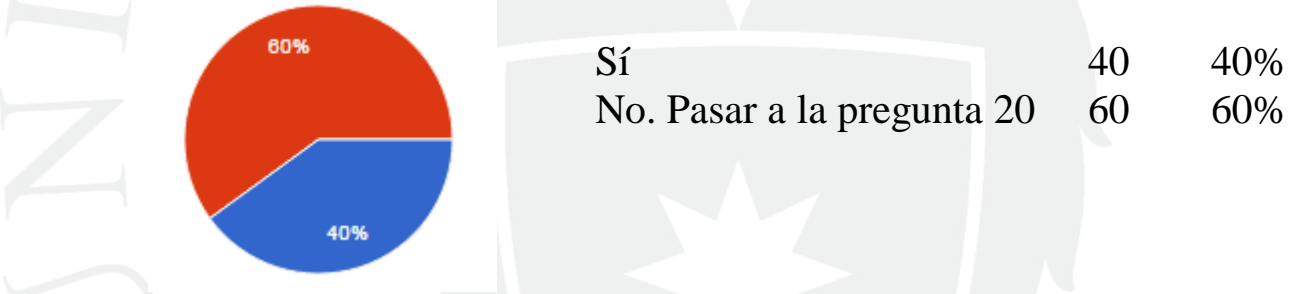

Nota: Elaboración propia.

Fuente: Resultados de las encuestas.

Claro está que estos no eran los resultados (Figura 3.5.16) que se esperaban ver, ya que si esta demostrados que el tráfico los afecta. Con estas repuestas se puede intuir que las personas no son conscientes de este efecto que tiene el tráfico en ellos. Si se pudiera hacer un experimento en donde no exista tráfico el desempeño laboral de las personas aumentaría considerablemente por diferentes razones como: más tiempo de descanso, mayores posibilidades de ventas, estarían más relajados, podrían controlar mejor sus horarios, etc.

A las personas que respondieron que sí les afectaba se les pidió que expliquen por qué creen que el tráfico está incluyendo en su desempeño laboral y las razones que brindaron algunos fueron las siguientes: 
- Tiempo perdido. Se podrá destinar en mayor rendimiento laboral.

- Porque en ocasiones por más que se sale temprano, el tráfico es impredecible y origina tardanza.

- Mala imagen y se empieza el día estresado.

- En las mañanas tengo que dedicarle unos minutos a poder relajarme luego de manejar una hora en el tráfico.

- Llega a estresar e incluso a veces hace que me tarde unos minutos. Antes nunca llegaba tarde.

- A veces hay retraso, lo cual, impide iniciar mis pendientes de manera oportuna.

- Al tener un horario de entrada en el trabajo y llegar con retraso me ocasiona malestar con mi jefe directo (llamada de atención).

Estas respuestas demuestras que las personas ven los efectos de la congestión vehicular de diferentes maneras, pero todos llegan a la conclusión de que el efecto principal es que el tráfico les hace perder tiempo que puede ser empleado en diferentes cosas como: actividades personales, mayor número de citas, entre otros.

Por otro lado, este no es el único malestar que les genera, sino que se ve interés en ellos en llegar temprano a su trabajo, pero el tráfico no siempre es el mismo y les causa mala imagen ante sus jefes y clientes, lo que se traduce en una mala imagen de la empresa ante potenciales clientes. Esto genera que se les hagan una llamada de atención a los asesores.

Es importante saber que harían o qué hacen las personas para que no les afecten la congestion vehicular en los diferentes aspectos de su vida, ya que con sus opiniones e ideas se puede aportar a realizar un cambio tanto en la empresa donde trabajan como en la ciudad en general. Las opciones que brindaron algunos son las siguientes:

- Propondría horarios flexibles.

- Trabajar desde el hogar. 
- Salir mucho más temprano de casa.

- Comprar un auto.

- Movilizarme en bicicleta.

- Lo ideal es llegar muy temprano, para evitar tráfico y así disminuir el estrés, pero también salir antes del trabajo para no coger las horas pico. Optimizando tiempos.

- Mejor organización de paraderos. Evitar los carros piratas que son los principales ocasionadores de tráfico.

- Mudarme a un distrito más cercano.

- Que los municipios proporcionen bicicletas.

Todas estas opciones son muy interesantes, pero algunas son drásticas, como mudarse ya que esto no es tan sensillo de aplicar. Otras son más faciles como: salir más temprano, preparar tus cosas un día antes, etc. También encontramos unas creativas como el flex time, que todavia no es muy común en el Perú, pero ya se esta aplicando en otros paises.

Estas empresas aseguradoras ya han comenzado a implementar un poco del flex time, pero no es beneficioso para todos los puestos especialmente para los vendedores. El programa que tienen es el E-day, el cual les permite trabajar un día desde su hogar. Pero a parte de este método podrían comenzar a aplicar otras opciones existentes como las video conferencias, para que así no se preocupen en llegar a tiempo a las reuniones o pueden realizar sus citas online.

También era interesante saber cuánto afecta el problema del tráfico en la vida personal de los trabajadores. Si este afecta mucho hará que estén de mal humor y termine afectando su desempeño laboral. 


\section{Figura 3.5.17}

Preguntas 21. ¿Con qué frecuencia pierde sus actividades personales debido a la congestión vehicular? (actividades de ocio en general)

\begin{tabular}{|llll}
\hline $30 \%$ & Siempre & 0 & $0 \%$ \\
Casi siempre & 0 & $0 \%$ \\
En ocasiones & 60 & $60 \%$ \\
Casi nunca & 30 & $30 \%$ \\
Nunca & 10 & $10 \%$
\end{tabular}

Nota: Elaboración propia.

Fuente: Resultados de las encuestas.

Como se observa en la Figura 3.5.17, el tráfico no afecta mucho en sus actividades personales, esto se puede deber a que ellos toman las precauciones necesarias para no tener que trasladarse en hora pico. Los encuestados comentaron que cuando tiene una reunión familiar o algún evento se organizan para salir temprano de sus trabajos. Esto nos demuestra que las personas si toman las debidas medidas para que el tráfico no afecte cuando se trata de actividades recreativas, pero no tanto cuando se trata su empleo. También hay que tomar en consideración que se debe de trabajar todos los días y las actividades personales son de vez en cuando.

En este punto se comienza a realizar preguntas dirigida a los jefes y gerentes, ya que es importante que ellos conozcan cómo se movilizan sus trabajadores, para así poder determinar si la congestión vehicular actual los afecta. 


\section{Figura 3.5.18}

Pregunta 22. Si maneja un equipo ¿sus trabajadores se movilizan utilizando el servicio público?
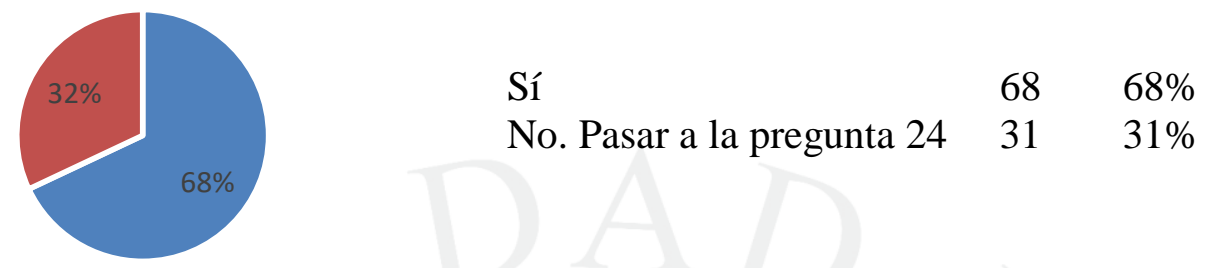

Nota: Elaboración propia.

Fuente: Resultados de las encuestas.

Más del 50\% de los jefes/gerentes de equipos respondieron que sí conocen cómo se traslada sus colaboradores, específicamente en el servicio público. Por lo cual, ahora debemos saber más o menos cuántas personas por grupo son las que se movilizan en el servicio público y lo que esto implica. En este caso como los equipos tienen diferentes números de personas la pregunta se realizó en porcentaje por equipo.

\section{Figura 3.5.19}

Pregunta 23. En porcentaje ¿cuántos de sus colaboradores utilizan el servicio público?

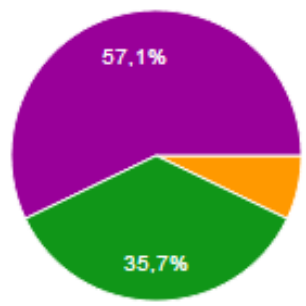

$\begin{array}{lll}\text { Menos del } 20 \% & 0 & 0 \% \\ \text { Entre el } 20 \% \text { y } 40 \% & 0 & 0 \% \\ \text { Entre el } 40 \% \text { y } 60 \% & 6 & 7.1 \% \\ \text { Entre el } 60 \% \text { y } 80 \% & 33 & 35.7 \% \\ \text { Entre el } 80 \% \text { y } 100 \% & 53 & 57.1 \%\end{array}$

Nota: Elaboración propia.

Fuente: Resultados de las encuestas.

Como se ve en los resultados (Figura 3.5.19), la mayoría de personas de los equipos se moviliza en el servicio público (buses, combis, etc.). Estas son en general los 
vendedores. Esto implica que tarden más tiempo en trasladarse, ya que los buses suelen ir por vías congestionadas y tiene que detenerse en todos los paraderos.

Por otro lado, es muy importante saber lo que piensan los jefes, ya que si su equipo se ve perjudicado esto los afecta a ellos, porque la base de su trabajo es que sus grupos obtengan los mejores resultados.

Figura 3.5.20

Pregunta 24. Si maneja un equipo ¿siente que su equipo se perjudica por la congestión vehicular actual?
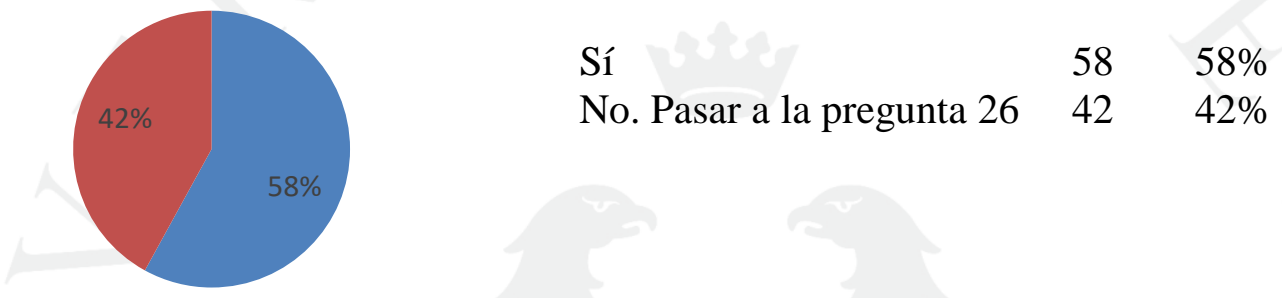

No. Pasar a la pregunta $26 \quad 42 \quad 42 \%$

Nota: Elaboración propia.

Fuente: Resultados de las encuestas.

Los resultados (Figura 3.5.20) no son lo que se esperaban, ya que sólo un poco más de la mitad respondió que sí. Esto se puede deber a que las personas que dijeron que no sean gerentes, que sólo tiene la supervisión de jefes los cuales no necesitan se deben movilizar para realizar sus laborales.

Luego de conocer que la mayoría de los supervisores si consideran que el tráfico afecta a sus equipos, es importante saber de qué manera está perjudicándolos. A continuación, las respuestas obtenidas:

- $\quad$ El desenfoque de sus actividades en el trabajo.

- Tardanzas y mal humor.

- Tardan demasiado en visitar clientes. Ahora hacen menos visitas de campo.

- Puntualidad y estrés. 
- Pierden control sobre el manejo de su tiempo acusando al tráfico por sus tardanzas.

- $\quad$ El empleo de tiempo en el tráfico.

- La gente llega mortificada por el tráfico y eso les ocasiona estrés.

- Les toma muchas horas del día movilizarse generando gastos y cansancio.

Casi todos estan de acuerdo que pieden tiempo, pero esto conlleva a otras cosas como: estrés, mal humor, mal manejo de sus tiempos, etc. Al ya saber cuales son las causas que afectan a los trabajadores, ahora se debe de buscar una manera como ayudarlos.

La siguiente pregunta se realizó de manera general para todos los encuestados, para que ellos mismos se den cuenta de cuánto les esta afectando este problema. De esta manera podran hacer un análisis personal para ver cómo el tráfico los afecta y estar concientes de esto. Esta pregunta mideo la gravedad del problema.

Figura 3.5.21

Pregunta 26. En general, ¿qué tan grave es el problema de congestión para su trabajo?

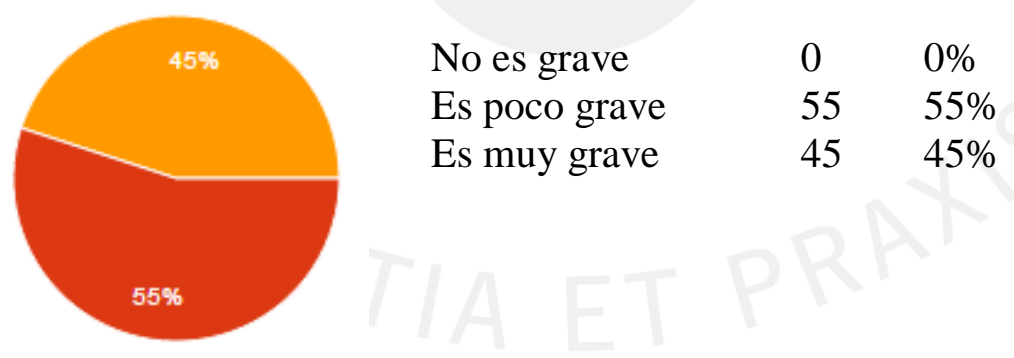

Nota: Elaboración propia.

Fuente: Resultados de las encuestas. 
Por lo general, lo encuestados han demostrado que sí existe un problema, pero que a unos les afecta más que a otros. Esto debido a que, como se vio en la primera parte de la encuesta, hay personas que se tienen que movilizar más que otras a lo largo del día.

\subsection{Desarrollo de la investigación}

Las empresas que se ven más afectadas son las que ganan a través de sus vendedores, como es el caso de las empresas aseguradoras de vida. El tráfico los afecta mucho, ya que pasan muy poco tiempo en la oficina porque la mayor parte de su trabajo es ir a visitar a sus clientes y el traslado de un cliente a otro les puede tomar horas, ya que a veces las distancias son muy largas o las citas son en horas en que el tráfico es muy denso y actualmente existe congestión a lo largo de todo el día.

Todo esto genera que deban de programar bien sus tiempos y sus citas considerando cuánto se van a tardar en movilizarse de un lado a otro y tratando de que de una cita a otra la distancia no sea muy larga, lo que les genera más trabajo y a veces no es posibles ya que ellos tienen que estar a la disposición de sus clientes.

Sería más fácil para ellos si el tráfico no fuera tan denso a lo largo de todo el día, ya que podrían tener más citas diarias para generar más ventas, lo cual ayudaría tanto a los ingresos de las personas como de la empresa donde trabajan.

$\mathrm{Al}$ ser empresas que tienen como principal recurso a sus vendedores, se debe conocer el perfil de estos. En las entrevistas realizadas fueron proporcionados diez rasgos y calificativos que utilizan para definir a un buen vendedor. Siendo estos los siguientes:

- DGV (Disposición General para la Venta): Es el índice más discriminativo de los buenos vendedores. Señala a un sujeto con facilidad para establecer en la venta relaciones con los demás, con un matiz de combatividad (para elevar las ventas o persuadir al cliente), pero moderada por un control suficiente de sí mismo.

- R. (Receptividad): Señala a un sujeto con buenas cualidades empáticas (ponerse en lugar de los demás, escuchar, comprender, etc.) y con posibilidades de adaptación rápida y fácil a situaciones y personas diferentes, lo cual implica capacidad de control de sí y resistencia a la frustración. Se corresponde con el tipo 
receptivo de venta, esa acción sedentaria o de representación en el mercado ya implantado, y con la que se mantiene la actividad comercial.

- A (Agresividad): La variable no tiene un matiz peyorativo; supone la capacidad para soportar situaciones conflictivas o para provocarlas con el deseo de ganar; implica también actitud dominante, por poder o por ascendencia, en sujetos seguros, que no rechazan los riegos por algo útil, activos y dinámicos. Se corresponde con un segundo tipo agresivo de venta, de apertura de mercados, acción competitiva ante otros clientes o productos.

I. Comprensión: Aptitud para la empatía capacidad para situarse en el lugar del cliente, saber escuchar, intuición. Indica un sujeto empático y objetivo en sus relaciones humanas, intuitivo y capaz de integrar en su contexto un seceso cualquiera.

II. Adaptabilidad: Flexibilidad, capacidad para adaptarse, aptitud para desempeñar un papel, mimetismo. Alude a un sujeto de fácil y rápida adaptación a situaciones y personas diferentes, flexible en sus actividades (intelectuales o de relación) y capaz de desempeñar su papel y de cierto mimetismo.

III. Control de sí mismo: Disciplina personal, estabilidad emocional, perseverancia, tenacidad. Señala a un sujeto controlado, dueño de sí mismo y capaz de una buena administración de su potencial intelectual, psicológico o físico; es una persona organizada, perseverante y hábil para ocultar sus sentimientos.

IV. Tolerancia a la frustración: Capacidad para soportar las situaciones de inferioridad o de digerir los fracasos, aptitud para dosificar la implicación en una situación. Indica un sujeto que soporta adecuadamente las acciones frustrantes, capaz de comprender los fracasos (aunque sean provisionales) y que no personaliza demasiado las situaciones en que se ve implicado. 
V. Combativilidad: Acometividad comercial, afán de vencer, capacidad para luchar. Alude a un sujeto capaz de entrar en conflicto y soportar los desacuerdos; se refiere a esa persona porfiada y polémica que ejemplifica lo que se llama agresividad comercial.

VI. Dominancia: Dominio personal, persuasión, ascendencia, autoridad natural, don de cautivar al cliente, capacidad de manipulación, voluntad de poder. Señala al sujeto con voluntad de domino, de ganar o manipular a los demás, persuasivo o cautivador en su entorno, dominante o con ascendencia, esa cualidad propia de personas de elevada jerarquía.

VII. Seguridad: Que define una persona segura de sí misma, confiada en sí misma. Indica un sujeto seguro de sí mismo, que le gustan las situaciones nuevas o inesperadas y que es capaz de enfrentarse, si es necesario, a los riesgos.

VIII. Actividad: Que apunta a una persona dinámica, entusiasta, vigorosa, energética, animosa, activa. Alude al sujeto activo y dinámico en el sentido físico, que soporta mal la pasividad e inactividad. (una puntuación baja sólo señala a la persona poco deportiva)

IX. Sociabilidad: Aptitud para establecer contactos, inteligencia social, gusto por las relaciones personales, don de gentes. Se refiere al sujeto extrovertido, capaz de crear nuevos contactos y convivir con los demás, que prefiere su compañía a la soledad y sensible a la importancia de las prelaciones humanas. Esta variable no interviene en la obtención de R y A; sin embargo, es importante para la venta, pues está en la base de esta actividad.

X. Gusto por el juego: Deseo de aventura y de juego, aceptación de riegos, vivir al día, afán lúdico. 
La importancia dada a cada rasgo o escala dependerá del análisis del puesto, de la estructura de la empresa y del equipo de ventas donde vaya a incorporarse el vendedor. Así como del producto y de la configuración del mercado donde vaya a trabajar. Para estar seguros de que los vendedores tienen lo que buscan aplican un pequeño cuestionario a la hora de la entrevista de trabajo (Anexo 2), ellos ya saben que si cumple con esas características será un buen vendedor.

Muchas empresas deciden que los vendedores no tengan hora de entrada con tal de que cumplan con sus metas, pero hay otras que les exigen a todos sus empleados que lleguen a la oficina a las 8:30am en punto para que comiencen a hacer su "hora de fuerza", la cual consiste en realizar llamadas a empresas y personas para coordinar citas. Entonces, ¿cómo medimos cuánto están perdiendo las personas y las empresas cuando existe impuntualidad?

Las empresas aseguradoras de vida tienen diferentes maneras de remunerar a sus vendedores, pero la mayoría tiene una ganancia básica baja más su variable, ya que sus verdaderos ingresos vienen de las ventas que realicen. Los vendedores de las diferentes áreas tienen metas que cumplir, por ejemplo: los de SCTR Mix tienen que lograr realizar veinte ventas a diferentes empresas mensualmente y los de Workside tienen que lograr entrar al menos a dos empresas lo que presenta venderle el producto a un promedio de cuarenta personas en total por mes.

Entonces, si los vendedores llegan tarde a su hora de fuerza pueden estar perdiendo la oportunidad de conseguir una cita con una empresa potencial para generar una venta. Por otro lado, hay áreas que exigen tener un mínimo de citas diarias como ocurre en rentas vitalicias y en vida individual, ellos tienen que cumplir con acudir a tres citas por día, por eso, si no acuden a tiempo al trabajo pueden estar perdiendo una reunión para cumplir con su mínimo.

Los vendedores de seguros de vida corporativos que tienen que acudir a empresas para que los trabajadores firmen con ellos, tienen que recorrer grandes distancias, ya que ellos aseguran mayormente a empresa de manufactura o industriales que suelen estar ubicados en el distrito como: Independencia, Ventanilla, Ate o Lurín, y como se observa en el mapa de la figura 3.6.1, estos distritos se encuentran muy separados unos de otros, lo cual, significa largar hora de recorrido y con el tráfico este tiempo puede ser mucho mayor. 
Figura 3.6.1

Mapa de Lima Metropolitana detallando los distritos

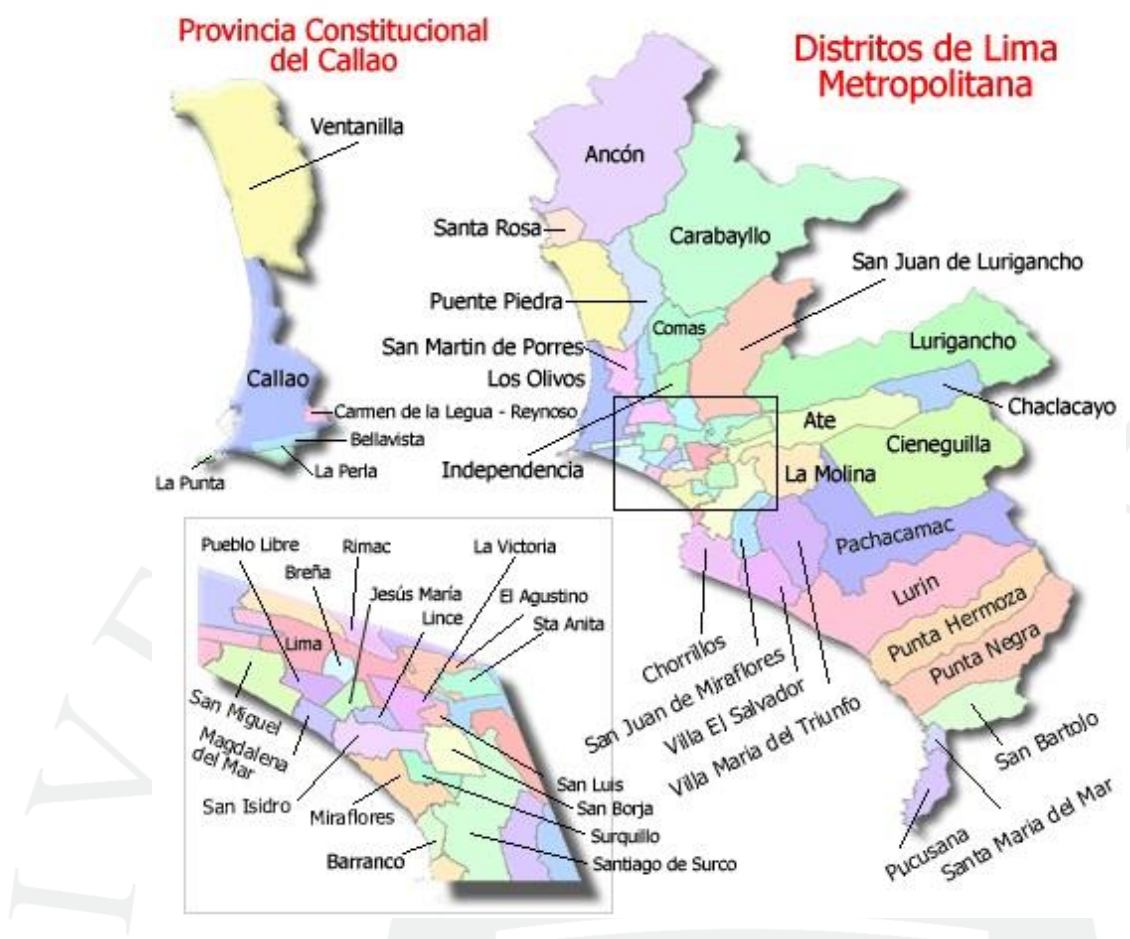

Nota: Mapa del Perú por Establecimientos de Salud según Distritos Lima Metropolitana

Fuente: Ministerio de Salud

Recuperado de http://www.minsa.gob.pe/portada/estadistica/callao.htm

Para calcular más o menos cuánto se tardaban los vendedores en trasladarse del centro financiero de Lima Metropolitana hacia los diferentes distritos mencionados anteriormente, se quiso hacer un experimento utilizando la aplicación de celular que está siendo muy utilizada actualmente: Waze. Pero al colocar la ruta fue una sorpresa ver un aviso informando que no existían rutas a esos destinos, lo que quiere decir que las personas que tienen que ir a estos sitios no utilizan esta aplicación para encontrar rutas alternativas que suelen ser más rápidas, ya que Waze tiene rutas más cortas o rápidas gracias a sus usuarios que las publican y que generan avisos sobre cómo está el tráfico, si hay policías, accidentes, entre otros.

Si la población que habita o que se suele movilizar en estos distritos aportara rutas a esta aplicación esto podría generar un cambio en la sociedad, no sólo proporcionando información importante, sino que también la congestión se reduciría porque existirían caminos alternos confiables. Pero hay que tomar en cuenta que actualmente la aplicación 
se encuentra trabajando para que se puedan detectar áreas peligrosas, para que sus usuarios sean conscientes de por dónde están pasando y las medidas que deben de tomar.

Otras de las causas por las cuales no existen estas rutas pueden ser que las personas que realizan este recorrido lo hacen en servicios público y no en vehículos propios. Esto fue confirmado con el gerente entrevistado, más del 50\% de su fuerza de ventas no cuenta con vehículo propio o no lo utiliza para trabajar.

Para tener una imagen más clara de cuánto es lo que se están perdiendo las empresas en números, se han elaborado una serie de indicadores que ayudan a tener una idea más clara de esta gran perdida.

Tabla 3.6.1

Indicadores de Ganancias y Pérdidas por Vendedor al 2016 (en Miles de Nuevos Soles)

\begin{tabular}{|c|c|c|c|}
\hline VARIABLES & $\mathbf{2 0 1 6}$ & \multicolumn{2}{|c|}{ INDICADORES } \\
\hline Primas Ganadas & $\mathrm{S} / 3,836,852.46$ & $\begin{array}{c}\text { Primas Ganadas por } \\
\text { Vendedor }\end{array}$ & S/ 705.953 \\
\hline $\begin{array}{c}\text { Siniestros } \\
\text { Incurridos }\end{array}$ & $\mathrm{S} / 2,386,995.90$ & $\begin{array}{c}\text { Siniestros Incurridos por } \\
\text { Vendedor }\end{array}$ & S/ 439.190 \\
\hline Comisiones & S/ $170,963.11$ & Comisión por Vendedor & S/ 31.456 \\
\hline Fuerza de Ventas & 5435 & & \\
\hline
\end{tabular}

Nota: Elaboración propia

Fuente: Recopilados de la SMV y la Memoria Anual 2016.

Recuperado de http://www.smv.gob.pe y http://www.bvl.com.pe

Como se observa en la tabla un vendedor puede hacerle ganar, en promedio, a una empresa 705'953 soles al año sólo en primas. Las comisiones ganadas por parte de un vendedor son de 31 ' 456 soles al año. Con estos datos ya se puede comenzar a tener un estimado de cuánto pierde una empresa sólo por tardanzas, considerando que apenas llegan a sus centros de trabajo son productivos. 
Tabla 3.6.2

Sueldo de un vendedor

\begin{tabular}{|l|l|}
\hline Mensual & S/. 3,429 \\
\hline Diario (considerando 20 días al mes) & S/. 171.45 \\
\hline Por hora (considerando 8 horas al día) & S/. 21.43 \\
\hline Por media hora & S/. 10.72 \\
\hline
\end{tabular}

Nota: Elaboración propia

Los ingresos del vendedor mensualmente son de 3'429 soles aproximadamente (considerando básico, comisión y gratificaciones), esto significa que gana al día alrededor de 171.45 soles considerando que trabajan 20 días al mes, por lo cual, les pagan 21.43 soles la hora, 10.72 soles por media hora. Si todos los asesores (en total Pacifico, Rimac, Mapfre, La Positiva e Interseguros tienen 5435 vendedores) se atrasan 30 minutos, como indicaron las encuestas, estas empresas estarían perdiendo 58'263.2 soles diarios, lo que significan 1'165'264 soles al mes, considerando 4 semanas al mes y 5 días a la semana. Pero qué pasa si tienen tardanzas todos los días del año, perderían 13'983'168 de soles. Como se mencionó estas empresas tiene el $81.75 \%$ del mercado, por lo que sí lo mismo sucede en todo el sector este estaría perdiendo S/. 17'104'792.66 anuales a causa de las tardanzas.

El análisis anterior sólo ve lo perdido por las empresas y el sector asegurador, porque la forma de pago es mensual. Pero los trabajadores también se ven afectados a causa del tráfico vehicular de los últimos años. Entre los años 2000 y 2011 los vendedores podían ganar hasta de 5 primas al día por medio de visitas, actualmente no pueden cerrar más de 2 primas, por temas de movilización. Considerando que la fuerza de venta tiene una forma de pago variable (básico + comisión por ventas + bono) la comisión es la que se ve afectada. Esta es en promedio del $4.64 \%$ de la prima ganada.

Entonces, si cada vendedor hace ganar a la empresa S/. 705'953 al año en primas, al mes sería S/. 58'829.38. Considerando que todos los días ganan 2 primas en 2 citas diferentes, lo que significa que ganan 40 primas al mes. Con una comisión de $4.64 \%$ el vendedor gana al mes por primas S/. 2'729.68. Cinco años atrás podían realizar 5 citas al día, lo que equivale a ganaban 5 primas, esto significaba para ellos una ganancia en 
comisiones por S/. 6’824.21. Lo que significa que cada vendedor está perdiendo S/.4'094.53 menos al mes, cifra significativa para cualquier familia. Esto significa que los trabajadores de las empresas analizadas están dejando de percibir 49’134.33 de soles anuales cada uno, S/. 267’045.08 mil soles anuales en conjunto. Si esta situación es replicada en todo el sector de seguros de vida, sus vendedores están dejando de ganar 326'660.64 mil soles.

A causa de que los vendedores están cerrando 2 citas al día en lugar de 5 las empresas dejan de tener la posibilidad de ganar las primas generadas de esas 3 citas. Como se mencionó cada asesor vende S/. 705'953 en primas anuales con sólo 2 primas ganadas al día, todos los vendedores de las cinco empresas en cuestión generan S/.3'836'852.46. Si pudieran vender 5 primas al día ganarían 9'592'131.15 miles de soles al año. Por lo que están perdiendo 5'755'278.69 miles de soles anualmente en conjunto a causa de que sus asesores no pueden realizar más de 2 citas al día porque existe mucha congestión vehicular a lo largo de todo el día. Teniendo la misma situación en todo el sector de seguros de vida, este estaría perdiendo S/. 7’040’096.26 (miles de soles).

Si se suma lo que las empresas pierden por lar tardanzas y la reducción en las citas que realizan sus vendedores, estas están dejando de percibir 5'756'676.86 miles de soles (Tabla 3.6.3) Si este escenario lo replicamos en todo el sector las perdidas ascenderías a S/. 7’084'422.76 lo que representa el 1.08\% del PBI (considerando el PBI del 2016 de \$192,1 miles de millones a un tipo de cambio de S/.3.4) (CIA World Factbook, 2017)

Para contrarrestar estos efectos, las empresas decidieron contratar mayor personal de ventas para así seguir llegando a todo el mercado limeño y que sus ingresos no se vean afectados tan significativamente, ya que sólo gastarían el pago de planillas.

Tabla 3.6.3

Perdidas monetarias anuales (en miles de Nuevos Soles)

\begin{tabular}{|l|l|l|l|}
\hline & $\begin{array}{c}\text { Pacifico, Rimac, Mapfre, } \\
\text { Interseguros y La } \\
\text { Positiva }\end{array}$ & \multicolumn{1}{|c|}{$\begin{array}{c}\text { Vendedores de las 5 } \\
\text { empresas analizadas }\end{array}$} & $\begin{array}{c}\text { Sector de seguros } \\
\text { de vida }\end{array}$ \\
\hline Tardanzas & S/. 13'983.17 & S/. & S/. 17'104.79 \\
\hline Citas & S/. 5'755'278.69 & S/. 22'253.74 & S/. 7'040'096.26 \\
\hline Total & S/.5'769'261.86 & S/. 22'253.74 & S/. 7'084'422.76 \\
\hline
\end{tabular}

Nota: Elaboración propia 
Por otro lado, es interesante saber cuántos siniestros han ocurrido en el año, porque a más siniestros más desembolsos debe generar las empresas aseguradoras. Si este número es muy alto puede ser un indicador de que algo anda mal, probablemente no se están midiendo detalladamente los riesgos antes de que se realice la firma del contrato. Como vemos los siniestros son casi la mitad de las primas ganas, por lo cual, esto puede interpretarse en que los vendedores no están haciendo un trabajo adecuado, lo que puede indicar una baja productividad de las personas.

Para saber si de verdad se ha generado un cambio se tienen que comparar los estados financieros de las empresas, de al menos 5 años consecutivos. Por lo tanto, es importante saber si en estos últimos años las empresas a generando una variación en sus ventas. Según la tabla 3.6.4 el sector ha tenido subidas y bajadas en los últimos 5 años, pero es impactante observar la baja del 2014 y que la cifra se repita en el año 2016.

Tabla 3.6.4

Variación de ventas del sector de seguros de vida 2012 - 2016 (en Miles de Nuevos Soles)

\begin{tabular}{|c|c|c|}
\hline ÃNO & $\begin{array}{c}\text { VENTA DE } \\
\text { PRIMAS }\end{array}$ & $\begin{array}{c}\text { VARIACION } \\
\text { PORCENTUAL }\end{array}$ \\
\hline 2012 & S/ 2,610,987.70 & \\
\hline 2013 & S/ 3,162,032.79 & $21.10 \%$ \\
\hline 2014 & S/ 2,680,909.84 & $-15.22 \%$ \\
\hline 2015 & S/ 3,739,081.97 & $39.47 \%$ \\
\hline 2016 & S/ 3,836,852.46 & $2.61 \%$ \\
\hline
\end{tabular}

Nota: Elaboración propia

Fuente: recopilados de la SMV

Recuperado de http://www.smv.gob.pe

No sólo es importante saber cuánto es lo que ha vendido el sector, también se debe de tomar en cuenta que tan rentable han sido las empresas en los últimos años. Es por esto que se realizó la tabla 3.6.4, la cual muestra los activos, patrimonios y utilidad de las empresas en conjunto. Con estos datos se ha podido desarrollar los ratios de rentabilidad más importantes el ROA (activos totales entre utilidades) y el ROE (patrimonio entre utilidades). 
Tabla 3.6.5

Variación en la rentabilidad 2012-2016 (miles de soles)

\begin{tabular}{|c|c|c|c|}
\hline AÑO & ACTIVOS & PATRIMONIO & UTILIDAD \\
\hline $\mathbf{2 0 1 2}$ & S/ $15,420,323.77$ & S/ $2,229,352.46$ & S/ 409,180.33 \\
\hline $\mathbf{2 0 1 3}$ & S/ $18,205,426.23$ & S/ $2,269,827.87$ & S/ 684,647.54 \\
\hline $\mathbf{2 0 1 4}$ & S/ $21,187,479.51$ & S/ $2,867,323.77$ & S/ 608,442.62 \\
\hline $\mathbf{2 0 1 5}$ & S/ $25,439,258.20$ & S/ 3,066,844.26 & S/ 660,348.36 \\
\hline $\mathbf{2 0 1 6}$ & S/ $27,917,930.33$ & S/ 3,846,598.36 & S/ 798,627.05 \\
\hline
\end{tabular}

\begin{tabular}{|c|c|c|c|c|}
\hline AÑO & ROA & $\begin{array}{c}\text { VARIACIÓN \% } \\
\text { ROA }\end{array}$ & ROE & $\begin{array}{c}\text { VARIACIÓN } \\
\text { \% ROE }\end{array}$ \\
\hline $\mathbf{2 0 1 2}$ & $2.65 \%$ & & $18.35 \%$ & \\
\hline $\mathbf{2 0 1 3}$ & $3.76 \%$ & $41.72 \%$ & $30.16 \%$ & $64.34 \%$ \\
\hline $\mathbf{2 0 1 4}$ & $2.87 \%$ & $-23.64 \%$ & $21.22 \%$ & $-29.65 \%$ \\
\hline $\mathbf{2 0 1 5}$ & $2.60 \%$ & $-9.61 \%$ & $21.53 \%$ & $1.47 \%$ \\
\hline $\mathbf{2 0 1 6}$ & $2.86 \%$ & $10.20 \%$ & $20.76 \%$ & $-3.58 \%$ \\
\hline
\end{tabular}

Nota: Elaboración propia

Fuente: recopilados de la SMV

Recuperado de http://www.smv.gob.pe

Como era de esperarse los ratios de rentabilidad también muestran una fuerte baja en el 2014, pero como se observar en la tabla 3.6.5 el ROA en el 2015 siguió bajando quedando en negativo, en cambio en el ROE por más que no ha tenido un gran variación en el 2015 se volvió positivo, pero en el 2016 volvió a ser negativo.

Lo que se va a tratar de demostrar es que existe una relación directa entre el incremento del tráfico en Lima Metropolitana y la disminución de las utilidades de las empresas aseguradoras de vida independientemente de otros factores políticos y económicos que también pueden afectar positiva o negativamente las utilidades de las empresas.

En el 2014 hubo una contracción del gasto público, lo que género que el PBI no haya crecido como se esperaba. Esto afecto a muchos sectores, pero según el diario Gestión (2015) en el 2014 los seguros de vida crecieron en un 17.8\%.

A continuación, se detallan hechos que generaron un incremento del tráfico vehicular en el 2014: 
- Las elecciones Municipales y Provinciales, siempre todo tipo de elecciones genera incertidumbre en la población. En este mismo año, por más que Susana Villarán fue retirada de la alcaldía de Lima se comenzó la reforma en Lima del Corredor Azul y el Corredor Verde. La mala aplicación de esta reforma genero muchos conflictos entre las autoridades y huelgas de los transportistas (Portal PQS, 2014)

- $\quad$ "Nuestro país fue cede de la cumbre por el cambio climático, COP 20. Por más de dos semanas, representantes de 196 países, activistas y diversas ONG se encontraron en nuestra capital para encontrar medidas para cuidar el medio ambiente" (Portal PQS, 2014). Siempre que se realizan cumbres en Lima se cierran calles principales como la avenida Javier Prado por seguridad, esto ha terminado perjudicando a la población.

- $\quad$ Ese año también se generó la huelga de los médicos, la cual duro 150 días (Portal PQS, 2014). Todo tipo de huelga genera congestión, ya que las personas marchan por las calles para que sus reclamos sean escuchados.

$\mathrm{Al}$ ver estos resultados tanto con respecto a la baja en la rentabilidad, en las ventas. Las empresas del sector que se está analizando comenzaron a realizar un plan exhaustivo de mejora de clima laboral. En dicho plan se buscaba realizar actividades, otorgar beneficios, aportar a la cultura empresarial y generar mejoras en ámbitos generales. Todo esto buscaba la satisfacción, orgullo, tranquilidad, motivación y bienestar de los empleados. Algunos de las medidas que se realizaron en el 2015 para combatir los efectos generados en el 2014 fueron los siguiente:

- $\quad$ Viernes, horario de verano $(8: 30-1: 00 \mathrm{pm})$

- Viernes de casuales, en donde los colaboradores puedan ir en jean al trabajo.

- Activaciones como: dinámicas grupales, activaciones, reconocimiento en eventos, integraciones, full days, entre otras.

- Plan EPS a partir del primer ascenso en fuerza de ventas. En algunas empresas era a partir del segundo ascenso. 
- Plan de accidentes personales, para atención medica de la fuerza de ventas que no tiene EPS. Esto se aplica desde su primer día de trabajo.

- Reestructuración de política salarial con mejores incentivos de acuerdo a resultados.

- Fiesta por aniversario de la compañía en Lima y Provincias (Arequipa - Trujillo). Además, un evento cuando cada área cumple un año más.

- Implementación de comités mensuales en distintas áreas para monitorear los avances e impulsar la producción, recogiendo la opinión de los líderes de cada equipo.

- Difusión de la estrategia de la compañía, política laboral y resultados del negocio en comité de áreas.

Tocando otro punto, también es interesante saber cuánto gastan los trabajadores en concepto de traslado. A continuación, se puede observar la tabla 3.6.5, la cual muestra cuadros con datos similares, pero a la misma vez diferentes. La idea de esta tabla es conocer los gastos anuales de las personas, dependiendo de su puesto y si tienen carro o no. Todos estos datos han sido lo más aproximados posible a la realidad. 
Tabla 3.6.6

Cuadros de gastos anuales por concepto de traslado según puesto y por cómo se movilizan

JEFE/GERENTE CON CARRO
\begin{tabular}{|l|r|}
\hline Combustible, lubricantes, llantas & 6,120 \\
\hline Permisos, peajes, parqueo & \\
\hline Velocidad Operacional (km/h) & $30-60$ \\
\hline Horas de funcionamiento & $7: 30-19: 00$ \\
\hline Kilómetros / Año & 3,360 \\
\hline Mantenimiento/Reparaciones & 1,500 \\
\hline Depreciación del vehículo & 10,080 \\
\hline Horas de viaje & 400 \\
\hline Costos laborales $x$ traslado & 25,000 \\
\hline Total & $\mathbf{S / . 4 2 , 7 0 0 . 0 0}$ \\
\hline
\end{tabular}

\begin{tabular}{|c|c|}
\hline JEFE/GERENTE EN BUS & \\
\hline Combustible, lubricantes, Ilantas & 720 \\
\hline \multicolumn{2}{|l|}{ Permisos, peajes, parqueo } \\
\hline Velocidad Operacional $(\mathrm{km} / \mathrm{h})$ & $30-60$ \\
\hline Horas de funcionamiento & 7:00 - 19:30 \\
\hline Kilómetros / Año & 3,360 \\
\hline \multicolumn{2}{|l|}{ Mantenimiento/Reparaciones } \\
\hline \multicolumn{2}{|l|}{ Depreciación del vehículo } \\
\hline Horas de viaje & 500 \\
\hline Costos laborales $\mathrm{x}$ traslado & 31,250 \\
\hline Total & S/. 31,970.00 \\
\hline
\end{tabular}

JEFE/GERENTE EN TAXI
\begin{tabular}{|l|r|}
\hline Combustible, lubricantes, Ilantas & 4,800 \\
\hline Permisos, peajes, parqueo & \\
\hline Velocidad Operacional (km/h) & $30-60$ \\
\hline Horas de funcionamiento & $7: 00-19: 30$ \\
\hline Kilómetros / Año & 3,360 \\
\hline Mantenimiento/Reparaciones & \\
\hline Depreciación del vehículo & 400 \\
\hline Horas de viaje & 25,000 \\
\hline Costos laborales x traslado & $\mathbf{5 / . 2 9 , 8 0 0 . 0 0}$ \\
\hline Total &
\end{tabular}

\section{ASESOR CON CARRO}

\begin{tabular}{|l|r|}
\hline Combustible, lubricantes, Ilantas & 12,360 \\
\hline Permisos, peajes, parqueo & 1,296 \\
\hline Velocidad Operacional (km/h) & $30-60$ \\
\hline Horas de funcionamiento & $7: 00$ - 20:00 \\
\hline Kilómetros / Año & 8,400 \\
\hline Mantenimiento/Reparaciones & 1,500 \\
\hline Depreciación del vehículo & 10,080 \\
\hline Horas de viaje & 960 \\
\hline Costos laborales x traslado & 11,333 \\
\hline Total & $\mathbf{S / . 3 6 , 5 6 9 . 3 3}$ \\
\hline
\end{tabular}

ASESOR EN BUS
\begin{tabular}{|l|r|}
\hline Combustible, lubricantes, llantas & 3,600 \\
\hline Permisos, peajes, parqueo & \\
\hline Velocidad Operacional $(\mathrm{km} / \mathrm{h})$ & $30-60$ \\
\hline Horas de funcionamiento & $7: 30-20: 00$ \\
\hline Kilómetros / Año & 8,400 \\
\hline Mantenimiento/Reparaciones & \\
\hline Depreciación del vehículo & 1,200 \\
\hline Horas de viaje & 14,167 \\
\hline Costos laborales x traslado & $\mathbf{S / . 1 7 , 7 6 6 . 6 7}$ \\
\hline Total &
\end{tabular}

ASESOR EN TAXI
\begin{tabular}{|l|r|}
\hline Combustible, lubricantes, Ilantas & 9,600 \\
\hline Permisos, peajes, parqueo & \\
\hline Velocidad Operacional (km/h) & $30-60$ \\
\hline Horas de funcionamiento & $7: 30-20: 00$ \\
\hline Kilómetros / Año & 8,400 \\
\hline Mantenimiento/Reparaciones & \\
\hline Depreciación del vehículo & 960 \\
\hline Horas de viaje & 11,333 \\
\hline Costos laborales $x$ traslado & S/.20,933.33 \\
\hline Total &
\end{tabular}

Nota: Elaboración propia.

Fuente: Datos recogidos de las entrevistas y encuestas realizadas a las empresas aseguradoras.

Se ha considerado que los gerentes se trasladan 100 minutos al día y tienen un sueldo de 10,000 soles mensuales. Los que cuentas con un carro, se ha propuesto que el auto es un Toyota Yaris del año. Con respecto al asesor, se le colocó un sueldo anual de 46,000 soles. Con los resultados que se observa, es claro que los más perjudicados son las personas con vehículo propio, pero más los asesores considerando la diferencia de salarios. La sorpresa ha sido que los gerentes tienen un mayor costo de oportunidad con respecto al tiempo que pierden en el tráfico, a pesar de que ellos se trasladan menos que los asesores. Esto se debe a que los gerentes/jefes ganan más por hora. 


\section{CONCLUSIONES}

Recién ahora que se ha terminado con toda la explicación del tema, se han presentado los antecedentes, las posibles causas y se le dio un análisis a los resultados de las encuestas, se pueden establecer las conclusiones.

- Se puede concluir que sí se cumple con la hipótesis general. Existe un problema en la capital del Perú con respecto a la congestión vehicular, siendo este un obstáculo para el crecimiento personal y profesional de los trabajadores del sector de seguros de vida entre el 2012 y el 2016, ya que este está afectando económicamente a las empresas aseguradoras y a sus trabajadores en Lima Metropolitana.

- Más del 28\% de la población total del Perú habita en la capital, esto sucede con el traslado de zonas rurales a urbanas que tuvo un boom en el año 1972. Entre los años 2012 y 2016 el crecimiento fue de $5.14 \%$, en este mismo periodo el parque automotor de Lima creció en $23.99 \%$ y en el 2016 en PBI registro un crecimiento de $4.5 \%$.

- A causa de las tardanzas de los trabajadores mayormente generadas por la congestión vehicular las empresas Pacifico, Rimac, Mapfre, Interseguros y La Positiva están perdiendo S/. 13,983,168.00 anuales. Y porque sus trabajadores están realizando 3 citas diarias menos están perdiendo anualmente S/.5,755,278,690.00. Por lo que el sector está dejando de ganar S/.7,057,201,049.54 anuales, lo que representa el 1.08\% del PBI.

- Las pérdidas de la fuerza de venta de las empresas analizadas son de S/.267,045,077.03 anules en conjunto, todo a causa que no pueden realizar más citas en un día porque movilizarse en la ciudad es muy complicado. Esto nos indica que mensualmente cada vendedor está dejando de ganar S/. 4,094.53 monto significativa para las familias. 


\section{RECOMENDACIONES}

\section{Hipótesis General}

- A lo largo del trabajo se pueden apreciar diferentes soluciones que no se basan sólo en una idea, sino que son opciones que abarcan distintos campos para atacar el problema de diversos lados y así llegar a la raíz del problema. Pero algunas recomendaciones para que la economía de una empresa de seguros de vida o sus vendedores es que en conjunto la compañía y los trabajadores deben que aplicar el flex time, utilizar la tecnología para que las citas no sean presenciales y para realizar ciertas labores e incentivar el pull car y el uso de bicicletas.

\section{Hipótesis Específica 1}

- Principalmente se debe de combatir el gran problema del incumplimiento de leyes de tránsito y la Ley N`29237 de revisiones técnicas anuales, ya que se podría retirar de circulación gran número de unidades del parque automotor. También, a través de la educación se puede instruir a los niños la importancia del cumplimiento de estos mandatos.

- Se debe generar un plan de obras viendo prioridades, que no sean simultaneas ya que puede generar más congestión. Deben asegurar que estas se van a elaborar en el tiempo establecido, sólo se deben de realizar en las noches y madrugadas para no entorpecer el tráfico. No sólo las obras en vías públicas deben ser en horas pm sino también la distribución de mercadería en camiones, el recojo de basura y reciclaje, el riego de plantas, todo lo que involucre camiones que deben parar en la pista y bloquearla.

- Se espera que, con el nuevo proyecto de ley, Autoridad de Transporte Urbano para Lima y Callao, se pueda combatir la informalidad del servicio de transporte público, se comiencen a utilizar los taxímetros, ordene las calles de todas las ciudades, se generen paraderos formales, se aplique una mejor señalización de las vías, se aplique las leyes de transporte y las multas sean ejecutadas y pagadas. 
- Es muy importante generar una descentralización, pero para lograrlo se debe investir en todo tipo de medio de transporte terrestre como: autopistas, carreteras, trenes, etc.

- No se debería aplicar el impuesto a los vehículos nuevos, sino debería ser para los autos mayores a 20 años. Para que esto se pueda realizar el gobierno debe promover los lessing vehicular, así sería más sencillo para las personas contar siempre con un vehículo al cual no se le aplique el impuesto.

Hipótesis Específica 2

- Dejar de exigirle a los vendedores que acudan a la oficina a marcar hora de ingreso.

- Las empresas también pueden aportar con medios de transporte colectivos para su personal.

- Las empresas de todo el Perú en conjunto con el Ministerio de Trabajo deberían acordar comenzar a pagar por hora, así las compañías no perderían dinero por las personas que llegan tarde y probablemente los empleados comiencen a llegar temprano, ya que de eso depende su sueldo del mes.

- Otorgar la tecnología necesaria para que puedan realizar más labores online y que poco a poco dejen de ser presenciales.

Hipótesis Especifica 3

- Impulsar el uso de bicicletas aportaría tanto a la congestión vehicular como a la salud de las personas.

- Apoyarse en la tecnología para encontrar rutas alternas sin congestión vehicular y para no tener que realizar todas sus labores en la oficina.

- Organizarse con compañeros para hacer pull car.

- Incentivar las citas online 


\section{REFERENCIAS}

American Marketing Association (2017). Dictionary of Marketing Terms. Recuperado de: www.marketingpower.com

Asociación Automotriz del Perú (2015). Ventas que reflejan la economía. Lima:

Derteano, Edwin. Recuperado de: http://www.aap.org.pe

Banco Central de Reserva del Perú. (2016). Indicadores económicos. Lima. Recuperado del sitio de internet del Banco Central de Reserva:

http://www.bcrp.gob.pe/docs/Estadisticas/indicadores-trimestrales.pdf

Blog WordPress.com (2010, May.). Desarrollo de los Conos en Lima. Recuperado de:

https://grupo4cultura.wordpress.com/2010/05/24/migraciones/

Centro Canadiense de Seguridad y Salud Ocupacional - Recursos Naturales

Canadienses de Seguridad y Salud Ocupacional (1997). Dióxido de Carbono -

Efectos en la Salud. Recuperado de:

http://www.ccsso.ca/oshanswers/chemicals/chem_profiles/carbon_dioxide/healt h_cd.html

Cia World Factbook (2017, Jul.) Perú Producto Bruto Interno. Recuperado de: https://www.indexmundi.com/es/peru/producto_interno_bruto_(pib).html

Comunidad Andina (2015) Parque Vehicular en la Comunidad Andina 2005 - 2014

Recuperado de:

http://intranet.comunidadandina.org/Documentos/DEstadisticos/SGde707.pdf

Datakey Instituto de Inversiones (2017) Cálculo del tamaño de muestra para

determinar la proporción de elementos que posee una característica.

Recuperado de: http://www.datakey.galeon.com/muestra.html

Diccionario de Marketing, de Cultura S.A (1999) Vendedor. Recuperado de:

https://www.urbe.edu/UDWLibrary/InfoBook.do?id=1678

Di Negro, G. (2012) Caos vehicular: pequeñas soluciones para un gran problema.

Terra. Recuperado de: https://noticias.terra.com.pe/peru/caos-vehicular- 
pequenas-soluciones-para-un-gran-

problema,75a181fbd3817310VgnVCM4000009bcceb0aRCRD.html

Discovery Chanel (2016) Don't drive here. Recuperado de:

https://press.discovery.com/emea/dsc/programs/dont-drive-here/

Domingo Begazo, J. y Torres Agurto, R. (2009). El PBI ¿un indicador anacrónico?

Revista de Investigación de la Facultad de Ciencias Administrativas de la

UNMSM. [versión PDF]. Recuperado de:

http://revistasinvestigacion.unmsm.edu.pe/index.php/administrativas/article/vie w/8889/7720

El Comercio (2016) Ollanta Humala decretó aumento del sueldo mínimo a S/850.

Recuperado de: http://elcomercio.pe/politica/gobierno/ollanta-humala-decretanuevo-aumento-sueldo-minimo-noticia-1890383

Economipedia (2017) Economía. Recuperado de:

http://economipedia.com/definiciones/economia.html

Evaluando la Gestión en Lima (2013). Lima Cómo Vamos Observatorio Ciudadano.

Recuperado de: http://www.limacomovamos.org/cm/wp-

content/uploads/2014/09/Reporte_movilidad_2013.pdf

Expansión (2016). Ghana registra un incremento de su población. Recuperado de:

http://www.datosmacro.com/demografia/poblacion/ghana

Fajardo, C. (2013) Caos perjudica el rendimiento. Recuperado de: https://peru21.pe/economia/trafico-afecta-empleados-121007

Frers, C (2016) El dióxido de carbono y su impacto en el cambio climático. Eco Joven.

Recuperado de: http://www.ecojoven.com/seis/10/co2.html

Gestión (2015). Seguros de vida crecen en $17.8 \%$ en el 2014. Recuperado de:

http://gestion.pe/mercados/seguros-vida-crecen-178-2014-2124072

Gestión (2016). Venta de vehículos nuevos creció $2.7 \%$ en abril. Recuperado de: http://gestion.pe/mercados/venta-vehiculos-nuevos-crecio-27-abril-2160805

Gitman, L. (1992) Fundamentos de Administración Financiera. México: Harla S.A

Guiltinan, J. y Gordon W. (1984). Administración de Mercadeo. Estrategias y

Programas. McGraw-Hill, México: McGraw-Hill 
Han multado a 2.109 conductores por no tener revisión técnica en lo que va del año (25 de junio del 2013). La Prensa. Recuperado de: http://laprensa.peru.com/actualidad/noticia-lo-que-va-ano-han-multado-2109conductores-no-tener-revision-tecnica-8944

Hospital de Harvard medical school (2012). Traffic affects our health. Recuperado de: http://hms.harvard.edu/

Instituto Nacional de Estadística e Informática (2007). Población total, crecimiento intercensal, anual y tasa de crecimiento promedio anual, según año censal. Lima. Recuperado de: www.inei.gob.pe

Instituto Nacional de Estadística e Informática (2012). Parque Automotor en Circulación a Nivel Nacional. Recuperado de: https://www.inei.gob.pe/estadisticas/indice-tematico/transport-andcommunications/

Instituto Nacional de Estadística e Informática (2015) Población Limeña. Recuperado de: http://proyectos.inei.gob.pe/web/poblacion/

Instituto Nacional de Estadística e Informática (2016) Cerca de 10 millones de personas viven en Lima Metropolitana. Lima. Recuperado de: https://www.inei.gob.pe/prensa/noticias/cerca-de-10-millonesde-personas-viven-en-lima-metropolitana-8818/

Javier Rodríguez F. y Gómez Bravo L. (1991). Indicadores de calidad y productividad en la empresa. [versión PDF]. Recuperado de: http://scioteca.caf.com/bitstream/handle/123456789/863/Indicadores\%20de $\% 20$ calidad $\% 20$ y $\% 20$ productividad $\% 20$ en $\% 201 \mathrm{a} \% 20$ empresa.PDF?sequence $=1 \&$ is Allowed $=\mathrm{y}$

Kanno, F. (28 de febrero del 2016) Inseguridad ciudadana: PPK explica su plan para combatir la delincuencia - SOS América [archivo de video]. Recuperado de: http://www.americatv.com.pe/sos-america/reportajes/inseguridad-ciudadanappk-explica-su-plan-combatir-delincuencia-noticia-47783

La República (2016) Lima tiene 5 veces más taxis que otras capitales de Latinoamérica. Recuperado de: http://larepublica.pe/impresa/sociedad/759589lima-tiene-5-veces-mas-taxis-que-otras-capitales-de-latinoamerica 
La República (28 de julio del 2017) Mensaje a la Nación: Este es el discurso que PPK pronunció ante el Congreso. Recuperado por:

http://larepublica.pe/politica/1066975-mensaje-a-la-nacion-este-es-el-discursoque-ppk-pronuncio-ante-el-congreso

La República (30 de julio del 2017) San Luis: matan a joven que intentó frustrar robo de celular a su prima. Recuperado de: http://larepublica.pe/sociedad/1067662san-luis-matan-a-joven-que-intento-frustrar-robo-de-celular-a-su-prima-video

Legge, A. (15 de octubre del 2015). Traffic congestion puts brakes on our productivity. Calgary Herald. Recuperado de: http://fresno.ulima.edu.pe/ss_bd00102.nsf/RecursoReferido?OpenForm\&id=PR OQUEST-41716\&url=/docview/1442323991 accountid=45277

Lima necesita rediseñar su infraestructura vial (27 de setiembre del 2012). Capital. Recuperado de: http://www.capital.com.pe/actualidad/lima-necesita-redisenarsu-infraestructura-vial-noticia-540382

Lowery, F. (11 de febrero de 1995). Traffic delays can cost dearly in workers' time, productivity. Sun Sentinel. Recuperado de: http://fresno.ulima.edu.pe/ss_bd00102.nsf/RecursoReferido?OpenForm\&id=PR OQUEST-41716\&url=/docview/388663426? accountid=45277

Mac, D. (02 de noviembre del 2003). Stuck in traffic? Ask your employer for help. Boston Globe. Recuperado de: http://fresno.ulima.edu.pe/ss_bd00102.nsf/RecursoReferido?OpenForm\&id=PR OQUEST-41716\&url=/docview/404865640?accountid=45277

Ministerio de Salud. Mapa del Perú por Establecimientos de Salud según Distritos Lima Metropolitana. Recuperado del sitio de internet del Ministerio de Salud: http://www.minsa.gob.pe/portada/estadistica/callao.htm

Ministerio de transporte y comunicaciones (2015). Parque Automotor Nacional 19952015. Recuperado del sitio de internet del Ministerio de transporte y comunicaciones: https://www.mtc.gob.pe/cnsv/estadisticas/Parque\%20vehicular\%20nacional\%20 1995-2015.pdf 
Ministerio de transporte y comunicaciones (2008). Reglamento nacional de inspecciones técnicas vehiculares. Recuperado del sitio de internet del Ministerio de transporte y comunicaciones: http://www.mtc.gob.pe/portal/home/publicaciones_arch/reglamento_inspeccione s_vehiculares_version_final.pdf

Municipalidad de Lima crea entidad para gestión del tránsito (02 de enero del 2017). El Comercio. Recuperado de: http://elcomercio.pe/sociedad/lima/municipalidadlima-crea-entidad-gestion-transito-noticia1957619?ref=flujo_tags_92347\&ft=nota_4\&e=titulo

Perú21 (27 de junio del 2016) INEI: Crece inseguridad en Lima, 90.6\% teme ser víctima de un delito. Recuperado de: https://peru21.pe/lima/inei-creceinseguridad-lima-90-6-teme-victima-delito-221835

Portal PQS (29 de diciembre del 2014) Los siete sucesos que marcaron al Perú en el 2014. Recuperado de: http://www.pqs.pe/actualidad/noticias/los-siete-sucesosque-marcaron-al-peru-en-el-2014

Proexpansión (2008). Antídotos para la congestión y la inseguridad en el tránsito. Recuperado de: http://araper.pe/ckfinder/userfiles/files/pdf1.pdf

Quispe, L. (13 de enero del 2017) ¿Protransporte o Protránsito?, por Luis Quispe Candia. El Comercio. Recupero de: http://elcomercio.pe/opinion/colaboradores/protransporte-protransito-luisquispe-candia-noticia-1960078?ref=flujo_tags_92347\&ft=nota_3\&e=titulo

Ramírez, L. (14 de junio del 2016) Seguridad vial: La informalidad genera tantas muertes como la caída de 100 aviones. Gestión. Recuperado de: http://gestion.pe/economia/transporte-peru-informalidad-sector-genera-tantasmuertes-como-caida-100-aviones-2163213

Reyna, C. (9 de diciembre de 2009). La informalidad en el transporte público [mensaje en un blog]. Recuperado de https://creynatransportelima.blogspot.pe/2009/12/sabe-ud-lo-que-es-informalidad-en-el.html

Rischmoller, D. (11 de agosto del 2013). Lima, la ciudad de 9 millones y con más taxis que Nueva York. Terra. Recuperado de http://noticias.terra.com.pe/peru/lima-la- 
ciudad-de-9-millones-y-con-mas-taxis-que-nueva-

york,f0daab3fd02a0410VgnVCM3000009acceb0aRCRD.html

RPP Noticias (4 de setiembre del 2012). Sepa qué enfermedades puede causar el caos vehicular. Vital. Recuperado de: http://vital.rpp.pe/salud/sepa-queenfermedades-puede-causar-el-caos-vehicular-noticia-518652

Servicio de Administración Tributaria de Lima (2015). Impuesto al Patrimonio Vehicular. Recuperado de https://www.sat.gob.pe/websitev8/Modulos/contenidos/tri_ImpVeh_info.aspx\# menusCabecera

Servindi (29 de julio del 2016). Conozca el discurso presidencial de PPK. Recuperado de: https://www.servindi.org/actualidad-noticias/29/07/2016/conozca-eldiscurso-presidencial-de-ppk

SiSeguros (2017). Definición de compañías aseguradoras. Recuperado de: http://www.siseguros.com.mx/WikiSeguros/Definicion-CompaniasAseguradoras.php

Superintendencia de Banca y Seguros del Perú (2017). Ranking de Primas y Seguros Netas por Ramos. Recuperado de: http://www.sbs.gob.pe/app/stats_net/stats/EstadisticaBoletinEstadistico.aspx?p= 25\#

Sutherland, B. (1995). Employer-based, trip-reduction program scrapped. San Diego Business Journal, 16(30), 4. Recuperado de http://fresno.ulima.edu.pe/ss_bd00102.nsf/RecursoReferido?OpenForm\&id=PR OQUEST-41716\&url=/docview/226946683?accountid=45277

Thompson, I. (2017). Definición de vendedor. Recuperado de: https://www.promonegocios.net/venta/definicion-vendedor.html

Thomson, I. y Bull, A. (2002). La congestión del tránsito urbano: causas y consecuencias económicas y sociales. Revista de la Cepal, (76), 110-121.

Recuperado de http://repositorio.cepal.org/bitstream/handle/11362/10804/076109121_es.pdf?se quence $=1 \&$ is Allowed $=\mathrm{y}$ 
Trome (15 de agosto del 2017) Congreso: Comisión de Constitución cambió horario de sesiones de 8 a 9 a.m. por esta increíble razón. Recuperado de:

http://trome.pe/actualidad/congreso-comision-constitucion-cambio-horariosesiones-razon-video-59170

Universo Formulas (2017) Variable Dependiente. Recuperado de:

http://www.universoformulas.com/matematicas/analisis/variable-dependiente/

Waze: Lima es la peor capital de Sudamérica para conducir (17 de setiembre del 2016).

El Comercio. Recuperado de: http://elcomercio.pe/sociedad/lima/waze-limapeor-capital-sudamerica-conducir-noticia1932287?ref=flujo_tags_92347\&ft=nota_6\&e=titulo

Zamora Torres. A. (2008). Rentabilidad y ventaja comparativa: un análisis de los sistemas de producción de Guayaba en el Estado de Michoacán (tesis de maestría). Instituto de Investigaciones Económicas y Empresariales de la Universidad Michoacana de San Nicolás de Hidalgo.

183.913 vehículos vendidos en el 2014 (2015, Ene.) Publimetro. Recuperado de http://publimetro.pe/actualidad/noticia-183913-vehiculos-vendidos-2014-30455 


\section{BIBLIOGRAFIA}

Angulo, M. y Sarmiento, J. (2000). El concepto de rentabilidad en marketing. Ponencia presentada en el primer congreso nacional de profesor de costos y contabilidad directiva. Santafé de Bogotá D.C.: Pontificia Universidad Javeriana. Recuperado de: http://www.javeriana.edu.co/decisiones/Julio/documentos/marketing.pdf

Barrio G., De Dios Luna J., De la Fuente L., Jiménez E., Lardelli P., Martinez V. y Pulido J. (2012) Informe final del proyecto 0100dgt21262. Diseño de un cuestionario sobre movilidad y exposición al tráfico rodado. Proyecto de aplicación. Dirección General del Tráfico. Recuperado de: http://www.dgt.es/Galerias/la-dgt/centro-de-documentacion/estudios-e-

Bolsa de Valores de Lima. Memoria Anual. Recuperado de: http://bvl.com.pe/

Bull, A. Thomson I. La congestión del tránsito urbano: causas y consecuencias económicas y sociales. Recursos Naturales e Infraestructura.

Cequea, M. Rodriguez C (2010) La productividad desde una perspectiva humana. Research Gate. Recuperado de: http://www.researchgate.net/publication/260390327

Comunidad Andina (2016). Parque vehicular en la Comunidad Andina, 2006-2015. Recuperado del sitio de internet de la Comunidad Andina: http://intranet.comunidadandina.org/Documentos/DEstadisticos/SGDE755.pdf

Downs, A. (2003) Still Stuck in Traffic: Coping with Peak-Hour Traffic Congestion. Washington, DC, USA: Brookings Institution Press. Recurperado de: http://site.ebrary.com/lib/bibudlima/detail.action?docID

Infobras - Centro de Información de Obras Públicas (2016). Obras públicas en elaboración en Lima Metropolitana. Recuperado de: https://apps.contraloria.gob.pe/ciudadano/

Instituto Nacional de Estadística e Informática (2015). Día Mundial de la Población. Recuperado de: 
https://www.inei.gob.pe/media/MenuRecursivo/publicaciones_digitales/Est/Lib 1251/Libro.pdf

Golob T., Regan A. (2003) Traffic congestion and trucking managers use of automated routing and scheduling. University of California Transportation Center. Recuperado de: http://escholarship.org/uc/item/74z234n4

Harriet, T., Poku, K., \& Anin, K. E. (2013). An assessment of traffic congestion and its effect on productivity in urban ghana. International Journal of Business and Social Science, 4(3). Recuperado de: http://fresno.ulima.edu.pe/ss_bd00102.nsf/RecursoReferido?OpenForm\&id=PR OQUEST-41716\&url=/docview/1321484059?accountid=45277

Kessler R. (2008). Organización Mundial de la Salud Cuestionario sobre salud y desempeño (CSD): versión de referencia para ensayos clínicos. World Health Organization. Recuperado de:

http://www.hcp.med.harvard.edu/hpq/ftpdir/HPQ\%20Clinical\%207day_Spanish_Final.pdf

Lecaros Alfaro, D. (2016). Implementación de un sistema de evaluación del clima laboral en una entidad del estado (trabajo de investigación para optar la licenciatura en Administración). Universidad de Lima.

Lewis, D. (2008). America's traffic congestion problem: Toward a framework for nationwide reform. (). Washington: Brookings Institution Press. Recuperado de: http://fresno.ulima.edu.pe/ss_bd00102.nsf/RecursoReferido?OpenForm\&id=PR OQUEST-41716\&url=/docview/213969303 accountid=45277

Los peores embotellamientos de la historia (2014) Recuperado de: http://www.carmudi.com.mx/journal/los-peores-embotellamientos-de-lahistoria/

Ministerio del Interior - Dirección de Gestión en Tecnología de la Información y Comunicaciones-Dirtepoles - PNP (2015). Número de accidentes registrados en todo el Perú 2012-2014. Recuperado de:

https://www.inei.gob.pe/estadisticas/indice-tematico/traffic-accidents/

Ministerio de Transporte y Comunicaciones (2015) Accidentes de tránsito 2005-2015. Recuperado de: 
https://www.mtc.gob.pe/cnsv/estadisticas/Accidentes\%20de\%20Transito\%2020 05-2015.pdf

Protransporte (2015) Programa de chatarreo. Recuperado de:

http://www.protransporte.gob.pe/programa_de_chatarreo.pdf

Rosenbloom, S. (2005). Still stuck in traffic: Coping with peak-hour traffic congestion. American Planning Association. Journal of the American Planning Association, 71(4), 458. Recuperado de:

http://fresno.ulima.edu.pe/ss_bd00102.nsf/RecursoReferido?OpenForm\&id=PR OQUEST-41716\&url=/docview/229619341?accountid=45277

Web Calentar (2017). El mundo: África - Ghana. Recuperado de: http://www.webcalendar.org/es/world/africa/ghana/kumasi--02

Wikipedia (2017) Ghana. Recuperado de: https://es.wikipedia.org/wiki/Ghana

¿Cuántos habitantes tiene Lima a 482 años de su fundación? (18 de enero del 2017).

RPP Noticias. Recuperado de: http://rpp.pe/economia/economia/inei-lima-tiene9-millones-111-mil-habitantes-noticia-1024523 
ANEXOS 
Anexo 1

\section{ENCUESTA: Efectos del tráfico en las personas}

1. ¿Cuentas con un auto propio con el que se moviliza?

a) Sí

b) No. Pasar a la pregunta 11 .

2. ¿Utilizas su vehículo para ir o volver de su centro laboral?

a) Sí. Pasar a la pregunta 4 .

b) No

3. ¿Por qué no utiliza su carro para ir a trabajar?

4. ¿Cuánto tiempo tiene que conducido durante un día laborable para ir a su centro de trabajo?

a) Menos de media hora

b) Media hora

c) Más de media hora

d) Una hora

e) Más de una hora

5. ¿Cuánto tiempo tiene que conducido durante un día laborable para llegar a su hogar?

a) Menos de media hora

b) Media hora

c) Más de media hora

d) Una hora

e) Más de una hora

6. ¿Conduce fuera de los límites de su distrito en la semana por temas de trabajo?

a) Sí

b) No

7. ¿En qué distrito vive?

8. ¿A qué hora sale de su hogar para dirigirse al trabajo?

a) Antes de las 6am

b) Entre las 6 y $6: 30 \mathrm{am}$

c) Entre las 6:30 y $7 \mathrm{am}$

d) Entre las 7 y 7:30 am

e) Entre las 7:30 y 8 am 
f) Entre las 8 y 8:30 am

9. ¿Cuánto suele gastar en combustible semanalmente?
a) Menos de 50 soles
b) Entre 50 y 100 soles
c) Más de 100 soles

10. ¿Tiene donde estacionar cerca o en su centro de trabajo? Pasar a la pregunta 14.
a) Sí
b) No

11. Normalmente, ¿Cómo te movilizas?
a) Taxi
b) Autobús
c) Bicicleta
d) Peatón
e) Otro:

12. ¿Aproximadamente cuánto tiempo emplea para viajar en: taxi, autobús, bicicleta, otro?
a) Menos de media hora
b) Media hora
c) Más de media hora
d) Una hora
e) Más de una hora

13. ¿Aproximadamente cuánto tiempo caminas al día por motivos laborales?
a) No camino
b) Menos de media hora
c) Media hora
d) Más de media hora
e) Una hora
f) Más de una hora

14. ¿Cree que el tráfico afecta su salud?
a) Sí
b) No

15. ¿Cuáles son los principales efectos que tiene el tráfico en su salud? Puede marcar más de una opción.

a) Estrés 

b) Cansancio
c) Mal humor
d) Malestar físico
e) Otro:

16. ¿La empresa donde trabaja hace algo para contrarrestar el estrés causado por el tráfico?

a) Sí.

b) No. Pasar a la pregunta 18

17. ¿Qué hace la empresa donde trabaja para contrarrestar los efectos causados por el tráfico?

18. ¿Cree que el tráfico está afectando su desempeño en el trabajo?

a) Sí

b) No. Pasar a la pregunta 20 .

19. ¿Por qué cree que el tráfico afecta su desempeño laboral?

20. ¿Qué haría usted para contrarrestar los efectos que tiene el tráfico en su desempeño laboral?

21. ¿Con qué frecuencia pierde sus actividades personales debido a la congestión vehicular?
a) Siempre
b) Casi siempre
c) En ocasiones
d) Casi nunca
e) Nunca

22. Si manejas un equipo ¿tus trabajadores se movilizan utilizando el servicio público?
a) Sí
b) No. Pasar a la pregunta 24 .

23. En porcentaje ¿cuántos de sus colaboradores utilizan el servicio público?
a) Menos del $20 \%$
b) Entre el $20 \%$ y $40 \%$
c) Entre el $40 \%$ y $60 \%$
d) Entre el $60 \%$ y $80 \%$
e) Entre el $80 \%$ y $100 \%$ 
24. Si manejas un equipo ¿sientes que tus trabajadores se perjudican por la congestión vehicular?
a) Sí
b) No. Pasar a la pregunta 26

25. ¿De qué manera está afectando el tráfico a su equipo?

26. En general, ¿qué tan grave es el problema de congestión para su trabajo?
a) No es grave
b) Es poco grave
c) Es muy grave 
Anexo 2

GU:

Fuente de Reclutamiento:

Fecha:

\section{ELIMINADOR}

1) ¿Su edad actual está entre 23 y 40 ?

$\mathrm{SI} \mathrm{NO}$

2) ¿Tiene estudios secundarios concluídos?

$\mathrm{SI} \mathrm{NO}$

3) ¿Tiene alguna experiencia laboral?

$\mathrm{SI} \mathrm{NO}$

4) ¿Tiene alguna experiencia en ventas?

$\mathrm{SI} \mathrm{NO}$

El candidato queda eliminado si alguna de las respuestas a las preguntas 1, 2, 3 o 4 es NO.

Responda la pregunta 5 solo si está desempleado

5) ¿Tiene más de 12 meses de desempleo?

$\mathrm{SI} \mathrm{NO}$

El candidato queda eliminado si la respuesta es SI.

\section{EVALUADOR}

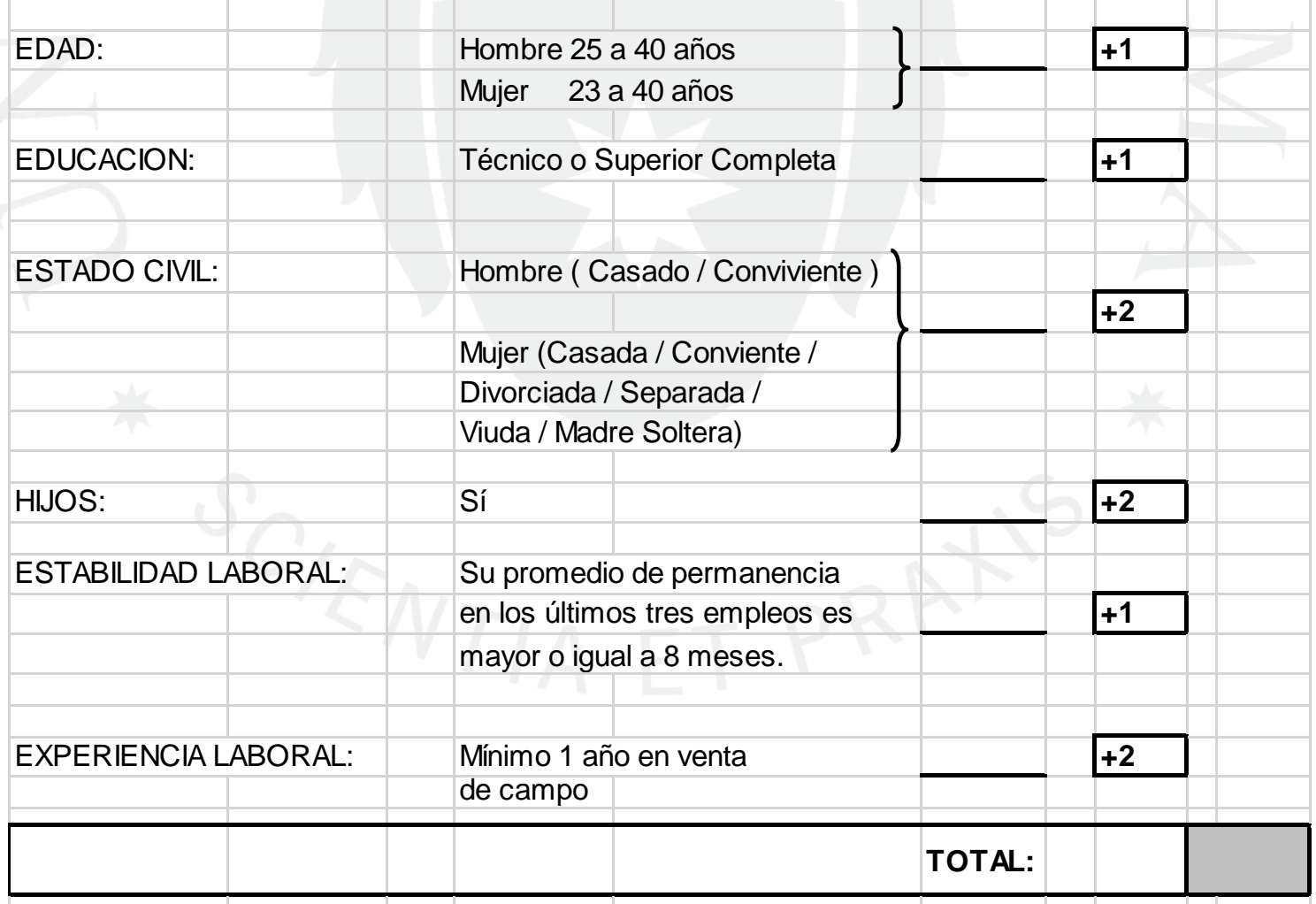

\section{VALIDO: 4 ó más}

ELIMINADO: 3 ó menos 